UNIVERSIDADE DE SÃO PAULO

FACULDADE DE MEDICINA DE RIBEIRÃO PRETO

PROGRAMA DE PÓS-GRADUAÇÃO EM NEUROCIÊNCIAS

THAMIRES MÁXIMO NEVES FELICE

Associação dos fatores de risco para paralisia cerebral com os aspectos clínicos e funcionais

Ribeirão Preto - SP 
THAMIRES MÁXIMO NEVES FELICE

Associação dos fatores de risco para paralisia cerebral com os aspectos clínicos e funcionais

Versão corrigida. A versão original encontra-se disponível tanto na Biblioteca da Unidade que aloja o Programa, quanto na Biblioteca Digital de Teses e Dissertações da USP (BDTD)

Tese apresentada ao Programa de Pós-Graduação em Neurologia, Subárea Neurociências, da Faculdade de Medicina de Ribeirão Preto da Universidade de São Paulo (FMRP-USP), como parte dos requisitos para obtenção do título de Doutora em Ciências.

Orientadora: Profa. Dra. Luzia Iara Pfeifer

Ribeirão Preto - SP 
Autorizo a reprodução e a divulgação total ou parcial deste trabalho, por qualquer meio convencional ou eletrônico, para fins de estudo e pesquisa, desde que citada a fonte.

\author{
Catalogação na publicação \\ Serviço de Biblioteca e Documentação
}

Faculdade de Medicina de Ribeirão Preto da Universidade de São Paulo

Felice, Thamires Máximo Neves

Associação dos fatores de risco para paralisia cerebral com os aspectos clínicos e funcionais, 2021.

$98 \mathrm{p}$.

Tese de Doutorado, apresentada à Faculdade de Medicina de Ribeirão Preto da Universidade de São Paulo: Área de Concentração: Neurociências.

Orientadora: Pfeifer, Luzia Iara

1. Paralisia cerebral; 2. Fatores de risco; 3. Desenvolvimento infantil; 4. Epidemiologia. 
Nome: FELICE, Thamires Máximo Neves

Título: Associação dos fatores de risco para paralisia cerebral com os aspectos clínicos e funcionais

\author{
Tese apresentada ao Programa de Pós-Graduação em Neurologia, \\ Subárea Neurociências, da Faculdade de Medicina de Ribeirão Preto da \\ Universidade de São Paulo (FMRP-USP) para obtenção do título de \\ Doutora em Ciências.
}

Aprovado em: 24 de novembro de 2021.

Banca Examinadora

Nome: Profa. Dra. Profa. Dra. Luzia Iara Pfeifer

Instituição: Faculdade de Medicina de Ribeirão Preto da Universidade de São Paulo Julgamento: Aprovado

Nome: Profa. Dra. Ana Paula Hamad

Instituição: Faculdade de Medicina de Ribeirão Preto da Universidade de São Paulo Julgamento: Aprovado

Nome: Prof. Dr. Jair Lício Ferreira Santos

Instituição: Faculdade de Medicina de Ribeirão Preto da Universidade de São Paulo Julgamento: Aprovado

Nome: Profa. Dra. Maria Madalena Moraes Sant'Anna

Instituição: Faculdade Método de São Paulo

Julgamento: Aprovado 


\section{DEDICATÓRIA}

A todas as crianças com déficit motor funcional, aos seus familiares que buscam incansavelmente pelo aperfeiçoamento de suas habilidades e aos profissionais que as acompanham, guiando e estimulando o seu desenvolvimento. 


\section{AGRADECIMENTOS}

Agradeço primeiramente a Deus pela minha vida, família, saúde e oportunidades de crescimento pessoal e profissional. Sou grata pela minha vida e pelo seu amor incondicional.

Aos meus pais, que sempre me incentivam a buscar novos conhecimentos e conquistar objetivos e sonhos. Agradeço a educação que me deram, pelos valores transmitidos, ensinamentos, amor e fortaleza. Amo muito vocês!

Aos meus avós, que tão docemente me apoiam a cada visita e conversa, são meus tesouros que tenho profunda admiração e respeito. Obrigada pelo carinho de sempre! Em especial ao vovô Ruy, que mesmo não estando mais entre nós, sei que está sorrindo, orgulhoso e feliz por este momento.

Ao meu marido, meu grande amor, por todo o suporte, companheirismo, compreensão, paciência, auxílio e amor transmitido. Você é meu porto seguro, minha certeza de que tudo ficará bem ao final de cada dia. Minha jornada fica mais leve por ter você ao meu lado!

Ao meu irmão querido, que mesmo longe fisicamente, sei que sempre posso contar. A vida nos deu um laço lindo que jamais irá se desfazer, como é bom estar com você!

À minha orientadora querida Profa. Dra. Luzia Iara Pfeifer, por ter me acolhido, acreditar no meu trabalho, me guiar e incentivar. Obrigada pela sua atenção, compreensão e todos os ensinamentos transmitidos. É um exemplo de ser humano para mim.

Ao Prof. Dr. Jair Lício Ferreira Santos pela paciência, direcionamento, atenção em cada reunião e e-mail trocado, sempre com muito cuidado com os dados, transmitindo serenidade e bondade.

Aos integrantes do LEPTOI pelo acolhimento, momentos compartilhados e amizade. Em especial, à aluna Mariana Grecco Faro, que foi fundamental nas coletas e em todo o direcionamento com os dados. Mari, seus valores são incríveis, sempre sorrindo e transmitindo leveza, segurança e excelência em tudo. Sou extremamente grata a você!

Aos familiares das crianças pela paciência, prontidão, carinho e confiança em compartilhar um pouco da história de vocês. Sem vocês nada teria sentido.

Aos profissionais dos serviços de saúde que me receberam, compartilharam seu tempo, sabedoria e informações para que este trabalho fosse desenvolvido. Agradeço imensamente a cada um por toda a paciência, auxílio e sabedoria.

O presente trabalho foi realizado com apoio da Coordenação de Aperfeiçoamento de Pessoal de Nível Superior - Brasil (CAPES). 
"Conheça todas as teorias, domine todas as técnicas, mas ao tocar uma alma humana, seja apenas outra alma humana" 


\section{RESUMO}

FELICE, Thamires Máximo Neves. Associação dos fatores de risco para paralisia cerebral com os aspectos clínicos e funcionais. 2021. Tese (Doutorado) - Faculdade de Medicina de Ribeirão Preto, Universidade de São Paulo, Ribeirão Preto, 2021.

Introdução: A paralisia cerebral (PC) descreve um grupo de desordens permanentes relacionadas ao desenvolvimento do movimento e da postura, que causa limitações funcionais atribuídas a distúrbios não-progressivos no cérebro fetal ou infantil em desenvolvimento. Devido à escassez de pesquisa tanto em âmbito nacional quanto no município de Ribeirão Preto - SP, à falta de consistência nos dados encontrados na literatura e a dificuldade encontrada no estudo de mestrado em verificar o desfecho do acompanhamento e diagnóstico dos bebês de risco no município, esta pesquisa se fez necessária para se conhecer mais profundamente a relação entre as ocorrências pré e peri natais, o diagnóstico, o início da intervenção e aspectos clínicos e funcionais da criança com PC. Desta forma, espera-se auxiliar na criação de estratégias mais planejadas para as políticas de saúde que tornem o cuidado com o bebê de risco e com as crianças com PC mais rápido e eficaz. Objetivos: Identificar os fatores de risco para paralisia cerebral nas crianças e adolescentes com PC que estão em reabilitação na rede pública no município de Ribeirão Preto - SP e verificar se há associação entre estes fatores de risco e as características clínicas e funcionais das crianças e adolescentes. Método: Trata-se de um estudo observacional retrospectivo. Os critérios de inclusão do estudo foram as crianças e adolescentes com PC que frequentavam os serviços de reabilitação da rede pública no município de Ribeirão Preto - SP, no período de agosto de 2019 a março de 2020. Por meio de entrevista, os responsáveis relataram os dados sobre a saúde materna, o período gestacional e perinatal, aspectos clínicos e funcionais das crianças e adolescentes da amostra. Os aspectos clínicos e funcionais também foram verificados com os profissionais. Após análise descritiva de todas as variáveis, foram realizados testes de associação entre os fatores de risco, informações sobre diagnóstico e intervenção, as classificações funcionais (função motora grossa e habilidade manual) e locomoção, bem como com as características atuais da saúde e desenvolvimento da criança. Resultados: Os serviços informaram acompanhar 146 crianças e adolescentes no período de coleta e, após o contato e entrevistas, 61 participaram deste estudo. A escolaridade materna teve associação com a habilidade manual e a locomoção da criança e, o fato de a gravidez ter sido desejada teve associação com a função motora e a locomoção em casa. A idade da criança quando teve a 
suspeita do atraso do desenvolvimento teve associação com a deficiência cognitiva e epilepsia e, a topografia teve associação com a idade da notícia (diagnóstico). Conclusão: $\mathrm{Na}$ amostra, o fato de as crianças terem mães mais jovens e com maior grau de instrução favoreceu sua função manual, função motora e locomoção. Foi verificado que quanto maior o comprometimento motor e a presença de déficits associados mais cedo a criança foi diagnosticada, provavelmente por apresentarem mais sinais clínicos alterados. Por fim, alertamos sobre a necessidade de um adequado acompanhamento do desenvolvimento infantil com triagem e uso de instrumentos validados e recomendados, bem como a realização do diagnóstico e intervenção multiprofissional precoce e oportuna. A família deve ser informada da condição da criança e atuar em conjunto com os profissionais para que o tratamento seja focado no contexto da família e a criança tenha uma participação ativa, tanto na escola como na comunidade.

Palavras-chave: Paralisia cerebral, fatores de risco, desenvolvimento infantil, epidemiologia. 


\begin{abstract}
FELICE, Thamires Máximo Neves. Association of risk factors for cerebral palsy with clinical and functional aspects. 2021. Tese (Doutorado) - Faculdade de Medicina de Ribeirão Preto, Universidade de São Paulo, Ribeirão Preto, 2021.
\end{abstract}

Introduction: Cerebral palsy (CP) describes a group of permanent disorders related to the development of movement and posture, which cause functional limitations attributed to nonprogressive disorders in the developing fetal or infant brain. Due to the lack of research both nationally and in the city of Ribeirão Preto - SP, the lack of consistency in the data found in the literature and the difficulty found in the master's study in verifying the outcome of monitoring and diagnosis of babies at risk in the city, this research was necessary to gain a deeper understanding of the relationship between pre and perinatal events, the diagnosis, the beginning of the intervention and clinical and functional aspects of the child with CP. In this way, it is expected to help in the creation of more planned strategies for health policies that make the care of babies at risk and children with CP faster and more effective. Objectives: To identify the risk factors for cerebral palsy in children and adolescents with $\mathrm{CP}$ who are undergoing rehabilitation in the public network in the city of Ribeirão Preto - SP and to verify if there is an association between these risk factors and the clinical and functional characteristics of children and adolescents. Method: This is a retrospective observational study. The study inclusion criteria were children and adolescents with $\mathrm{CP}$ who attended public rehabilitation services in the city of Ribeirão Preto - SP, from August 2019 to March 2020. Through an interview, those responsible reported the data on maternal health, the gestational and perinatal period, clinical and functional aspects of the children and adolescents in the sample. Clinical and functional aspects were also checked with professionals. After descriptive analysis of all variables, association tests were performed between risk factors, information on diagnosis and intervention, functional classifications (gross motor function and manual skill) and locomotion, as well as with the current characteristics of health and development of the kid. Results: The services reported monitoring 146 children and adolescents during the collection period and, after contact and interviews, 61 participated in this study. Maternal education was associated with the child's manual skills and locomotion, and the fact that the pregnancy was desired was associated with motor function and locomotion at home. The child's age when the developmental delay was suspected was associated with cognitive impairment and epilepsy, and the topography was associated with 
the age of the news (diagnosis). Conclusion: In the sample, the fact that the children had younger mothers with a higher level of education favored their manual function, motor function and locomotion. It was found that the greater the motor impairment and the presence of associated deficits, the earlier the child was diagnosed, probably because they had more altered clinical signs. Finally, we warn about the need for adequate monitoring of child development with screening and use of validated and recommended instruments, as well as early and timely diagnosis and multiprofessional intervention. The family must be informed of the child's condition and act together with professionals so that the treatment is focused on the family context and the child has an active participation, both in school and in the community.

Key words: Cerebral palsy, risk factors, child development, epidemiology. 


\section{LISTA DE FIGURAS}

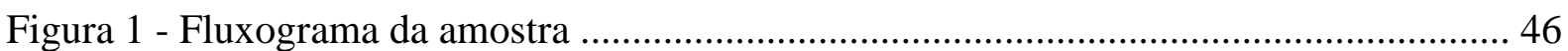




\section{LISTA DE QUADROS}

Quadro 1 - Exames solicitados por período da gestação no pré-natal de baixo risco 20

Quadro 2 - Fatores de risco para a realização do pré-natal pela atenção básica de saúde ...... 22

Quadro 3 - Fatores de risco relacionados à gestante ........................................................... 24

Quadro 4 - Informações para classificar o risco ao nascer .................................................... 26

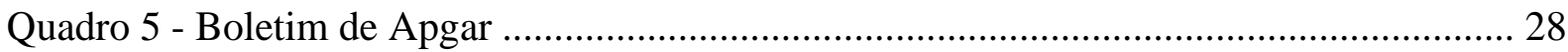




\section{LISTA DE TABELAS}

Tabela 1 - Doenças maternas e hábitos deletérios ............................................................ 47

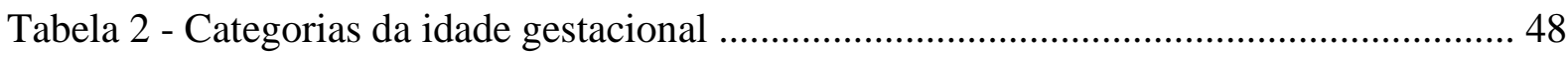

Tabela 3 - Número e porcentagem da amostra que realiza terapias ..................................... 51

Tabela 4 - Frequência e porcentagem nas classificações usando os instrumentos ................. 52

Tabela 5 - Resultados da Anova para as variáveis contínuas .............................................. 53

Tabela 6 - Resultados dos testes de associação entre as variáveis funcionais e de risco ........ 55

Tabela 7 - Resultados dos testes de associação entre as variáveis funcionais e de diagnóstico e

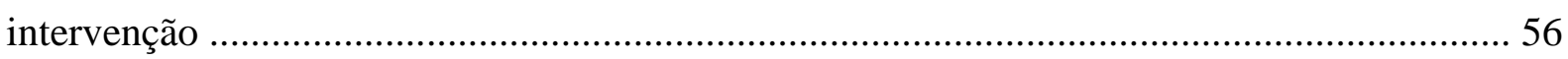

Tabela 8 - Resultados dos testes de associação entre as variáveis funcionais e características atuais

Tabela 9 - Resultados dos testes de associação entre as variáveis de características atuais e de risco 58

Tabela 10 - Resultados dos testes de associação entre as variáveis de características atuais e de diagnóstico e intervenção 60 


\section{LISTA DE SIGLAS}

CER Centro de Reabilitação

CFCS Communication Function Classification System

CIF Classificação Internacional de Funcionalidade, Incapacidade e Saúde

CNPq Conselho Nacional de Desenvolvimento Científico e Tecnológico

DST Doenças Sexualmente Transmissíveis

EDACS Eating and Drinking Ability Classification System

FAEPA Fundação de Apoio ao Ensino, Pesquisa e Assistência

FAPESP Fundação de Amparo à Pesquisa do Estado de São Paulo

FMRP Faculdade de Medicina de Ribeirão Preto

FMS Functional Mobility Scale

GMFCS Gross Motor Function Classification Sistem

HINE Hammersmith Infant Neurological Evaluation

HIV Vírus da Imunodeficiência Humana

LEPTOI Laboratório de Ensino e Pesquisa de Terapia Ocupacional na Infância e Adolescência

MACS Manual Ability Classification System

MATER Centro de Referência em Saúde da Mulher de Ribeirão Preto

NASF Núcleo Ampliado de Saúde da Família

OMS Organização Mundial da Saúde

ONU Organização das Nações Unidas

PC Paralisia Cerebral

RM Ressonância Magnética

RN Recém-nascido

SUS Sistema Único de Saúde

TCLE Termo de Consentimento Livre e Esclarecido

TORCHS Toxoplasmose, rubéola, citomegalovírus, herpes, HIV, sífilis

UBS Unidade Básica de Saúde

US Ultrassom

USP Universidade de São Paulo

UTI Unidade de Terapia Intensiva

WHO World Health Organization 


\section{SUMÁRIO}

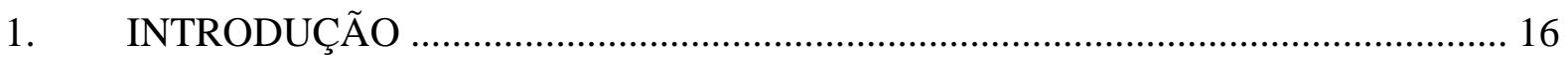

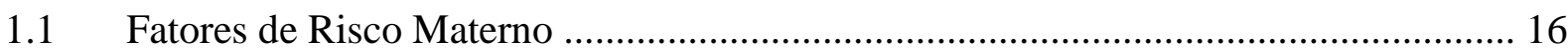

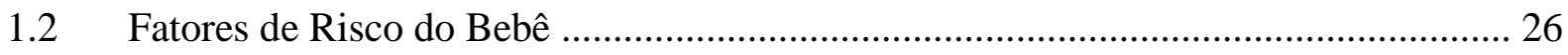

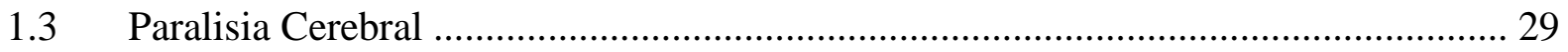

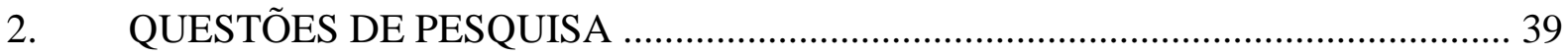

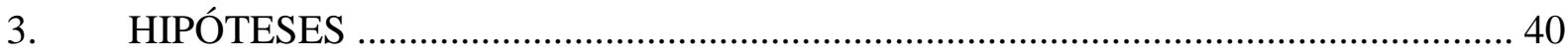

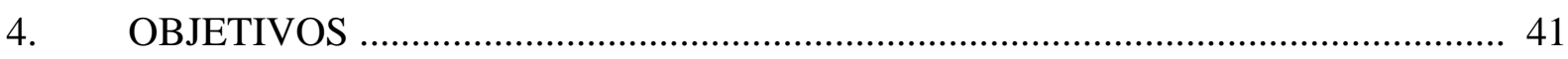

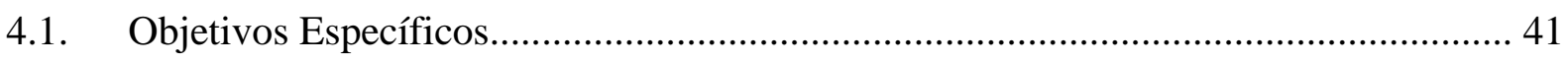

5. MATERIAL E MÉTODO …......................................................................... 42

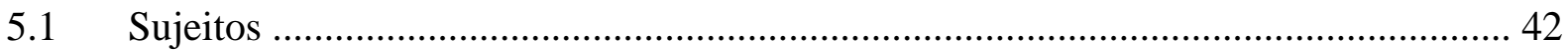

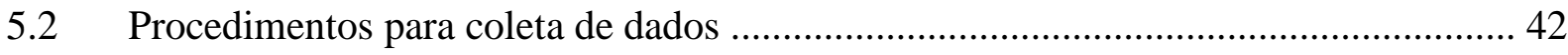

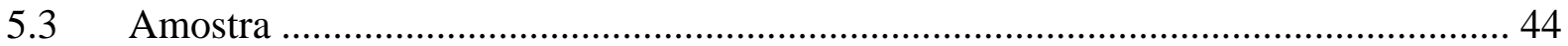

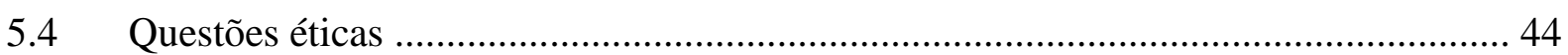

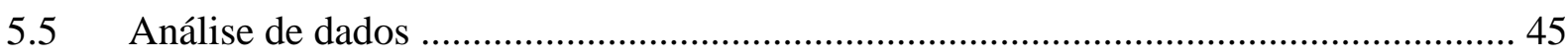

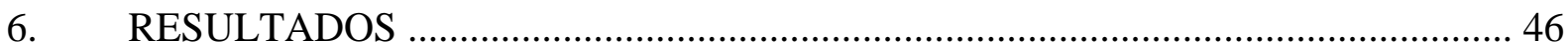

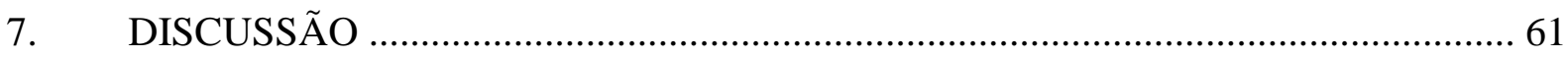

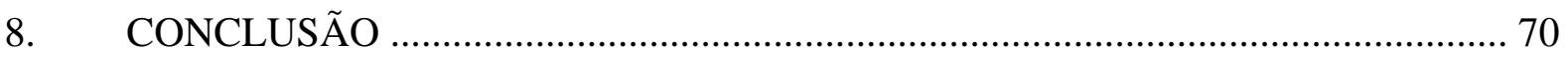

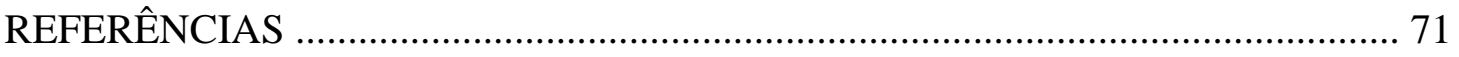

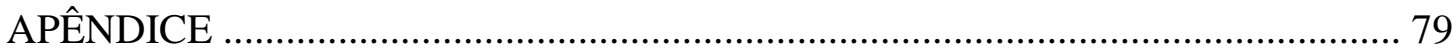

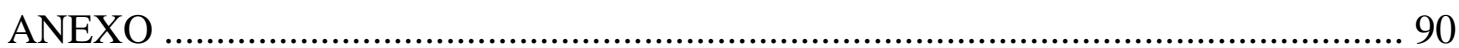




\section{APRESENTAÇÃO}

O universo infantil sempre me encantou! Nasci em Varginha - MG e já na escola gostava de visitar o berçário e a educação infantil no recreio, tinha muitas dúvidas e incertezas de qual caminho seguir profissionalmente, mas uma coisa era clara: tinha que envolver bebês e crianças.

Em 2006, com 17 anos, saí de casa e iniciei a graduação em fisioterapia na Pontifícia Universidade Católica de Minas Gerais (PUC - MG), em Poços de Caldas, mas por algumas dificuldades locais e anseios, em 2007 me inscrevi e me preparei para o processo seletivo de transferência da Faculdade de Medicina de Ribeirão Preto da Universidade de São Paulo (FMRP - USP).

Em 2008 mudei para Ribeirão Preto - SP e fui me encantando ainda mais com a fisioterapia e com todas as áreas de atuação, envolvendo a promoção, prevenção e reabilitação em saúde. Me permiti conhecer mais sobre a profissão, a ter experiências com outras áreas, com iniciações científicas, ligas e projetos de extensão, mas não deixei a infância de lado.

No final da faculdade, após participar do Projeto RONDON, a saúde pública me encantou com as diretrizes de assistência, o olhar humano, o cuidado integral e a importância do trabalho em equipe. $\mathrm{E}$, ao prestar os processos seletivos, a dúvida foi grande entre fazer um aprimoramento em fisioterapia na infância ou uma residência multiprofissional. Mas, após muitas reflexões, escolhi a Residência Multiprofissional em Atenção Integral à Saúde da FMRP - USP, no qual hoje sou extremamente grata pela experiência que obtive com outros profissionais, pelas orientações, trabalhos desenvolvidos e pela oportunidade de, mesmo com uma grade curricular ampla de ações, consegui direcionar o cuidado e a assistência na infância, participando de campanhas de promoção de saúde infantil, ambulatórios de prescrição de órteses e dispositivos de auxílio, atuando na estimulação precoce, conhecendo serviços de assistência à criança e realizando atendimentos de reabilitação.

Em dois destes serviços, uma sementinha estava nascendo para mais tarde dar o fruto deste projeto. Realizava um estágio no serviço de Estimulação Precoce da prefeitura, onde acompanhava os bebês de risco, e me chamou a atenção a forma de como esses bebês eram identificados precocemente, mas não havia informações sobre o perfil destas crianças e sobre o desfecho no diagnóstico de paralisia cerebral. No Centro de Reabilitação do Hospital das Clínicas, conheci a Profa. Dra. Luzia Iara em um atendimento em conjunto com a terapeuta ocupacional do serviço, e me encantei com a doçura que a professora falou com a criança e explicou o caso para as alunas que acompanhavam no estágio. Após isto, a fisioterapeuta do 
serviço, que fazia mestrado com a professora na época, só fez elogios e me explicou sobre o processo seletivo para o mestrado.

Desta forma, após o término da residência, a professora e eu marcamos uma reunião logo cedo para conversarmos sobre um possível projeto e, a epidemiologia, os bebês de risco, a dificuldade no diagnóstico precoce da paralisia cerebral e a vontade de saber mais sobre o perfil e as lacunas destas informações fizeram nascer este trabalho aos poucos.

Este trabalho faz parte dos estudos do grupo de pesquisa do LEPTOI - Laboratório de Ensino e Pesquisa de Terapia Ocupacional na Infância e Adolescência ${ }^{1}$, dentro da linha de pesquisa "Desempenho ocupacional de crianças e adolescentes em diferentes contextos".

O LEPTOI reúne ações e projetos de pesquisa, ensino e extensão que se propõem a integrar aspectos clínicos e sociais, a partir de duas linhas centrais de pesquisa: Formação profissional (perfil dos estudantes de Terapia Ocupacional, acompanhamento de ingressantes, através do processo de tutoria institucional, desenvolvimento de estratégias de ensino em terapia ocupacional: tecnologia e arte) e Desempenho ocupacional de crianças e adolescentes em diferentes contextos (desenvolvimento em condições adversas - violência doméstica, pobreza e institucionalização; doenças crônicas, hospitalização, deficiências; comportamento lúdico e de lazer de crianças e adolescentes, cuidadores), linha na qual se insere o presente estudo.

Pretende-se, desta forma, aprofundar a compreensão acerca da influência dos eventos de vida sobre o desenvolvimento de crianças e adolescentes, na perspectiva da Terapia Ocupacional e áreas afins, ou seja, atentando para as habilidades de desempenho mais importantes na garantia da participação em contextos de vida, para cada etapa deste período do curso de vida (infância e adolescência).

Com o interesse de ingressar no mestrado e colocar em prática o projeto elaborado, me inscrevi no final de 2015 no Programa de Pós-graduação do Departamento de Neurologia da FMRP USP.

O objetivo do mestrado foi verificar os fatores de risco para paralisia cerebral no período de 5 anos (2010-2014) no município de Ribeirão Preto - SP, buscando identificar a proporção de crianças nascidas na rede pública e que foram identificadas como apresentando risco de atraso de desenvolvimento e, dentre estas, as diagnosticadas com paralisia cerebral.

\footnotetext{
${ }^{1}$ Grupo de pesquisa implementado pela Profa. Dra. Luzia Iara Pfeifer em janeiro de 2005, na Faculdade de Medicina de Ribeirão Preto - FMRP - USP. Em janeiro de 2008 a Profa. Dra. Maria Paula Panúncio Pinto, passou a integrar, em parceria, a coordenação do laboratório. O LEPTOI vem sendo mantido com o auxílio financeiro da FMRP, FAEPA, CNPq e FAPESP.
} 
Dos nascidos vivos na rede pública no período, $23,3 \%$ foram considerados com risco de atraso do desenvolvimento. Ao todo, foram analisados 481 prontuários e em 76,92\% não havia informação da saúde prévia da mãe e a maioria não planejou a gravidez. Cerca de $65 \%$ das crianças apresentavam indícios de alterações neurológicas e 73,4\% tiveram alta por abandono.

O mestrado proporcionou diversos aprendizados e estreitamento de laços com outros profissionais de saúde, porém, houve muita frustação ao verificar os dados e devido ao número de altas por abandono, não foi possível verificar o desfecho, comprometendo as análises de associação, estimativa da prevalência de paralisia cerebral e uma intervenção mais direcionada no período de maior neuroplasticidade e melhor prognóstico da criança.

Em 2018 o mestrado foi concluído e diante dos dados encontrados e a falta da resposta de onde e como estariam estes bebês, demos sequência com o projeto do doutorado no mesmo ano.

Este estudo incialmente teve como ideia central verificar nos serviços de reabilitação as crianças que estavam no banco de dados do mestrado, mas para nossa surpresa, apenas uma criança foi localizada nos serviços e, por este motivo, um novo direcionamento foi necessário. Desta forma optamos por estudar a associação dos fatores de risco para paralisia cerebral com os aspectos clínicos e funcionais

Espera-se que os resultados aqui apresentados possam contribuir para os estudos na área da infância, adequações nos serviços e melhoria na gestão em saúde. 


\section{INTRODUÇÃO}

O desenvolvimento infantil é tema de grande relevância em quase todos os programas de governos devido ao fato de que cuidar e favorecer o desenvolvimento saudável, principalmente na primeira infância, promoverá bases para enfrentar situações complexas no futuro (CYPEL et al., 2013).

Bronfenbrenner (1996) defende uma estrutura para promoção de saúde e desenvolvimento infantil como sendo uma acomodação progressiva mútua entre o ser humano e as características do ambiente em que o indivíduo vive. O autor retrata que a criança está inserida no seu contexto familiar, que por sua vez pertence à uma comunidade inserida em uma sociedade. Desta forma, o desenvolvimento infantil sofre influências dos fatores intrapessoais, interpessoais, institucionais e culturais.

Por ser integral, o desenvolvimento infantil deve ser contemplado de forma integrativa e envolve várias áreas de conhecimento e de assistência. Considerando sua integralidade, a Classificação Internacional de Funcionalidade, Incapacidade e Saúde (CIF) vai ao encontro com a abordagem biopsicossocial, incluindo funções e estrutura do corpo, atividades, participação social, fatores ambientais e pessoais (FARIAS; BUCHALLA, 2005).

A CIF foi criada pela Organização Mundial da Saúde (OMS) e visa unificar a linguagem a respeito dos componentes e estados relacionados à saúde e bem-estar, priorizando a funcionalidade como componente da saúde e reconhecida como modelo de estruturação para avaliação, formulação de problemas e metas para intervenção no tratamento de pacientes com alguma deficiência (OMS, 2003), sendo muito recomendada não só para dados epidemiológicos, mas como abordagem conceitual em crianças com paralisia cerebral com uma visão coerente de diferentes perspectivas da saúde: biológica, individual e social.

\subsection{Fatores de Risco Materno}

Segundo Reppold et al. (2002), os fatores de risco são condições ou variáveis ambientais, biológicas, genéticas ou sociais associadas à uma grande probabilidade de ocorrência de resultados negativos no desenvolvimento infantil em qualquer área.

O cuidado pré-natal compreende um conjunto de ações durante o período da gestação que requerem investimentos tanto por parte da mulher, como de profissionais e de serviços que se dedicam à oferta desse cuidado. A atenção pré-natal é utilizada como um indicador de 
boa prática, assim como uma medida de qualidade de cuidados clínicos e de saúde pública (GAZMARIAN et al., 1999; DYE; WOJTOWCZ, 1999).

A Organização Mundial da Saúde (OMS - World Health Organization WHO) em suas agendas de ações globais: Strategies toward Ending Preventable Maternal Mortality (World Health Organization, 2015) e a Every Newborn: an Action Plan to End Preventable Deaths (World Health Organization, 2014), prevê que toda gestante e recém-nascido devem receber cuidados de qualidade durante o pré-natal, parto e pós-natal.

Apesar da redução importante da mortalidade infantil no Brasil nas últimas décadas, os indicadores de óbitos neonatais apresentaram uma velocidade de queda aquém do desejado. Os óbitos ainda ocorrem por causas evitáveis, principalmente no que diz respeito às ações dos serviços de saúde e, entre elas, a atenção pré-natal, ao parto e ao recém-nascido (BRASIL, 2012a).

Segunda a Nota Técnica para Organização da Rede de Atenção à Saúde com Foco na Atenção Primária à Saúde e na Atenção Ambulatorial Especializada - Saúde da Mulher na gestação, parto e puerpério (2019), a Organização das Nações Unidas (ONU) e Organização Mundial da Saúde (OMS) têm desenvolvido ações mundiais para a redução desses indicadores, definindo metas globais, como os Objetivos de Desenvolvimento Sustentável (ODSs), que estabelecem esforços para redução de mortes evitáveis até 2030. Este documento também informa que no último triênio disponível nos sistemas de informação (2015 a 2017), a razão de mortalidade materna apresentou pequenas variações, permanecendo pouco abaixo de 60 mortes por 100 mil nascidos vivos (superior aos parâmetros recomendados pela OMS de 20 mortes). Da mesma maneira, a taxa de mortalidade infantil no último triênio citado, variou de 12,39 em 2015 a 12,43/1.000 nascidos vivos em 2017, mas 18 estados da federação ainda estão acima da média nacional.

Estes dados corroboram com a preocupação com a qualidade da atenção à saúde da mulher, na gestação, parto e puerpério. Sabe-se, segundo a Nota Técnica (2019) que 26,4\% das mulheres não tiveram acesso ou o acesso foi inadequado ou intermediário ao pré-natal; $55,7 \%$ dos nascimentos foram por cesariana; a taxa de prematuridade é superior a $10 \%$ dos nascimentos; foram registrados em torno de 49 mil casos de sífilis materna, com 25.377 casos de sífilis congênita, dos quais $37,8 \%$ foram diagnosticados tardiamente (no parto ou após o parto).

Desta forma, a assistência pré-natal adequada, com a detecção e a intervenção precoce das situações de risco, bem como um sistema ágil de referência hospitalar e a qualificação da assistência ao parto, são os grandes determinantes dos indicadores de saúde relacionados à 
mãe e ao bebê que têm o potencial de diminuir as principais causas de mortalidade materna e neonatal e proporcionar uma melhor sobrevida e desenvolvimento (BRASIL, 2012a).

Um instrumento importante na melhoria dos índices de morbidade e mortalidade materna e infantil é a avaliação pré-concepcional, que é a consulta que o casal faz antes de uma gravidez, objetivando identificar fatores de risco ou doenças que possam alterar a evolução normal de uma futura gestação. As atividades desenvolvidas na avaliação préconcepcional devem incluir anamnese e exame físico, com exame ginecológico, além de alguns exames laboratoriais para avaliar o risco gestacional. A história clínica busca identificar situações de saúde que podem complicar a gravidez, como diabetes prégestacional, a hipertensão, as cardiopatias, os distúrbios da tireoide e os processos infecciosos, incluindo as doenças sexualmente transmissíveis (DST). O uso de medicamentos, o hábito de fumar e o uso de álcool e drogas ilícitas precisam ser verificados, e a futura gestante deve ser orientada quanto aos efeitos adversos associados. Na história familiar, destaca-se a avaliação de doenças hereditárias, pré-eclâmpsia, hipertensão e diabetes. Na história obstétrica, é importante registrar o número de gestações anteriores e de partos pré-termo, o intervalo entre os partos, o tipo de parto, o peso ao nascimento e as complicações das gestações anteriores, como abortamento, perdas fetais e hemorragias e malformações congênitas (BRASIL, 2012a).

A partir destas orientações e planejamento, o objetivo do acompanhamento pré-natal é assegurar o desenvolvimento da gestação, permitindo o parto de um recém-nascido saudável, sem impacto para a saúde materna, inclusive abordando aspectos psicossociais e as atividades educativas e preventivas (BRASIL, 2012a).

De acordo com o Ministério da Saúde (BRASIL, 2012a) o total de consultas pré-natais deve ser de, no mínimo, 6 (seis), com acompanhamento intercalado entre médico e enfermeiro, e deve seguir uma lógica de solicitação de exames por período gestacional (Quadro 1) . Sempre que possível, as consultas devem ser realizadas mensalmente até a $28^{\mathrm{a}}$ semana, quinzenalmente da $28^{\mathrm{a}}$ até a $36^{\mathrm{a}}$ semana, e semanalmente da $36^{\mathrm{a}}$ até a $41^{\mathrm{a}}$ semana. Quando o parto não ocorre até a $41^{\mathrm{a}}$ semana, é necessário encaminhar a gestante para a avaliação do bem-estar fetal, incluindo avaliação do índice do líquido amniótico e monitoramento cardíaco fetal, sendo aconselhada a indução do parto por ter menor risco de morte neonatal e perinatal.

No Sistema Único de Saúde (SUS), a unidade básica de saúde (UBS) deve ser a porta de entrada preferencial da gestante por ser o local de atenção estratégico para melhor acolher suas necessidades, inclusive proporcionando um acompanhamento longitudinal e continuado, principalmente durante a gravidez. As consultas possuem um roteiro para solicitação de 
exames específicos por trimestre gestacional, assim como as vacinas de rotina estipuladas pelo Ministério da Saúde. Já as gestantes com maiores riscos requerem atenção especial e o cronograma de vacinação, consultas e exames variam de acordo com os riscos identificados e a condição da gestação (BRASIL, 2012a). 
Quadro 1. Exames solicitados por período da gestação no pré-natal de baixo risco.

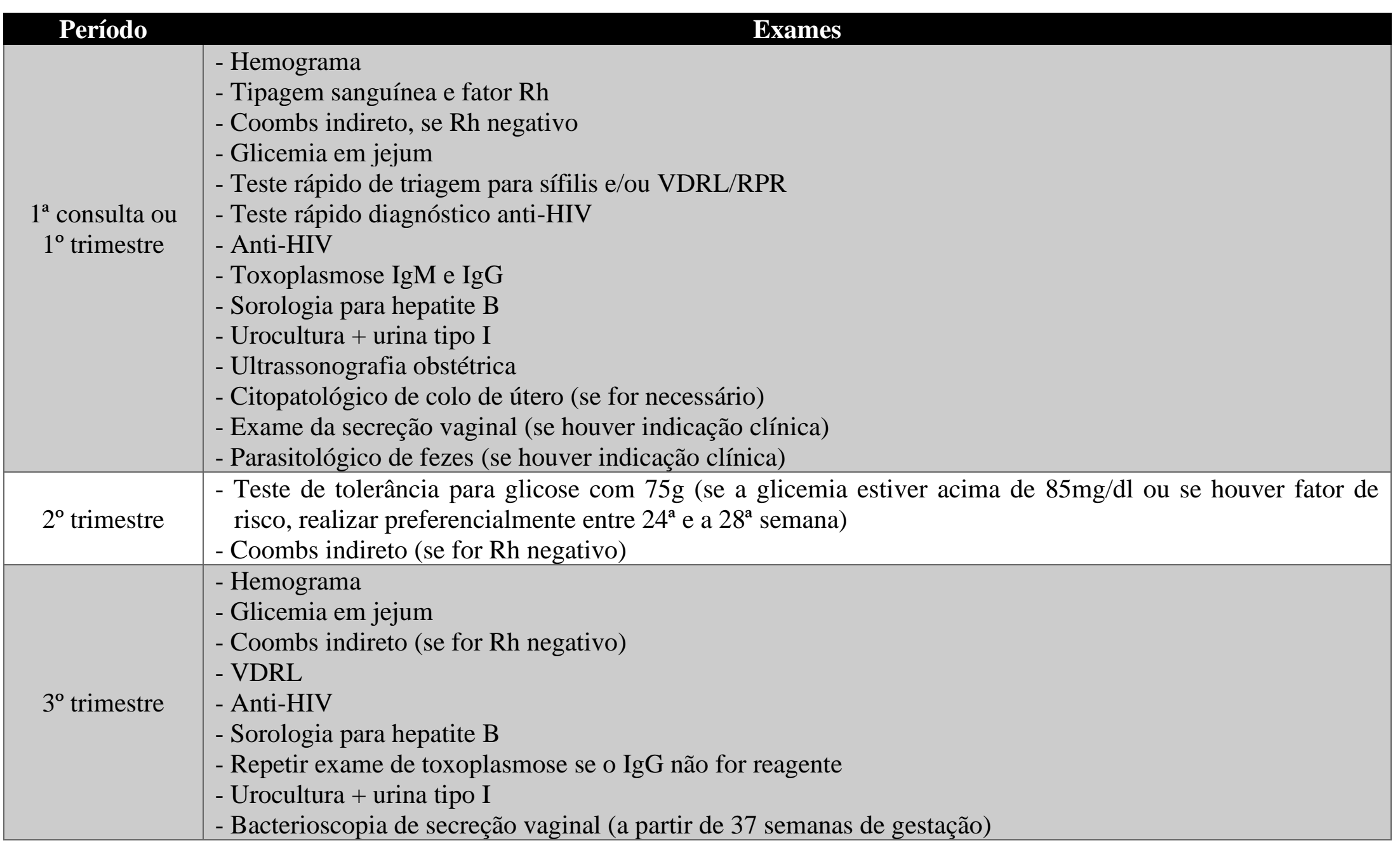

Fonte: Brasil (2005), adaptado. 
Para nortear melhor as ações do pré-natal, foram criados passos para uma melhor qualidade de assistência (BRASIL, 2012a), sendo eles:

- $1^{\circ}$ passo: Iniciar o pré-natal na atenção primária à saúde até a $12^{\mathrm{a}}$ semana de gestação;

- $2^{\circ}$ passo: Garantir os recursos humanos, físicos, materiais e técnicos necessários à atenção pré-natal;

- $3^{\circ}$ passo: Toda gestante deve ter assegurado a solicitação, realização e avaliação em termo oportuno do resultado dos exames preconizados no atendimento pré-natal;

- $4^{\circ}$ passo: Promover a escuta ativa da gestante e dos acompanhantes, considerando aspectos intelectuais, emocionais, sociais e culturais;

- $5^{\circ}$ passo: Garantir o transporte público gratuito da gestante para o atendimento prénatal, quando necessário.

- $6^{\circ}$ passo: É direito do(a) parceiro(a) ser cuidado (realização de consultas, exames e ter acesso a informações) antes, durante e depois da gestação;

- $7^{\circ}$ passo: Garantir o acesso à unidade de referência especializada, caso seja necessário;

- $8^{\circ}$ passo: Estimular e informar sobre os benefícios do parto fisiológico, incluindo a elaboração de um plano de parto.

- $9^{\circ}$ passo: Toda gestante tem direito de conhecer e visitar previamente o serviço de saúde no qual será realizado o parto;

- 10 passo: As mulheres devem conhecer e exercer os direitos garantidos por lei no período gravídico-puerperal.

Pelo fato de a gestação ser um fenômeno fisiológico, deve ser vista como uma experiência de vida saudável que envolve mudanças dinâmicas do olhar físico, social e emocional da gestante. No entanto, devido a alguns fatores de risco, algumas gestantes podem apresentar maior probabilidade de intercorrências, sendo consideradas como gestantes de alto risco (BRASIL, 2012a).

Com o objetivo de reduzir a morbimortalidade materno-infantil e ampliar o acesso com qualidade, é necessário que se identifiquem os fatores de risco gestacional o mais precocemente possível. Dessa forma, o acolhimento com classificação de risco auxilia na agilidade no atendimento e na definição da necessidade de cuidado e da densidade tecnológica que devem ser ofertadas às gestantes em cada momento (BRASIL, 2012a).

Os fatores de risco podem ser agrupados de acordo com as características individuais da mulher, seus comportamentos e estilos de vida, a influência das redes sociais e comunitárias, 
as condições de vida e trabalho e a possibilidade de acesso a serviços, relacionando-se com o ambiente mais amplo de natureza econômica, cultural e econômica (MENDES, 2019).

A caracterização de uma situação de risco, todavia, não implica necessariamente referência da gestante para acompanhamento em pré-natal de alto risco. As situações que envolvem fatores clínicos mais relevantes e/ou fatores que podem ser evitados que demandem intervenções com maior densidade tecnológica devem ser necessariamente referenciadas, podendo retornar ao nível primário, quando se considerar a situação resolvida e/ou a intervenção já realizada. De qualquer maneira, a unidade básica de saúde deve continuar responsável pelo seguimento da gestante encaminhada a um diferente serviço de saúde (BRASIL, 2012a). Os fatores de risco que permitem a realização do pré-natal pela equipe da atenção básica estão descritos no Quadro 2.

Quadro 2. Fatores de risco para a realização do pré-natal pela atenção básica de saúde.

\begin{tabular}{|c|c|}
\hline $\begin{array}{c}\text { Características individuais e } \\
\text { condiçõos sociodemográficas } \\
\text { desfavoráveis }\end{array}$ & $\begin{array}{l}\text { - Idade menor do que } 15 \text { e maior do que } 35 \text { anos; } \\
\text { - Ocupação: esforço físico excessivo, carga horária } \\
\text { extensa, rotatividade de horário, exposição a agentes } \\
\text { físicos, químicos e biológicos, estresse; } \\
\text { - Situação familiar insegura e não aceitação da } \\
\text { gravidez, principalmente em se tratando de } \\
\text { adolescente; } \\
\text { - Situação conjugal insegura; } \\
\text { - Baixa escolaridade (menor do que cinco anos de } \\
\text { estudo regular); } \\
\text { - Condições ambientais desfavoráveis; } \\
\text { - Altura menor do que } 1,45 m \text {; } \\
\text { - Índice de massa corporal que evidencie baixo peso, } \\
\text { sobrepeso ou obesidade. }\end{array}$ \\
\hline História reprodutiva anterior & $\begin{array}{l}\text { - Recém-nascido com restrição de crescimento, pré- } \\
\text { termo ou malformado; } \\
\text { - Macrossomia fetal; } \\
\text { - Síndromes hemorrágicas ou hipertensivas; } \\
\text { - Intervalo interpartal menor do que dois anos ou maior } \\
\text { do que cinco anos; } \\
\text { - Nuliparidade e multiparidade (cinco ou mais partos); } \\
\text { - Cirurgia uterina anterior; } \\
\text { - Três ou mais cesarianas. }\end{array}$ \\
\hline Gravidez atual & $\begin{array}{l}\text { - Ganho ponderal inadequado; } \\
\text { - Infecção urinária; } \\
\text { - Anemia. }\end{array}$ \\
\hline
\end{tabular}

Fonte: Brasil (2012a), adaptado. 
Sabe-se que o pré-natal de alto risco abrange cerca de $10 \%$ das gestações que cursam com critérios de risco, o que aumenta significativamente nestas gestantes a probabilidade de intercorrências e óbito materno e/ou fetal. Desta forma, uma atenção especial é dispensada às grávidas com maiores riscos, a fim de reduzir a morbidade e a mortalidade materna e perinatal (BRASIL, 2012a). Os fatores relacionados à gestante estão descritos no Quadro 3 (na página seguinte). 
Quadro 3. Fatores de risco relacionados à gestante.

\begin{tabular}{|c|c|}
\hline Condições prévias & $\begin{array}{l}\text { - Cardiopatias; Hanseníase; Tuberculose; Pneumopatias graves (incluindo asma brônquica); } \\
\text { - Nefropatias graves (como insuficiência renal crônica e em casos de transplantados); } \\
\text { - Endocrinopatias (especialmente diabetes mellitus, hipotireoidismo e hipertireoidismo); } \\
\text { - Doenças hematológicas (inclusive doença falciforme e talassemia); } \\
\text { - Hipertensão arterial crônica e/ou caso de paciente que faça uso de anti-hipertensivo (PA>140/90mmHg antes de } 20 \\
\text { semanas de idade gestacional); } \\
\text { - Doenças neurológicas (como epilepsia); Doenças psiquiátricas que necessitam de acompanhamento (psicoses, } \\
\text { depressão grave etc.); Doenças autoimunes (lúpus eritematoso sistêmico, outras colagenoses); } \\
\text { - Alteraçães genéticas maternas; Antecedente de trombose venosa profunda ou embolia pulmonar; } \\
\text { - Ginecopatias (malformação uterina, miomatose, tumores anexiais e outras); } \\
\text { - Portadoras de doenças infecciosas como hepatites, toxoplasmose, infecção pelo HIV, sífilis terciária (US com } \\
\text { malformação fetal) e outras DSTs (condiloma); } \\
\text { - Dependência de drogas lícitas ou ilícitas; Qualquer patologia clínica que necessite de acompanhamento especializado. }\end{array}$ \\
\hline $\begin{array}{c}\text { História reprodutiva } \\
\text { anterior }\end{array}$ & $\begin{array}{l}\text { - Morte intrauterina ou perinatal em gestação anterior, principalmente se for de causa desconhecida; } \\
\text { - História prévia de doença hipertensiva da gestação, com mau resultado obstétrico e/ou perinatal (interrupção prematura } \\
\text { da gestação, morte fetal intrauterina, síndrome Hellp, eclâmpsia, internação da mãe em UTI); } \\
\text { - Abortamento habitual; Esterilidade/infertilidade. }\end{array}$ \\
\hline Gravidez atual & $\begin{array}{l}\text { - Restrição do crescimento intrauterino; Polidrâmnio ou oligoidrâmnio; Gemelaridade; Malformações fetais ou arritmia } \\
\text { fetal; } \\
\text { - Distúrbios hipertensivos da gestação (hipertensão crônica preexistente, hipertensão gestacional ou transitória); } \\
\text { - Infecção urinária de repetição ou dois ou mais episódios de pielonefrite (toda gestante com pielonefrite deve ser } \\
\text { inicialmente encaminhada ao hospital de referência, para avaliação); } \\
\text { - Anemia grave ou não responsiva a 30-60 dias de tratamento com sulfato ferroso; } \\
\text { - Portadoras de doenças infecciosas como hepatites, toxoplasmose, infecção pelo HIV, sífilis terciária (US com } \\
\text { malformação fetal) e outras DSTs (condiloma); Infecçães como a rubéola e a citomegalovirose adquiridas na gestação } \\
\text { atual; Evidência laboratorial de proteinúria; Diabetes mellitus gestacional; Desnutrição materna severa; } \\
\text { - Obesidade mórbida ou baixo peso (nestes casos, deve-se encaminhar a gestante para avaliação nutricional); } \\
\text { - NIC III (nestes casos, deve-se encaminhar a gestante ao oncologista); } \\
\text { - Alta suspeita clínica de câncer de mama ou mamografia com Bi-rads III ou mais (nestes casos, deve-se encaminhar a } \\
\text { gestante ao oncologista); } \\
\text { - Adolescentes com fatores de risco psicossocial. }\end{array}$ \\
\hline
\end{tabular}


Quadro 3 (continuação). Fatores de risco relacionados à gestante.

\begin{tabular}{|c|c|}
\hline $\begin{array}{c}\text { Necessidade de } \\
\text { encaminhamento à } \\
\text { urgência/emergência } \\
\text { obstétrica }\end{array}$ & $\begin{array}{l}\text { - Síndromes hemorrágicas (incluindo descolamento prematuro de placenta, placenta prévia), independentemente da } \\
\text { dilatação cervical e da idade gestacional; } \\
\text { - Suspeita de pré-eclâmpsia: pressão arterial > 140/90, medida após um mínimo de } 5 \text { minutos de repouso, na posição } \\
\text { sentada. Quando estiver associada à proteinúria, pode-se usar o teste rápido de proteinúria; } \\
\text { - Sinais premonitórios de eclâmpsia em gestantes hipertensas: escotomas cintilantes, cefaleia típica occipital, } \\
\text { epigastralgia ou dor intensa no hipocôndrio direito; } \\
\text { - Eclâmpsia (crises convulsivas em pacientes com pré-eclâmpsia); Crise hipertensiva (PA > 160/110); } \\
\text { - Amniorrexe prematura: perda de líquido vaginal (consistência líquida, em pequena ou grande quantidade, mas de forma } \\
\text { persistente), podendo ser observada mediante exame especular com manobra de Valsalva e elevação da apresentação } \\
\text { fetal; } \\
\text { - Isoimunização Rh; Anemia grave (hemoglobina < 8); } \\
\text { - Trabalho de parto prematuro (contrações e modificação de colo uterino em gestantes com menos de } 36 \text { semanas); } \\
\text { - IG a partir de } 41 \text { semanas confirmadas; } \\
\text { - Hipertermia (Tax > = 37,8C), na ausência de sinais ou sintomas clínicos de infecção de via aérea superior; } \\
\text { - Suspeita/diagnóstico de abdome agudo em gestantes; } \\
\text { - Suspeita/diagnóstico de pielonefrite, infecção ovular ou outra infecção que necessite de internação hospitalar; } \\
\text { - Suspeita de trombose venosa profunda em gestantes (dor no membro inferior, edema localizado e/ou varicosidade } \\
\text { aparente); } \\
\text { - Investigação de prurido gestacional/icterícia; } \\
\text { - Vômitos incoercíveis não responsivos ao tratamento, com comprometimento sistêmico com menos de } 20 \text { semanas; } \\
\text { Vômitos inexplicáveis no } 3^{\circ} \text { trimestre; } \\
\text { - Restrição de crescimento intrauterino; } \\
\text { - Oligoidrâmnio; } \\
\text { - Casos clínicos que necessitem de avaliação hospitalar: cefaleia intensa e súbita, sinais neurológicos, crise aguda de } \\
\text { asma etc. Nos casos com menos de } 20 \text { semanas, as gestantes podem ser encaminhadas à emeroência clínica. }\end{array}$ \\
\hline
\end{tabular}

Fonte: Brasil (2012a), adaptado. 


\subsection{Fatores de Risco do Bebê}

Para Ramey e Ramey (1998) as crianças que apresentam condições biológicas e/ou sob efeito de determinadas variáveis ambientais têm maior probabilidade de apresentar distúrbio ou atraso em seu desenvolvimento, sendo estas variáveis denominadas fatores de risco. Desta forma, os fatores de risco podem incluir atributos biológicos e genéticos da criança e/ou da família, bem como fatores da comunidade que influenciam, tanto o ambiente da criança quanto de sua respectiva família.

Além dos fatores maternos, descritos na sessão anterior de cuidados à gestante no período pré-natal, deve-se levar em consideração as observações sobre o parto, o período perinatal e condições extrínsecas, como nível socioeconômico.

De acordo com Brasil (2011), antes do parto é fundamental obter da mãe informações relacionadas a sua saúde e às condições da gestação para avaliar o risco de problemas ao nascimento e com base nestas informações o grau de risco é classificado em Alto, Médio e Baixo risco ao nascer. O Quadro 4 apresenta informações necessárias para a classificação do risco ao nascer.

Quadro 4. Informações para classificar o risco ao nascer.

\begin{tabular}{|c|c|}
\hline Perguntar & $\begin{array}{l}\text { - Gestação a termo? } \\
\text { - Líquido amniótico claro? } \\
\text { - Houve ruptura prematura de membranas? Há quanto tempo? } \\
\text { - A mãe teve ou tem febre? } \\
\text { - A mãe teve doenças durante a gravidez? (TORCHS }{ }^{1}, \text { hipertensão, infecção } \\
\text { urinária, diabetes, doença sistêmica grave) } \\
\text { - RN necessitou procedimentos de reanimação? }\end{array}$ \\
\hline Observar & $\begin{array}{l}\text { - Cor } \\
\text { - Respiração } \\
\text { - Choro } \\
\text { - Vitalidade } \\
\text { - Anomalias congênitas } \\
\text { - Sinais de infecção intrauterina } \\
\text { - Lesões graves decorrentes do parto }\end{array}$ \\
\hline Determinar & $\begin{array}{l}\text { - Peso e idade gestacional } \\
\text { - Temperatura axilar } \\
\text { - Frequência respiratória }\end{array}$ \\
\hline
\end{tabular}

Fonte: Brasil (2011), adaptado.

1TORCHS - toxoplasmose, rubéola, citomegalovírus, herpes, HIV, sífilis.

A gestação a termo era antigamente definida como um período de cinco semanas entre 37 e 42 semanas, mas após união conjunta da National Institute of Child Health and Human 
Development, do American College of Obstetricians and Gynecologists, da American Academy of Pediatrics, da Society for Maternal Fetal, do March of Dimes, e da World Health Organization (WHO), o período foi modificado (SPONG, 2013) e segue a classificação:

- Prematuro: menos que 36 semanas e 06 dias;

- Gestação a termo inicial: 37 semanas até 38 semanas e 06 dias;

- Gestação a termo: 39 semanas até 40 semanas e 06 dias;

- Gestação a termo tardio: 41 semanas até 41 semanas e 06 dias;

- Gestação pós-termo: 42 semanas ou mais.

O peso ao nascer é outro fator importante, sendo um parâmetro usado para avaliar as condições de saúde do recém-nascido e, quando considerado de baixo peso ao nascer (< $2.500 \mathrm{~g}$ ), está associado à maior mortalidade e morbidade neonatal e infantil (FERRAZ; NEVES, 2011). No outro extremo, a macrossomia fetal (> 4.000g) está relacionada à asfixia neonatal, maior risco de hipoglicemia fetal, rotura prematura de membranas, trabalho de parto prematuro, desproporção feto-pélvica, traumas esqueléticos, distúrbios hidroeletrolíticos, aspiração de mecônio, entre outros, interferindo no desenvolvimento (AMORIM et al., 2009).

Ferreira, Mello e Silva (2014) verificaram que prematuros apresentam maior risco de desenvolver sepse, e crianças com sepse foram 2,5 vezes mais propensas a desenvolver alterações neuromotoras na amostra com média de peso ao nascer de $1.119 \mathrm{~g}$ e idade gestacional média de 29 semanas e 6 dias.

Com relação ao risco de desenvolver sepse nesta população, Wheater e Rennie (2000) indicam um papel importante da infecção perinatal no desenvolvimento de PC nos prematuros de muito baixo peso, levantando a possibilidade de reduzir a incidência de PC, impedindo a infecção com a sugestão de mais pesquisas para verificar a possibilidade de uso de antibióticos profiláticos.

Dando enfoque à prematuridade, Saldir et al. (2010) ao estudar bebês com idade gestacional menor que 32 semanas verificaram que um em cada quatro recém-nascidos prematuros apresentavam risco no desenvolvimento neurológico. Participaram do estudo 169 recém-nascidos, onde 127 casos $(75,14 \%)$ tiveram desenvolvimento neurológico normal, enquanto $28(16,6 \%)$ e $14(8,3 \%)$ lactentes foram identificados com disfunção neurológica leve e grave anormalidade, respectivamente.

Desta forma, diversas podem ser as intercorrências no parto, e os fatores de risco devem ser observados, tais como: presença de infecções, presença e quantidade de mecônio, 
frequência respiratória > 60 ipm; presença de gemidos do RN; frequência cardíaca < 100 bpm ou > $160 \mathrm{bpm}$; enchimento capilar acima de 3 segundos; temperatura corporal $\geq 38^{\circ} \mathrm{C}$ ou $37,5^{\circ} \mathrm{C}$ em 2 ocasiões com 30 minutos de intervalo; saturação de oxigênio < $95 \%$ e a presença de cianose central confirmada pela oximetria de pulso se disponível, entre outros (BRASIL, 2017).

Ao nascimento, também é recomendável observar e avaliar as condições do recémnascido, principalmente a respiração, frequência cardíaca e tônus, para determinar se a ressuscitação é necessária de acordo com diretrizes reconhecidas de reanimação neonatal (BRASIL, 2017).

Quando é necessária a reanimação, o Boletim de Apgar (Quadro 5) é útil para avaliar a resposta do RN às manobras de reanimação no $1^{\circ}$ e $5^{\circ}$ minutos de vida, somando a pontuação $(0,1$ ou 2$)$ de cada sinal ao nascer. Ele também serve como um relatório numérico prático para descrever a condição de nascimento e a recuperação do RN (BRASIL, 2012a).

Quadro 5. Boletim de Apgar.

\begin{tabular}{|c|c|c|c|}
\hline Sinal & 0 & 1 & 2 \\
\hline Frequência cardíaca & Ausente & $<100$ & $>100$ \\
\hline Respiração & Ausente & Irregular & Choro forte \\
\hline Tônus muscular & Flacidez & $\begin{array}{l}\text { Alguma flexão de } \\
\text { extremidades }\end{array}$ & Boa movimentação \\
\hline $\begin{array}{l}\text { Reflexos } \\
\text { (estímulo nasal) }\end{array}$ & Ausente & Algum movimento & Espirros \\
\hline Cor & Cianose e/ou palidez & $\begin{array}{l}\text { Corpo róseo } \\
\text { extremidades } \\
\text { cianóticas }\end{array}$ & Róseo \\
\hline
\end{tabular}

Fonte: Apgar (1953), adaptado.

Felice e colaboradores (2019) realizaram um estudo para verificar os fatores de risco para paralisia cerebral no período de 5 anos (2010-2014) no município de Ribeirão Preto - SP, buscando identificar a proporção de crianças nascidas na rede pública e que foram identificadas como apresentando risco de atraso de desenvolvimento e, dentre estas, as diagnosticadas com paralisia cerebral, além de identificar os fatores de riscos mais prevalentes. A coleta de dados identificou os bebês de risco e os riscos materno, pré e perinatais nos prontuários das crianças que frequentaram o serviço de referência, onde o desfecho final era o diagnóstico de paralisia cerebral. Através de análises descritivas e testes de associação os autores verificaram que dos nascidos vivos no período, 23,3\% foram 
considerados com risco de atraso do desenvolvimento. Foram analisados 481 prontuários e em $76,92 \%$ não havia informação da saúde prévia da mãe e a maioria não planejou a gravidez. Cerca de $65 \%$ das crianças apresentavam indícios de alterações neurológicas e 73,4\% tiveram alta por abandono, o que dificultou a observação do desfecho, comprometendo as análises de associação, estimativa da prevalência de paralisia cerebral e uma intervenção mais direcionada no período de maior neuroplasticidade e melhor prognóstico, sendo necessárias adequações no serviço.

\subsection{Paralisia Cerebral}

A paralisia cerebral (PC) foi descrita inicialmente em 1843 por um médico ortopedista inglês, Willian John Little, que considerava a ausência do movimento nos membros como sendo proveniente de problemas cerebrais ocorridos durante o parto (LITTLE, 1966; ROTTA, 2002; BRASIL, 2013). Com o passar dos anos, as intercorrências obstétricas se tornaram cada vez mais preocupantes e iniciaram-se estudos quanto à fisiopatogenia das lesões cerebrais e o prognóstico para sequelas neurológicas (COURVILLE, 1950).

Little estudou crianças com quadro clínico de espasticidade e as relacionou com as intercorrências no nascimento, como apresentação pélvica, prematuridade, intercorrências no parto, demora para chorar e respirar, convulsões e coma nas primeiras horas de vida. Desta forma, em 1862 o médico estabeleceu a relação entre o quadro de rigidez muscular, espasticidade e paralisia com o parto anormal (ROTTA, 2002; MORRIS, 2007; BRASIL, 2013).

Durante muitos anos este quadro nosológico foi conhecido como "Síndrome de Little", mas outros pesquisadores como Sarah McNutt em 1885, Willian Osler em 1889 e Sachs e Peterson em 1890, continuaram os estudos e sugeriram novos termos de classificação, como hemiplegia infantil, hemiplegia bilateral espástica e paraplegia espástica. Investigando a etiologia, os pesquisadores chegam à conclusão de que qualquer uma destas três formas de apresentação clínica poderia resultar de uma variedade de causas (MORRIS, 2007).

Em 1893, Sigmund Freud propôs uma terminologia com base na identificação de três principais fatores causais: pré-natal (materno e congênito), perinatal e pós-natal. Em 1897 sugeriu a expressão Paralisia Cerebral, que foi consagrada por Phelps, ao se referir a um 
grupo de crianças que apresentavam comprometimentos motores variados causados por lesão no sistema nervoso central (ROTTA, 2002; MORRIS, 2007; BRASIL, 2013).

Em 1941, Phelps desenvolveu uma abordagem para o tratamento das crianças com PC, indicando fisioterapia, uso de órteses, bloqueios e, posteriormente, estabeleceu os quatro principais objetivos de tratamento: locomoção, autocuidado, fala e aspectos gerais (MORRIS, 2007).

Desta forma, Phelps estabeleceu seus critérios de classificação baseados no tratamento, mas havia a necessidade de classificação para fins de diagnóstico. Ele propôs que a classificação deveria ser pautada na funcionalidade, incluindo habilidades físicas e mentais, além da avaliação social, que precederia o tratamento. Então, agrupou os problemas de movimento sob o termo de discinesia e utilizou como subcategorias a espasticidade, atetose, sincinesia, ataxia e tremores (MORRIS, 2007; PAKULA; BRAUN; YEARGIN-ALLSOPP, 2009).

Em 1957, Mac Keith e Polani reuniram um grupo, "O clube de Little”, com o propósito de pensar na terminologia para a descrição da PC, sendo a seguinte: um problema permanente e não mutável de movimento e postura, que aparece nos primeiros anos de vida devido a um problema não progressivo do cérebro, resultado de interferência durante seu desenvolvimento. Com relação à classificação da manifestação clínica, utilizavam o termo espástico, com as subcategorias de hemiplegia, dupla hemiplegia e diplegia, sendo que as categorias que envolviam todo o corpo eram denominadas de distonia, coreoatetose, mista, atáxica e atônica (MAC KEITH; POLANI, 1959; MORRIS, 2007).

A classificação da PC foi revisada em 1964, por alguns membros do clube, devido ao fato de existir inconsistência na interpretação de termos como "espástico" entre diferentes profissionais e países. Sendo assim, em 1980, a Sociedade de Espasticidade (hoje denominada de SCOPE) uniu um grupo de especialistas para discutir e classificar a PC de acordo com a perspectiva epidemiológica (EVANS; ALBERMAN, 1985; EVANS, 1987; MORRIS, 2007).Como objetivo principal, o grupo tinha interesse em monitorar as taxas de incidência de PC na população como um marcador de saúde pública de cuidados de saúde perinatal e neonatal, mas os detalhes sobre a confiabilidade e validade não foram amplamente divulgados (MORRIS, 2007).

A partir do ano 2000, a padronização da definição da PC continuou sendo o foco dos estudos e, em 2004, foi realizado o Workshop Internacional sobre Definição e Classificação 
da Paralisia Cerebral em Bethesda, Maryland (EUA). Os objetivos do evento foram reavaliar a definição de PC, motivada por fatores como mudanças na prestação de cuidados a crianças com deficiência; reconhecimento de que crianças com erros inatos do metabolismo lentamente progressivos podem apresentar dificuldades motoras, as vezes, indistinguíveis das crianças com doenças não progressivas; aumento da disponibilidade de alta qualidade de imagens cerebrais para identificar deficiências estruturais do cérebro; reconhecimento de que o prejuízo no desenvolvimento motor é quase sempre associado a outras deficiências e, por último, maior compreensão sobre os antecedentes associados e correlacionados da PC (ROSENBAUM et al., 2007).

Os participantes concordaram que a PC não era um diagnóstico etiológico, mas um termo de descrição clínica. Desta forma, foram feitas restrições sobre o foco exclusivo em alterações motoras, tendo em vista que as pessoas com deficiências no neurodesenvolvimento frequentemente apresentam comprometimentos variados nas funções, necessitando de acompanhamento individualizado e multidimensional (ROSENBAUM et al., 2007; PAKULA; BRAUN; YEARGIN-ALLSOPP, 2009).

Por fim, segundo um consenso internacional mediado pela United Cerebral Palsy Researchand Educational Foundation (USA) e a Castang Foundation (UK) definiu-se que a PC descreve um grupo de desordens permanentes relacionadas ao desenvolvimento do movimento e da postura, que causa limitações funcionais atribuídas a distúrbios nãoprogressivos no cérebro fetal ou infantil em desenvolvimento (ROSENBAUM et al., 2007). As desordens motoras presentes na criança com paralisia cerebral são frequentemente acompanhadas por distúrbios da sensação, percepção, cognição, comunicação e comportamento podendo estar associada com a epilepsia e problemas musculoesqueléticos secundários (ROSENBAUM et al., 2007; NOVAK, 2014).

De acordo com Rosenbaum et al. (2007), para uma melhor compreensão e tratamento da PC, algumas características devem ser consideradas para a classificação, como as alterações motoras, acompanhamento da deficiência, anatomia, exames de neuroimagem e relação de causa e tempo.

Com relação às alterações motoras, a PC é classificada em três grupos de acordo com a alteração mais dominante, sendo eles: espástico, atáxico ou discinético. Dentro da classificação do discinético, há a diferenciação entre distonia e coreoatetose. É recomendável que o termo "misto" seja evitado (ROSENBAUM et al., 2007). 
O acompanhamento da deficiência deve ser realizado tendo em vista outras possíveis alterações associadas, como déficits auditivos ou visuais, convulsões, comprometimentos emocionais, comportamentais e musculoesqueléticos (ROSENBAUM et al., 2007). Uma meta-análise realizada em 2014, sobre as taxas globais de distúrbios associados e limitações funcionais na PC, registrou que três em cada quatro indivíduos sentem dor; um em cada dois apresenta algum grau de deficiência intelectual; um em cada três não deambula e adquire luxação de quadril; um em cada quatro apresenta problema de linguagem, epilepsia, distúrbio de comportamento, incontinência urinária; um em cada cinco apresenta distúrbio do sono; um em cada dez é deficiente visual (NOVAK, 2014).

No aspecto anatômico, a PC é classificada topograficamente em unilateral, quando um hemicorpo é comprometido, e em bilateral, quando ambos os lados são comprometidos (ROSENBAUM et al., 2007). Os exames de neuroimagem, embora auxiliem no diagnóstico, apresentam fraca correlação com o quadro clínico e não possuem esquema padronizado de classificação (ROSENBAUM et al., 2007). Já no que se refere a relação de causa e tempo de exposição à lesão, não foi estabelecida uma classificação, tendo em vista a grande diversidade de fatores de risco e causas etiológicas da PC (ROSENBAUM et al., 2007).

No que concerne aos distúrbios motores, a PC era descrita somente de acordo com alterações do movimento ou por descritores topográficos, porém, atualmente é recomendado também que a função motora grossa em crianças com PC seja mensurada e classificada de acordo com o Gross Motor Function Classification System - Expanded \& Revised (GMFCS E\&R) (PALISANO et al., 2008) já que as classificações por desordem de movimento e pela distribuição topográfica não são tão confiáveis (HOWARD et al., 2005; ROSENBAUM et al., 2007).

O GMFCS E\&R classifica a PC em cinco níveis, em faixas etárias diferentes de 0 a 18 anos, baseados na mobilidade funcional atividade capacidade de sentar-se e deambular, levando em consideração diversos ambientes no desempenho motor da criança e do adolescente (PALISANO et al., 2008). As faixas etárias são divididas em: inferior a 2 anos, de 2 a 4 anos, de 4 a 6 anos, de 6 a 12 anos e de 12 a 18 anos. Já os níveis, variam de acordo com a assistência que a criança necessita, sendo o nível I de maior independência e o nível V totalmente dependente (PALISANO et al., 2008) e foi adaptado transculturalmente para a população brasileira por Silva e colaboradores (2013). 
Levando em consideração o neurodesenvolvimento, sabe-se atualmente que até os 2 anos de idade pode haver mudanças nos níveis de classificação, mas após esta idade o nível se mantém estável (NOVAK, 2014). De acordo com o Australian Cerebral Palsy Report (ACPR GROUP, 2013), 32\% das crianças com PC de 2 a 4 anos de idade na Austrália são classificadas em nível I no GMFCS, 27\% em nível II, 12\% em nível III, 14\% em nível IV e 15\% em nível V (ACPR GROUP, 2013; NOVAK, 2014).

Pfeifer et al. (2009) realizam um estudo em uma cidade do estado de São Paulo para avaliar a relação entre gênero, idade, tipo motor, topografia e GMFCS em 100 crianças com idade entre 5 meses e 12 anos. Não houve diferença entre os gêneros e grupos etários e entre gênero e tipo motor. A topografia mais frequente foi a quadriplegia e com relação ao GMFCS, as crianças hemiplégicas pertenciam em maior parte ao nível I (93,3\%), as diplégicas ao nível III $(33,3 \%)$ e as quadriplégicas ao nível V $(71,1 \%)$.

Como o foco do GMFCS é determinar qual o melhor nível representa as habilidades atuais da criança ou adolescente com PC, considera-se o desempenho habitual (em casa, na escola e na comunidade) ao invés do melhor desempenho (PALISANO et al., 2008; SILVA et al., 2013). Como este instrumento não possibilitava a classificação da função manual, foi publicado o Manual Ability Classification System (MACS) em 2006 para crianças e adolescentes de 4 a 18 anos e o Mini-MACS em 2013 para 0 a 4 anos (ELIASSON, et al., 2016). O MACS enfatiza o desempenho manual durante a realização das atividades de vida diária no seu contexto (em casa, na escola e na comunidade) e não verifica qualidade ou avalia separadamente o membro superior afetado (ELIASSON et al., 2006; BRASIL, 2013). Assim como o GMFCS, ele classifica em cinco níveis, sendo o Nível I quando manipula objetos facilmente e o Nível 5 quando é dependente nas funções manuais e não manipulam objetos (ELIASSON et al., 2006; BRASIL, 2013) e foi adaptado culturalmente para o Brasil por SILVA et al., 2010.

Levando em consideração o enfoque classificatório, o GMFCS e o MACS não são medidas de desfecho para fins de comparações pré e pós alguma intervenção, mas possibilitam a descrição das habilidades, projetam um prognóstico acerca das reais necessidades do indivíduo e possibilitam comparações entre casos coletados em diferentes locais (ROSENBAUM et al., 2007).

Outro instrumento muito utilizado em crianças e adolescentes de 4 a 18 anos com paralisia cerebral é a Functional Mobility Scale (FMS) (GRAHAM et al., 2004; PALISANO 
et al., 2003). Ele foi criado para observar a função locomotora em ambientes do cotidiano e classifica em 6 níveis a mobilidade funcional de acordo com o tipo de equipamento utilizado, incluindo a marcha independente. A FMS é um instrumento classificatório simples e de fácil aplicação, onde os pesquisadores e terapeutas perguntam aos pais ou responsáveis a forma como a criança se locomove em sua residência, escola e comunidade, respectivamente representados pelas distâncias de 5m, 50m e 500m (KLEINER et al., 2008).

Com relação à comunicação, estima-se que aproximadamente $88 \%$ das crianças com PC tenham algum problema e, para classificar este domínio há o Communication Function Classification System (CFCS) (HIDECKER et al., 2011), que análogo ao GMFCS e ao MACS em 5 níveis, analisa a eficiência do indivíduo para emitir e para receber mensagens. $\mathrm{O}$ CFCS permite todos os métodos de comunicação, incluindo vocalizações, sinais manuais, figuras, geradores de voz levando em conta a eficiência alcançada com pessoas familiares e desconhecidas. Em relação às funções de alimentação, seguindo metodologia similar, foi elaborado o Eating and Drinking Ability Classification System (EDACS) (SELLERS et al., 2014).

Sabe-se que a PC é geralmente diagnosticada por volta dos 12 a 24 meses devido à falta de marcadores específicos, o que gera uma prática de "esperar para ver" (NOVAK, 2014, p. 1142). O diagnóstico precoce em 12 semanas de idade somente é possível em unidades de terapia intensiva neonatal onde os fatores de risco são identificáveis (e.g., prematuridade, encefalopatia, convulsões neonatais, acidente vascular cerebral neonatal ou pós-natal, nascimentos múltiplos, infecção pós-natal ou pós-parto e cirurgia). Por outro lado, diagnosticar precocemente crianças atermo sem a presença de fatores de risco identificáveis requer mais pesquisas (NOVAK, 2014).

O diagnóstico precoce é considerado a melhor prática, pois gera a oportunidade de uma rápida intervenção, justamente quando são possíveis os maiores ganhos de neuroplasticidade (MCINTYRE et al., 2011). Segundo Novak (2014) o diagnóstico da PC envolve a combinação de histórico de fatores de risco, exame neurológico, avaliação da qualidade do movimento, neuroimagem e exclusão de diagnósticos alternativos.

a. Histórico dos fatores de riscos.

Evidências recentes apontam para o fato de que a PC pode ser o resultado de uma combinação de fatores que incluem a predisposição genética associada a fatores desencadeantes presentes tanto no ambiente intra como extrauterino (NOVAK, 2014). 
Segundo Tâmega, Filho e Pinto (2011) os fatores de risco mais frequentes em lactentes para paralisia cerebral são: a infecção congênita (15\%), a infecção do sistema nervoso central $(10,6 \%)$ e o estado de mal convulsivo $(22,5 \%)$ sendo que a prematuridade esteve associada a esses fatores de risco em $50 \%$ dos lactentes. Complementarmente a estes dados, Gladstone (2010) relaciona a baixa idade gestacional, o baixo peso ao nascer, a asfixia perinatal, a leucomalácia periventricular ou subcortical, a hemorragia intraventricular grave, a isquemia cerebral e a lesão da substância cinzenta profunda como preditores para PC.

Em um estudo retrospectivo realizado no Hospital das Clínicas de Ribeirão Preto foram analisados, ao acaso, 35 prontuários de crianças com diagnóstico de PC entre 1982 e 1998, com o objetivo de verificar fatores etiológicos. As infecções congênitas (36\%) e agressão hipóxico-isquêmica (28\%) foram os mais frequentes fatores determinantes de PC entre 25 casos com etiologia definida (FUNAYAMA et al., 2000).

b. Exame neurológico.

Torna-se importante a realização de um exame neurológico acurado, preferencialmente utilizando o Hammersmith Infant Neurological Evaluation - HINE - já que sua pontuação auxilia na identificação da PC e seu nível de comprometimento.

O HINE é uma avaliação neurológica mais completa para identificar riscos de desenvolvimento em crianças de 2 a 24 meses de idade. Contém itens para avaliar a função dos nervos craniais, postura, movimentos, tônus e reflexos, sendo que sua pontuação foi padronizada e pode ajudar no prognóstico locomotor de 2 a 4 anos de idade (ROMEO et al., 2008).

c. Avaliação da qualidade do movimento.

Outro aspecto é a observação da qualidade do movimento do bebê. Isto pode ser realizado de suas formas: usando o Prechtl's General Movement (EINSPIELER; PRECHTL, 2005) para crianças menores de 04 meses de idade corrigida ou, utilizando o questionário familiar Developmental Assessment of Young Children (MAITRE, 2013) para crianças de 06 a 12 meses de idade, a partir da observação do movimento voluntário.

O Prechtl's General Movement, consiste em uma abordagem para avaliar funcionalmente o sistema nervoso de bebês através da qualidade do movimento espontâneo, chamado de movimentos globais (MG), sendo um excelente marcador para o 
comprometimento cerebral precoce e sua disfunção, já que considera os reflexos indicadores imprecisos (EINSPIELER; PRECHTL, 2005).

Já o Developmental Assessment of Young Children verifica o desenvolvimento na primeira infância em cinco domínios (cognição, comunicação, desenvolvimento sócioemocional, desenvolvimento físico e comportamento adaptativo) em crianças desde o nascimento até os 5 anos de idade e 11 meses. A avaliação é separada por faixas etárias e consiste em uma observação da criança, entrevista com os pais e a avaliação estruturada (MAITRE, 2013).

\section{d. Neuroimagem.}

Todas as crianças com diagnóstico ou suspeita devem realizar exame de ressonância magnética (RM). Além disso, outro fator que corrobora para um diagnóstico mais preciso é a evolução e aperfeiçoamento das técnicas ultrassonográficas (US), de tomografia computadorizada e ressonância magnética nuclear, que somadas aos avanços na assistência pré-natal colocaram em destaque as malformações cerebrais, infecções maternas, congênitas e amnióticas como possíveis causas de PC (JAW et al., 1998).

O exame de ressonância magnética é comprovadamente sensível e específico na definição do prognóstico de bebês com risco neonatal e sua sensibilidade e especificidade são próximas a $100 \%$. No entanto, a dificuldade prática e custos para o seu uso o torna reservado, na maioria dos cenários (PEREIRA, 2018).

e. Exclusão de diagnósticos alternativos, inclusive o relacionado a desordens progressivas.

Algumas condições médicas como, por exemplo, doenças metabólicas e alterações genéticas, podem mimetizar as manifestações clínicas da PC, particularmente aquelas que tem um curso de progressão relativamente lento. Estas condições são mais facilmente diagnosticadas de maneira incorreta e, por conta disso, é importante considerar as implicações das investigações genéticas e o uso dos exames de imagem em muitas destas condições (ZARRINKALAM et al., 2010).

Nos últimos anos, a compreensão da base genética para a PC teve grande avanço e é provável a presença da contribuição genética em um terço de todas as crianças com PC, 
principalmente naquelas sem fatores de risco convencionais, como a prematuridade e hipóxia (FAHEY et al., 2017).

Estudos recentes de base populacional em todo o mundo, segundo o Centers for Disease Control and Prevention (2021), relatam a prevalência da PC entre 1 a quase 4 por cada 1.000 nascidos vivos, e este quadro que tem se mantido relativamente estável ao longo de décadas e sendo a principal causa de incapacidade física em crianças (MORRIS, 2007; NOVAK, 2014).

Os dados demográficos apontam para a existência de 550 a 600 mil pacientes nos Estados Unidos, com acréscimo de 20 mil novos casos por ano. Havia um custo estimado de \$11,5 bilhões para as pessoas com PC nascidas nos Estados Unidos no ano de 2000 (JOSEPH et al., 2003). Estima-se que a incidência de PC nos países em desenvolvimento seja de 7/1.000 nascidos vivos e, nos países desenvolvidos, varie de 1,5 a 5,9/1.000 (HIMPENS et al., 2008), estas diferenças de incidências podem ser atribuídas às más condições de cuidados prénatais e ao precário atendimento primário às gestantes (BRASIL, 2013).

Segundo a revisão sistemática de Novak (2020), na última década grandes descobertas foram feitas no diagnóstico precoce, prevenção e tratamento, alterando incidência, prognóstico e responsividade ao tratamento da PC. Em países de alta renda, como a Austrália, a gravidade motora diminuiu e a incidência de PC diminuiu 30\% (GALEA et al., 2019). O prognóstico de marcha melhorou com os achados de que pessoas com PC não deambuladoras, epilepsia e deficiência intelectual concomitante são menos frequentes. Epidemiologistas propõem que a redução da incidência e da gravidade provavelmente se devem a uma combinação de intervenções abrangentes de terapia intensiva obstétrica e neonatal (NOVAK, 2020).

Observa-se que os maiores avanços foram com relação à prevenção. A taxa de paralisia cerebral caiu 30\% em alguns países de alta renda, reduzindo a prevalência para 1,4 por 1000 (GALEA et al., 2019; Register ACPR, 2018).

A diferença das taxas de países desenvolvidos e os de média e baixa renda ainda são preocupantes. Um exemplo é Bangladesh, a taxa de PC é mais do que o dobro da Austrália (3,4 contra 1,4 por 1000). Duas vezes mais crianças de Bangladesh têm deficiências motoras graves (GMFCS IV - V = 43,6\%, em comparação com 26\% na Austrália), e 78,2\% não recebem qualquer tipo de reabilitação (KHANDAKER et al., 2019).

Apesar de as taxas de prevalência serem de extrema importância para a orientação das políticas de saúde operacionais e no auxílio da alocação de recursos adequados há no Brasil 
uma carência de estudos com dados específicos sobre a prevalência e a incidência da PC. No Brasil, após a Lei no $7.853 / 89$ que tornou obrigatória a inclusão de itens específicos nos censos nacionais, o Censo Demográfico de 1991 incluiu pela primeira vez questões que atestaram a presença de 2.198 .988 pessoas com deficiência, em uma população total de 146.815.750 habitantes, o que representa 1,49 \% desta (BRASIL, 2010). O Censo de 2000, utilizando nova abordagem conceitual e metodológica, identificou 24,6 milhões de pessoas com algum tipo de deficiência (14,5\% da população brasileira). Foram detectados, no total de 24,6 milhões, $48 \%$ de pessoas com deficiência visual, $23 \%$ com deficiência motora (comprometimento do sistema locomotor), 17\% com deficiência auditiva, $8 \%$ com deficiência intelectual e $4 \%$ com deficiência física (alteração completa ou parcial de um ou mais segmentos do corpo humano) (BRASIL, 2010), mas não há dados específicos sobre a PC, podendo ela estar relacionada tanto com as deficiências motoras como às físicas. O Censo de 2010, último com resultados disponíveis, verificou que a deficiência mais recorrente no Brasil é a visual $(18,6 \%)$, seguida da motora $(7 \%)$, seguida da auditiva $(5,10 \%)$ e, por fim, da deficiência mental (1,40\%), sendo que cerca de 45.606 .048 milhões de pessoas têm algum tipo de deficiência (23,9\% da população geral).

Devido à escassez de pesquisa tanto em âmbito nacional quanto no município de Ribeirão Preto - SP, à falta de consistência nos dados encontrados na literatura e a dificuldade encontrada no estudo de mestrado em verificar o desfecho do acompanhamento e diagnóstico dos bebês de risco no município, esta pesquisa se faz necessária para se conhecer mais profundamente a relação entre as ocorrências pré e peri natais, o diagnóstico, o início da intervenção e aspectos clínicos e funcionais da criança com PC, permitindo, desta forma, a criação de estratégias mais planejadas para as políticas de saúde que tornem o cuidado com o bebê de risco e com as crianças com PC mais rápido e eficaz. 


\section{QUESTÕES DE PESQUISA}

Diante da carência de estudos nacionais sobre a prevalência e incidência da PC e sendo as taxas de extrema importância para a orientação das políticas operacionais de saúde e no auxílio da alocação de recursos adequados para a prevenção, levantam-se as seguintes questões de pesquisa:

- Quantas crianças com PC frequentam serviços de reabilitação da rede pública do município de Ribeirão Preto?

- Quais os riscos foram mais frequentes e qual o perfil das características dos períodos pré-natal e perinatal destas crianças?

- Quais associações existem entre os fatores de risco e o diagnóstico de PC?

- Qual a idade média da criança quando teve suspeita e quando recebeu o diagnóstico de PC?

- Quem levantou a suspeita do atraso para a família?

- Qual a idade que a criança inicia intervenção?

- Há associação entre o risco e o inicío da reabilitação?

- Há associação entre a topografia, GMFCS e o início da reabilitação? 


\section{HIPÓTESES}

- Espera-se conhecer a quantidade de crianças com PC que estão em reabilitação na rede pública, levando em consideração que a incidência seja de 1 a 4 para 1000 nascidos vivos.

- Espera-se que a saúde materna, as intercorrências na gestação e/ou no parto tenham associação com a PC, com sua topografia e nível funcional.

- Espera-se verificar os fatores de risco mais frequentes das crianças que estão em reabilitação na rede pública do município, identificando a correlação entre estes fatores de risco e o desfecho neurológico (PC), com sua topografia e nível funcional. 


\section{OBJETIVOS}

Esta pesquisa teve como objetivo principal realizar um estudo observacional retrospectivo dos fatores de risco para paralisia cerebral nas crianças e adolescentes com PC que estão em reabilitação na rede pública no município de Ribeirão Preto - SP e verificar se há associação entre estes fatores e as características clínicas e funcionais desta população.

\subsection{Objetivos específicos}

- Identificar os fatores de riscos mais prevalentes das crianças e adolescentes com PC que frequentam a reabilitação no município;

- Verificar se há associação entre os fatores de risco da paralisia cerebral com as classificações funcionais (função motora grossa e habilidade manual) e locomoção;

- Verificar se há associação entre os fatores de risco da paralisia cerebral com as características atuais da saúde e desenvolvimento da criança;

- Verificar se há associação entre as informações sobre diagnóstico e intervenção com as classificações funcionais e locomoção;

- Verificar se há associação entre as características atuais da saúde e desenvolvimento da criança com as classificações funcionais e locomoção;

- Verificar se há associação entre as características atuais da saúde e desenvolvimento da criança com as informações sobre diagnóstico e intervenção. 


\section{MATERIAL E MÉTODO}

O presente estudo é classificado como estudo observacional retrospectivo.

\subsection{Sujeitos}

Os critérios de inclusão do estudo foram as crianças e adolescentes com PC que frequentavam os serviços de reabilitação da rede pública no município de Ribeirão Preto - SP, no período de agosto de 2019 a março de 2020.

\subsection{Procedimentos para coleta de dados}

\subsubsection{Etapa 1: Identificação das crianças e adolescentes com PC nos serviços.}

Foi realizado contato com profissionais das instituições que prestam serviço ou tem parceria com a rede pública, com o aval da instituição, realizando um convite para participar da pesquisa e informar o número de crianças e adolescentes com PC que estavam em reabilitação, bem como seu contato através do preenchimento de uma planilha que foi enviada previamente por e-mail.

\subsubsection{Serviços da rede pública de Ribeirão Preto}

O conceito de ambiência na rede de cuidados à saúde da pessoa com deficiência é definido como o espaço físico, social, profissional e de relações interpessoais que deve estar relacionado a um projeto de saúde voltado para a atenção acolhedora, resolutiva e humana (BRASIL, 2017).

O Centro de Reabilitação (CER) é um local de atenção ambulatorial especializada em reabilitação que realiza diagnóstico, avaliação, orientação, estimulação precoce e atendimento especializado em reabilitação, concessão, adaptação e manutenção de tecnologia assistiva, constituindo-se em referência para a rede de atenção à saúde no território, e poderá ser organizado como CER II - composto por duas modalidades de reabilitação; CER III composto por três modalidades de reabilitação; e CER IV - composto por quatro modalidades de reabilitação (BRASIL, 2017).

O município de Ribeirão Preto possui todos os Centros de Reabilitação, mas também há parceria com instituições privadas para ser uma local de reabilitação, como por exemplo, com as Universidades, que possuem cursos de graduação na área e que possuem espaço físico para as práticas supervisionadas no estágio no último ano da graduação. 
Desta forma, considerando a reabilitação física e as áreas de fisioterapia, terapia ocupacional e fonoaudiologia, há em Ribeirão Preto 07 locais que prestam essa assistência, sendo eles:

- Associação dos Pais e Amigos dos Excepcionais de Ribeirão Preto (APAE);

- Centro de Reabilitação do Hospital das Clínicas (CER);

- Centro Integrado de Reabilitação do Hospital Estadual (CIR);

- Clínica de Fisioterapia do Centro Universitário Barão de Mauá (CBM);

- Clínica de Fisioterapia na Universidade de Ribeirão Preto (UNAERP);

- Clínica de Fisioterapia do Centro Universitário Estácio de Ribeirão Preto;

- Clínica de Fisioterapia da Universidade Paulista (UNIP).

\subsubsection{Etapa 2: Entrevista com os responsáveis.}

Inicialmente as entrevistas foram oferecidas de forma presencial enquanto a criança estava em atendimento terapêutico no serviço e interrompidas no período de férias de alguns serviços. Posteriormente, com o início da pandemia do coronavírus e recomendação de isolamento social, as entrevistas foram realizadas por meio telefônico, com a opção de ser no momento da chamada ou em horário previamente agendado.

Foram então coletados dados acerca do período gestacional, acompanhamento pré-natal e investigação de intercorrências, parto e desenvolvimento atual da criança através de um questionário elaborado para esta pesquisa (Apêndice I).

\subsubsection{Etapa 3: Verificação das informações com os profissionais.}

O objetivo desta etapa foi identificar a topografia e distúrbios do movimento, uso de órteses e dispositivos auxiliares, bem como classificações funcionais (Apêndice II). As classificações foram seguidas do protocolo estabelecido de utilização dos instrumentos, sendo eles: Gross Motor Function Classification System Expanded and Revised (GMFCS), Manual Ability Classification System (MACS) e Function Mobility Scale (FMS), disponíveis em língua portuguesa (GRAHAM et al., 2004; ELIASSON et al., 2006. SILVA et al., 2010).

\subsubsection{Instrumentos de classificação}

O GMFCS (Anexo 1) é um sistema de classificação ordinal (cinco níveis) em que uma série de descritores, complementada por ilustrações, pode ser usada para classificar a função motora grossa em crianças com PC de 0 a 18 anos, separadas por idade (PALISANO et al., 2007; PALISANO et al., 2008). Esta classificação possui validade e confiabilidade 
estabelecidas na literatura (PALISANO et al., 2008; SELLIER et al., 2012) e é a ferramenta mais importante que profissionais de saúde podem usar para uniformizar e descrever o nível de função motora grossa da criança, levando assim a uma maior acurácia no estabelecimento de um prognóstico e já passou pelo processo de adaptação transcultural para utilização junto à população brasileira (SILVA; PFEIFER; FUNAYAMA, 2010).

Com relação a habilidade global para manipular objetos o MACS (Anexo 2) é utilizado para crianças com paralisia cerebral de 4 a 18 anos de idade. Apresenta cinco níveis baseados na habilidade da criança iniciar sozinha a manipulação de objetos e se possui necessidade de adaptação ou assistência para realizar as atividades manuais na vida diária. Desta forma, o nível I inclui crianças com pequenas limitações e o nível V com limitações funcionais mais graves (ELIASSON et al., 2006). Esta classificação também passou pelo processo de adaptação transcultural para a população brasileira (SILVA; PFEIFER; FUNAYAMA, 2010).

Já a FMS (Anexo 3) descreve a mobilidade funcional em crianças com PC a partir dos 04 anos em três distâncias distintas, escolhidas para representar a mobilidade em casa (5 metros), na escola (50 metros) e na comunidade em geral (500 metros) (PALISANO, 2003; GRAHAN, 2004).

\subsection{Amostra}

Optou-se pela amostra de conveniência, considerando ser uma busca ativa nos serviços.

\subsection{Questões éticas}

Considerando o envolvimento de seres humanos, as exigências da Resolução 466/12 e da Resolução 510/2016 da Comissão Nacional de Ética em Pesquisa do Conselho Nacional de Saúde do Ministério da Saúde (BRASIL, 2012b; BRASIL, 2016) assim como cuidado ético da pesquisadora, o projeto de pesquisa foi submetido ao Comitê de Ética em Pesquisa da Faculdade de Medicina de Ribeirão Preto da Universidade de São Paulo e foi aprovado (Apêndice III), com número CAAE: 44249115.3.0000.5440.

Foi solicitada à Secretaria de Saúde de Ribeirão Preto a assinatura de um termo de aceite para que a pesquisa pudesse ser realizada nestes locais, com a aprovação do comitê de ética, para a realização deste estudo.

O Termo de Consentimento Livre e Esclarecido (TCLE) apresenta uma breve explicação sobre o projeto de pesquisa, e solicita o consentimento dos pais ou responsáveis das crianças com o diagnóstico de PC para participação na pesquisa. O TCLE apresenta linguagem clara e acessível demonstrando os objetivos da pesquisa, o processo para a coleta 
de dados, a ausência de benefícios diretos, a garantia do anonimato, o respeito ao desejo de interrupção da participação na pesquisa e a segurança de que os dados nunca serão utilizados para outro fim. O termo foi entregue e explicado oralmente aos pais ou responsáveis das crianças participantes.

Considera-se que toda pesquisa envolvendo seres humanos envolve risco. Entretanto, na presente pesquisa, os riscos são mínimos pela distância física das coletas, em sua última versão para a obtenção das informações, mas como havia o risco do incômodo ao responder as perguntas e resgatar possíveis memórias de causa de dor os participantes poderiam parar no momento que quisessem.

\subsection{Análise dos dados}

Foi realizada uma análise descritiva de todas as variáveis, através do Minitab. Para examinar a significância da associação (contingência) entre duas variáveis foi utilizado o Teste Exato de Fisher, que verifica se a variável da linha e a variável da coluna são independentes, sendo a hipótese nula $\left(\mathrm{H}_{0}\right)$ que a variável da linha e a variável da coluna são independentes. Em algumas análises foi utilizado o Chi Quadrado de Pearson, tendo em vista condições específicas que levaram a não convergência do teste exato.

Na comparação de médias segundo de algumas categorias foi empregada a Análise de Variância a um critério. Comparações múltiplas com correção de Sidak para o erro de primeira espécie foram empregadas para identificar as categorias que diferiam entre si (HAMILTON, 2004). 


\section{RESULTADOS}

Os serviços informaram acompanhar 146 crianças e adolescentes no período de coleta e, após o contato e entrevistas, 61 participaram deste estudo. A Figura 1 demonstra o fluxograma da amostra.

Figura 1. Fluxograma da amostra.

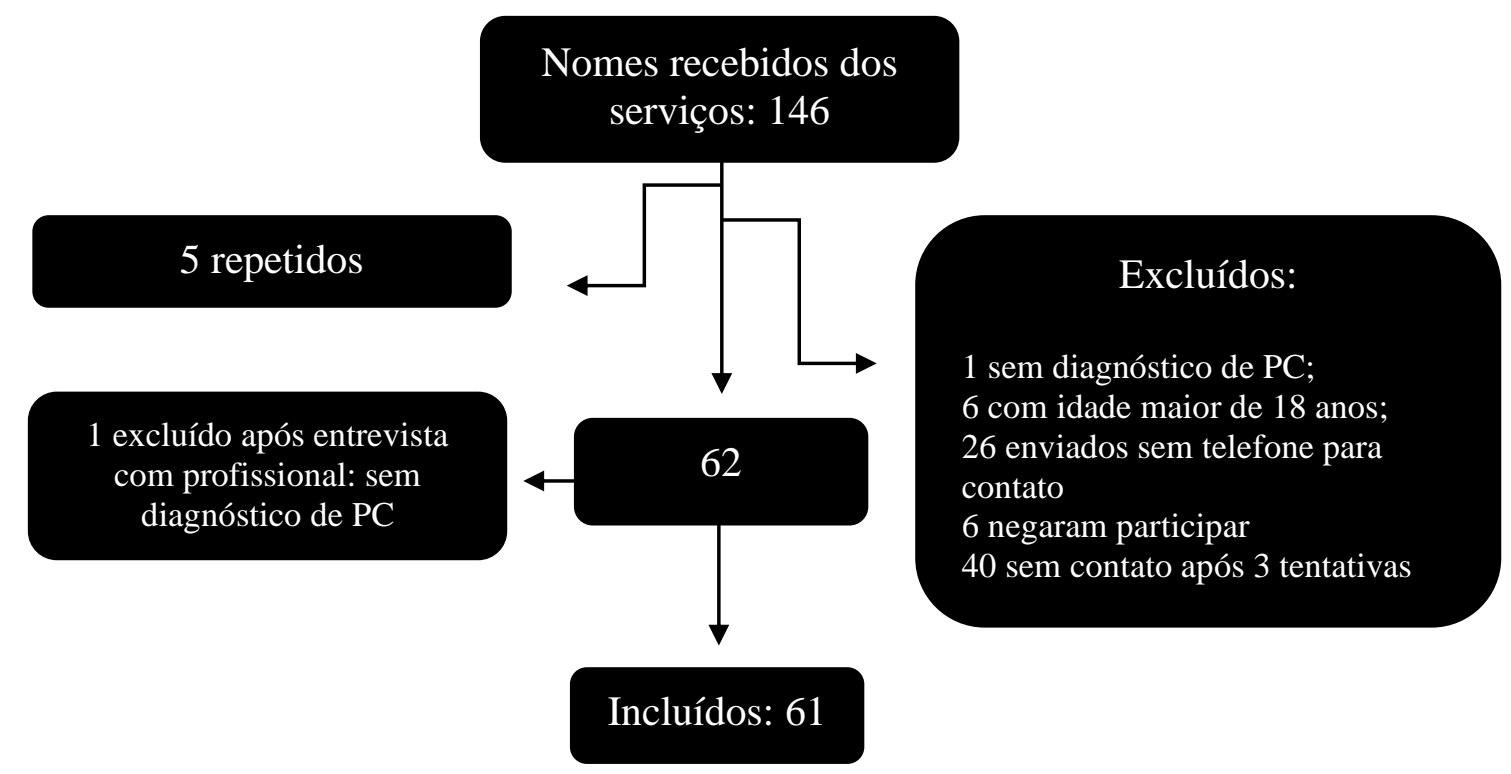

Fonte: própria.

Das 61 crianças e adolescentes que participaram do estudo, 14 (22,95\%) eram do sexo feminino e $47(77,05 \%)$ do sexo masculino, com média de idade de 7,05 anos $( \pm 4,03)$ variando de 1 a 15 anos.

O local da residência foi classificado de acordo com os distritos do município, sendo 22 crianças no distrito Norte (36,07\%), 10 crianças no distrito Sul e no Leste $(16,39 \%$ em cada), 08 crianças no distrito Oeste $(13,11 \%)$, 01 no distrito central (1,64\%). Algumas crianças residiam em outra cidade (07 crianças - 11,48\%) e frequentavam os serviços de saúde de Ribeirão Preto e em apenas 03 crianças (4,92\%) o local não foi especificado.

Com relação aos dados maternos, a média da idade da mãe foi de 27,98 anos $( \pm 6,67)$ com a mínima de 14 e máxima de 42 anos. A maioria (27 - 44,26\%) era casada, 25 (40,98\%) eram solteiras, $1(1,64 \%)$ viúva e $8(13,11 \%)$ divorciadas. A maioria das mães $(45 \%)$ concluíram o ensino médio; $16,67 \%$ médio incompleto; $16,67 \%$ tinham o ensino fundamental 
incompleto; $10 \%$ superior completo; $6,67 \%$ superior incompleto e 5\% concluíram o ensino fundamental. No momento da coleta de dados, 39 mães $(63,93 \%)$ trabalhavam somente em casa, $17(27,87 \%)$ eram assalariadas, $4(6,56 \%)$ estavam desempregadas e $1(1,64 \%)$ aposentada.

Sobre o planejamento da gestação, 55\% não planejou e em $16,67 \%$ a gestação não foi desejada. Apenas uma gestação foi por meio de reprodução assistida. A maioria $(93,10 \%)$ descobriu a gestação no primeiro trimestre $(6,90 \%$ descobriram no segundo trimestre), sendo que a maioria realizou o acompanhamento pré-natal (96,67\%). Apenas 3 mães não eram as mães biológicas e, portanto, não souberam relatar sobre o período gestacional. Na Tabela 1 constam as informações sobre as doenças maternas e se as mães tinham o hábito de fumar, beber ou usar drogas.

Tabela 1. Doenças maternas e hábitos deletérios.

\begin{tabular}{|c|c|c|c|c|c|}
\hline Dados maternos & $\begin{array}{c}\text { Não } \\
(\mathbf{N}-\%)\end{array}$ & $\begin{array}{c}\text { Sim, na } \\
\text { gestação } \\
(\mathbf{N}-\%)\end{array}$ & $\begin{array}{c}\text { Sim, antes da } \\
\text { gestação } \\
(\mathbf{N}-\%)\end{array}$ & $\begin{array}{l}\text { Na gestação e } \\
\text { antes (N- \%) }\end{array}$ & $\begin{array}{c}\text { Não soube } \\
\text { responder } \\
(\mathbf{N}-\%)\end{array}$ \\
\hline Doenças cardíacas & $58(95,08 \%)$ & $1(1,64 \%)$ & - & - & $2(3,28 \%)$ \\
\hline Doenças respiratórias & $52(85,25 \%)$ & $3(4,92 \%)$ & $3(4,92 \%)$ & $1(1,64 \%)$ & $2(3,28 \%)$ \\
\hline Doenças neurológicas & $56(91,80 \%)$ & - & - & $1(1,64 \%)$ & $4(6,56 \%)$ \\
\hline Doenças autoimune & $59(96,72 \%)$ & - & - & - & $2(3,28 \%)$ \\
\hline Doenças psicológicas & $56(91,80 \%)$ & $2(3,28 \%)$ & $1(1,64 \%)$ & - & $2(3,28 \%)$ \\
\hline Doenças ginecológicas & $48(78,69 \%)$ & $5(8,20 \%)$ & $6(9,84 \%)$ & - & $2(3,28 \%)$ \\
\hline Hipertensão & $50(81,97 \%)$ & $8(13,11 \%)$ & $1(1,64 \%)$ & - & $2(3,28 \%)$ \\
\hline Diabetes & $53(86,89 \%)$ & $5(8,20 \%)$ & $1(1,64 \%)$ & - & $2(3,28 \%)$ \\
\hline Herpes & $52(85,25 \%)$ & $2(3,28 \%)$ & $3(4,92 \%)$ & $1(1,64 \%)$ & $3(4,92 \%)$ \\
\hline Sarampo & $48(78,69 \%)$ & - & $7(11,48 \%)$ & - & $6(9,84 \%)$ \\
\hline Catapora & $22(36,07 \%)$ & $1(1,64 \%)$ & $33(54,10 \%)$ & - & $5(8,20 \%)$ \\
\hline Rubéola & $55(90,16 \%)$ & - & $1(1,64 \%)$ & - & $5(8,20 \%)$ \\
\hline Febre alta & $41(67,21 \%)$ & $1(1,64 \%)$ & $14(22,95 \%)$ & $1(1,64 \%)$ & $4(6,56 \%)$ \\
\hline Anemia & $40(65,57 \%)$ & $7(11,48 \%)$ & $10(16,39 \%)$ & $1(1,64 \%)$ & $3(4,92 \%)$ \\
\hline Toxoplasmose & $54(88,52 \%)$ & $1(1,64 \%)$ & $2(3,28 \%)$ & - & $4(6,56 \%)$ \\
\hline Sífilis & $55(90,16 \%)$ & $2(3,28 \%)$ & - & - & $4(6,56 \%)$ \\
\hline Infecção de urina & $27(44,26 \%)$ & $13(21,31 \%)$ & $16(6,23 \%)$ & $2(3,28 \%)$ & $3(4,92 \%)$ \\
\hline Corrimento vaginal & $33(51,10 \%)$ & $10(16,39 \%)$ & $14(22,95 \%)$ & $1(1,64 \%)$ & $3(4,92 \%)$ \\
\hline Hipotireoidismo & $56(91,80 \%)$ & $2(3,28 \%)$ & - & - & $3(4,92 \%)$ \\
\hline Hipertireoidismo & $56(91,80 \%)$ & $2(3,28 \%)$ & - & - & $3(4,92 \%)$ \\
\hline Uso de álcool & $42(68,85 \%)$ & $5(8,19 \%)$ & $12(19,68 \%)$ & $1(1,64 \%)$ & $1(1,64 \%)$ \\
\hline
\end{tabular}




\begin{tabular}{|l|l|l|l|l|l|}
\hline Uso de drogas & $58(95,08 \%)$ & $1(1,64 \%)$ & - & - & $2(3,28 \%)$ \\
\hline Uso de cigarro & $52(86,67 \%)$ & $4(6,67 \%)$ & $2(3,33 \%)$ & $2(3,33 \%)$ & $1(1,64 \%)$ \\
\hline
\end{tabular}

Fonte: própria.

A maioria $(83,05 \%)$ não apresentou aborto anterior, $13,56 \%$ tiveram aborto espontâneo e 3,39\% provocaram aborto. Na gestação da criança participante do estudo, $89,83 \%$ não tiveram ameaça ou tentativa de aborto (5,08\% tentaram provocar e 5,08\% tiveram ameaça).

A média da idade gestacional foi de 34,96 semanas $( \pm 5,45)$ variando de 21 a 42 semanas. A Tabela 2 demonstra as frequências da distribuição das idades gestacionais separadas por categorias.

Tabela 2. Categorias da idade gestacional.

\begin{tabular}{|l|c|c|}
\hline \multicolumn{1}{|c|}{ Idade Gestacional } & Número (N) & Porcentagem (\%) \\
\hline Prematuro & 31 & 50,82 \\
\hline Termo Inicial & 09 & 14,75 \\
\hline Termo & 13 & 21,31 \\
\hline Termo Tardio & 06 & 9,84 \\
\hline Pós termo & 02 & 3,28 \\
\hline
\end{tabular}

Fonte: própria.

Sobre os medicamentos utilizados na gestação, 19 mães $(31,15 \%)$ relataram não ter usado nenhum e, das que fizeram uso, a maioria $(21$ - 34,42\%) tomou vitaminas, seguido por uso de antibióticos (07 - 11,47\%).

Outro dado analisado foi a presença de intercorrências na gestação e apenas 01 mãe não soube relatar (adotiva) e 54 mães (90\%) relataram que tiveram intercorrências. Estas intercorrências foram agrupadas em 05 categorias:

a) Ocorrências clínicas da gestante (20,37\%): infecção de urina, problemas gastrointestinais, diabetes, hipertensão, pico hipertensivo, dengue ou suspeita de dengue, sinusite, resfriado forte, dores abdominais, cólica renal, toxoplasmose, herpes, anemia, infecção renal, corrimentos vaginais, obesidade, hipotensão, tonturas, alimentação não saudável, perda de peso, problemas com a tireoide, dores de cabeça;

b) Alterações na gestação (11,11\%): sangramentos, descolamento de placenta, necessidade de repouso, risco de aborto, contrações precoces, perda de líquido amniótico, fator Rh negativo e tomou vacina e teve reação; 
c) Pouco preparo (1,85\%): pré-natal tardio ou não fez o pré-natal;

d) Quedas e baques (1,85\%): quedas, trabalhou muito na gestação, sofreu violência do companheiro;

e) Problemas emocionais (5,56\%): dificuldade de aceitação, ansiedade, dificuldade para dormir, depressão, relatos de situação e momentos de estresse.

Em 59,26\% dos casos as intercorrências na gestação foram justapostas, ou seja, teve mais de uma categoria.

Com relação ao parto, 31 (50,82\%) foi normal, 28 (45,90\%) cesárea, 1 (1,64\%) fez uso de fórceps e 1 mãe (adotiva) não soube relatar. Ao serem questionadas sobre o motivo da cesárea, o mais frequente foi por sofrimento fetal $(11,47 \%)$, seguido por desproporção cefalopélvica, entre a cabeça do feto e a bacia da mãe $(9,83 \%)$.

A maioria das crianças $(25$ - 44,98\%) nasceu no Hospital das Clínicas de Ribeirão Preto, 09 (14,75\%) no Hospital Santa Casa de Misericórdia de Ribeirão Preto, 08 (13,11\%) MATER, 07 (11,48\%) no Hospital Materno Infantil Sinhá Junqueira e 12 (19,67\%) em outro local.

Já o peso ao nascer apresentou uma média de 2.388 gramas com um desvio padrão de 1.019 gramas, variando de 635 a 4.555 gramas. Quando analisado o Apgar, em 36 (59,01\%) casos não houve relato dos mesmos e, dos que foram informados, 10 (40\%) foram abaixo de 5 no primeiro minuto e 07 (28\%) foram abaixo de 7 no quinto minuto.

Assim como as intercorrências na gestação, também foram coletadas de forma descritiva as intercorrências no parto, presentes em 93,33\% da amostra, e foram agrupadas por categorias, resultando em 03 categorias:

a) Peri natais (5,36\%): trabalho de parto demorado, contração precoce, pouca e nenhuma dilatação, placenta presa, descolamento de placenta, parto induzido, parto demorado, pouco líquido amniótico, cesárea de urgência, problemas com a anestesia para cesárea, problemas com o cordão umbilical;

b) Com a mãe (1,79\%): alterações na pressão arterial, pico hipertensivo, préeclâmpsia, sangramento ou hemorragia no trabalho de parto ou parto, situação estressante, ausência de assistência médica, mãe estava em coma;

c) Com o bebê (25\%): anóxia, dificuldade ou desconforto respiratório, aspiração ou ingestão de mecônio, icterícia, sofrimento fetal, choro abafado, não chorou, ausência de movimentos ao nascer, crise convulsiva, parada cardíaca, hidrocefalia, deficiência renal, precisou amadurecer o pulmão, microcefalia, má formação. 
Em 62,29\% dos casos as intercorrências no parto foram justapostas, ou seja, teve mais de uma categoria, sendo a associação das 3 a mais frequente $(39,29 \%)$.

O tempo de internação dos bebês no pós-parto variou de 1 a 180 dias, e com relação ao local da internação, 56 bebês precisaram de unidade de terapia intensiva (UTI), sendo que a média da internação neste local foi de 31,23 dias e 36,07\% tiveram convulsão.

No que diz respeito aos critérios de identificação de risco e exames, 38 (62,30\%) realizaram exame de imagem na internação. Em 93,44\% das crianças houve a suspeita do atraso, sem o diagnóstico, sendo que em $47,27 \%$ a suspeita foi dos médicos e $41,82 \%$ dos pais. Em $70 \%$ dos casos foi realizado o encaminhamento para a estimulação precoce.

Ao ser questionado sobre a notícia do diagnóstico da paralisia cerebral, 20 famílias relataram não saber sobre a paralisia cerebral, sendo que destas famílias, 40\% disseram que o filho tem outros diagnósticos (mas não paralisia cerebral e relatam que não foram informadas sobre), $35 \%$ disseram que não tem paralisia cerebral, $10 \%$ que o filho não tem diagnóstico definido, $10 \%$ que o diagnóstico ainda está em investigação e 5\% não soube informar o diagnóstico. Vale ressaltar que a amostra foi levantada pelos profissionais que seguem a criança e que informaram os dados das que tinham paralisia cerebral.

Sobre a inserção escolar, $13(21,31 \%)$ não frequentavam a escola no período da coleta da pesquisa (agosto de 2019 a março de 2020), 43 (70,49\%) frequentava escola regular e 05 $(8,20 \%)$ a escola especial. Dos que estavam na escola, $40 \%$ frequentava a Educação Infantil, $46,67 \%$ ao Fundamental I e 13,33\% o Fundamental II. A presença de uma cuidadora na escola foi relatada em apenas 4 casos $(6,56 \%)$ e em 50,88\% a família relatou que a criança acompanhava o aprendizado referente a turma dos colegas de sala.

A presença de deficiências também foi verificada, sendo que 34,43\% apresentam deficiência visual (apenas 22,03\% usam óculos), 6,67\% apresentam deficiência auditiva, 47,54\% deficiência cognitiva, 31,15\% epilepsia associada, 8,20\% síndrome associada (não especificada), 24,59\% luxação de quadril, 14,75\% gastrostomia, 1,64\% usam sonda nasogástrica.

Foi realizada cirurgia em 52,46\% da amostra, sendo as mais frequentes do aparelho digestivo $(40,62 \%)$ e ortopédica $(37,5 \%)$. Em $59,37 \%$ foi realizado mais de um tipo de procedimento, tais como cirurgia no aparelho digestivo, cardíaca, cabeça e pescoço, neurológica, oftalmológica, ortopédica, proctológica, torácica, urológica.

A maioria das crianças e adolescentes faziam uso de algum medicamento (39,34\% não faziam uso de medicamentos) e foram agrupados em 03 categorias: 
a) Tratamento de questões neurológicas (31,15\%): anticonvulsivante, benzodiazepínico, antipsicótico, simpaticomiméticos, antidopaminérgico, relaxante muscular;

b) Para suplemento (1,64\%): suplemento de ferro e vitaminas;

c) Tratamento de outras manifestações clínicas (6,56\%): antiasmático, antihipertensivo, anticolinérgicos, anti-histamínico, laxante, antiácidos, antibiótico, hormonal, corticosteroide.

Em 21,31\% o uso de medicamentos era combinado, ou seja, mais de uma categoria.

No que diz respeito à reabilitação e a realização de terapias, a maioria das crianças e adolescentes realizavam fisioterapia $(93,44 \%)$. A Tabela 3 demonstra a frequência da realização de terapias.

Tabela 3. Número e porcentagem da amostra que realiza terapias.

\begin{tabular}{|l|c|}
\hline \multicolumn{1}{|c|}{ Terapias } & Frequência (N-\%)) \\
\hline Fisioterapia & $57(93,44 \%)$ \\
\hline Terapia ocupacional & $33(54,10 \%)$ \\
\hline Fonoaudiologia & $28(45,90 \%)$ \\
\hline Psicologia & $06(9,83 \%)$ \\
\hline Hidroterapia & $14(22,95 \%)$ \\
\hline Equoterapia & $02(3,28 \%)$ \\
\hline Natação adaptada & $01(1,64 \%)$ \\
\hline Musicoterapia & $01(1,64 \%)$ \\
\hline Pedagogia & $01(1,64 \%)$ \\
\hline
\end{tabular}

Fonte: própria.

Com relação ao tipo clínico, as alterações do movimento foram informadas pelos terapeutas e, em $81,97 \%$ da amostra o tipo espástico foi mais frequente, seguido do discinético (4,92\%), atáxico (3,28\%) e misto (espástico e atáxico, em 1,64\%), sendo que 02 $(3,28 \%)$ os terapeutas informaram que não eram classificáveis e $03(4,92 \%)$ não sabiam classificar. Quanto à topografia, $7(7,92 \%)$ não souberam responder (pais e terapeutas), 08 $(13,11 \%)$ tinham hemiparesia à esquerda, 06 (9,84\%) hemiparesia à direita, $23(37,70 \%)$ diparesia, 17 (27,87\%) quadriparesia, $2(3,28 \%)$ distonia, e $2(3,28 \%)$ ataxia.

Ao verificar o uso de órteses e dispositivos auxiliares, 10 (16,39\%) não usavam órteses e $26(42,62 \%)$ não usavam nenhum outro dispositivo. Dos que usavam órteses, 01 $(1,96 \%)$ usava no membro superior, $38(74,51 \%)$ no membro inferior e $12(23,53 \%)$ em ambos. Sobre os dispositivos, 05 (14,28\%) usavam andador, 19 (54,28\%) cadeira de rodas, 03 
$(08,57 \%)$ andador e cadeira de rodas, $01(02,86 \%)$ andador e equipamento de posicionamento, $06(17,15 \%)$ cadeira de rodas e equipamento de posicionamento e uma criança $(02,86 \%)$ possui todas as categorias (andador, cadeira de rodas e equipamento de posicionamento).

Quanto às classificações funcionais foram verificados os aspectos da função motora grossa (GMFCS), da função manual (MACS) e de deslocamento (FMS) e estão descritas na Tabela 4, sendo que 12 crianças eram menores de 04 anos e, portanto, não foram classificadas quanto à habilidade de locomoção por meio da FMS.

Tabela 4. Frequência e porcentagem nas classificações usando os instrumentos.

\begin{tabular}{|c|c|c|c|}
\hline Instrumentos & Classificação & Número $(\mathrm{N})$ & Porcentagem (\%) \\
\hline \multirow{5}{*}{ GMFCS } & Nível I & 13 & 21,31 \\
\hline & Nível II & 13 & 21,31 \\
\hline & Nível III & 03 & 4,92 \\
\hline & Nível IV & 15 & 24,59 \\
\hline & Nível V & 17 & 27,87 \\
\hline \multirow{5}{*}{ MACS } & Nível I & 15 & 24,59 \\
\hline & Nível II & 16 & 26,23 \\
\hline & Nível III & 13 & 21,31 \\
\hline & Nível IV & 10 & 16,39 \\
\hline & Nível V & 07 & 11,48 \\
\hline \multirow{8}{*}{ FMS - Casa (5 m) } & 1 & 03 & 4,92 \\
\hline & 2 & 01 & 1,64 \\
\hline & 3 & 0 & 0 \\
\hline & 4 & 02 & 3,28 \\
\hline & 5 & 07 & 11,48 \\
\hline & 6 & 11 & 18,03 \\
\hline & Engatinha & 09 & 14,75 \\
\hline & Não classificável & 16 & 26,23 \\
\hline \multirow{7}{*}{ FMS - Escola $(50 \mathrm{~m})$} & 1 & 09 & 14,75 \\
\hline & 2 & 02 & 3,28 \\
\hline & 3 & 0 & 0 \\
\hline & 4 & 01 & 1,64 \\
\hline & 5 & 08 & 13,11 \\
\hline & 6 & 09 & 14,75 \\
\hline & Não classificável & 20 & 32,79 \\
\hline \multirow{3}{*}{ FMS - Comunidade (500 m) } & 1 & 10 & 16,39 \\
\hline & 2 & 0 & 0 \\
\hline & 3 & 0 & 0 \\
\hline
\end{tabular}




\begin{tabular}{|l|l|l|l|}
\hline 4 & 01 & 1,64 \\
& 5 & 09 & 14,75 \\
& 6 & 08 & 13,11 \\
& Não classificável & 21 & 34,43 \\
\hline
\end{tabular}

Fonte: própria.

Para as variáveis contínuas foram realizadas análises de variâncias e os resultados estão descritos na Tabela 5. Foram analisadas a influência da idade materna, idade gestacional, peso ao nascer, dias de internação, idade da suspeita de alteração, idade do diagnóstico com o nível motor (GMFCS). Estas mesmas variáveis foram analisadas quanto à capacidade de locomoção avaliado pela FMS.

Houve diferença significativa entre a idade gestacional segundo o nível do GMFCS (p =0,0196), sendo que a média da idade gestacional no nível 5 difere da média do nível 4 $(\mathrm{p}=0,022)$. Outros dois achados se referem a idade da criança ao iniciar a reabilitação $(\mathrm{p}=$ 0,0288) e o peso ao nascer ( $\mathrm{p}=0,0034)$ segundo o nível do GMFCS, sendo que a média da idade do início da reabilitação no nível 2 difere da média do nível 1 ( $\mathrm{p}=0,025)$ e a média do peso ao nascer do nível 5 difere da média do nível 4 ( $\mathrm{p}=0,005)$. Houve diferença também entre a idade na notícia (momento do diagnóstico de atraso) segundo o nível de GMFCS (p = 0,0200), mas o contraste não conseguiu identificar qual nível foi a diferença.

Tabela 5. Resultados da Anova para as variáveis contínuas.

\begin{tabular}{|l|c|c|}
\hline \multicolumn{1}{|c}{ Variáveis } & $F=4,49$ & $\mathrm{p}=0,0034^{*}$ \\
\hline Peso ao nascer e GMFCS & $\mathrm{F}=1,05$ & $\mathrm{p}=0,4069$ \\
\hline Peso ao nascer e FMS - Casa & $\mathrm{F}=1,84$ & $\mathrm{p}=0,1276$ \\
\hline Peso ao nascer e FMS - Escola & $\mathrm{F}=1,83$ & $\mathrm{p}=0,1424$ \\
\hline Peso ao nascer e FMS - Comunidade & $\mathrm{F}=0,63$ & $\mathrm{p}=0,6551$ \\
\hline Dias de internação e GMFCS & $\mathrm{F}=0,28$ & $\mathrm{p}=0,9086$ \\
\hline Dias de internação e FMS - Casa & $\mathrm{F}=0,26$ & $\mathrm{p}=0,8969$ \\
\hline Dias de internação e FMS - Escola & $\mathrm{F}=0,27$ & $\mathrm{p}=0,8450$ \\
\hline Dias de internação e FMS - Comunidade & $\mathrm{F}=0,60$ & $\mathrm{p}=0,6654$ \\
\hline Idade da mãe segundo GMFCS & $\mathrm{F}=3,20$ & $\mathrm{p}=0,0196^{*}$ \\
\hline Idade gestacional segundo GMFCS & $\mathrm{F}=1,77$ & $\mathrm{p}=0,1480$ \\
\hline Idade da suspeita segundo GMFCS & $\mathrm{F}=3,38$ & $\mathrm{p}=0,0200^{*}$ \\
\hline Idade na notícia segundo GMFCS & $\mathrm{F}=2,92$ & $\mathrm{p}=0,0288^{*}$ \\
\hline Idade de início da reabilitação e GMFCS &
\end{tabular}

Fonte: própria. 
Após estes resultados, novas análises foram realizadas considerando novos agrupamentos das variáveis com o intuito de aumentar o $\mathrm{N}$ em cada variável e assim, o poder do teste. Desta forma, as variáveis GMFCS, MACS, FMS, Escolaridade da mãe, Tipo clínico, Topografia, Dispositivos e Órteses foram agrupadas conforme explicado abaixo:

- Os cinco níveis do GMFCS foram aglutinados em dois, sendo "deambulador" a junção dos níveis 1, 2 e 3 e "não deambulador" a junção nos níveis 4 e 5.

- Os cinco níveis do MACS foram aglutinados em dois, sendo "sem adaptação" a junção dos níveis 1 e 2 e "com adaptação" a junção dos níveis 3, 4 e 5.

- As classificações da FMS foram aglutinadas em "se locomove de forma independente" e "não se locomove de forma independente".

- A escolaridade da mãe foi categorizada como ensino Fundamental, Médio ou Superior, podendo ser completo ou incompleto.

- Os tipos clínicos foram classificados em espástica, atáxica, discinética ou não sabe.

- A topografia foi considerada como unilateral ou bilateral.

- Os dispositivos foram categorizados em andadores, cadeira de rodas, equipamento de posicionamento e sem dispositivos.

- As órteses foram agrupadas de acordo com o seu uso em membro superior, membro inferior e não faz o uso.

Para uma melhor análise e organização dos resultados, as variáveis foram separadas em categorias, sendo elas:

a) Variáveis de risco: idade materna ao nascer; escolaridade; planejamento da gestação; gestação desejada; pré natal; idade gestacional; uso de álcool, cigarro e drogas; aborto anterior; intercorrências na gestação; intercorrências na gestação (categorias); tipo de parto; idade gestacional (categorias); peso ao nascer; Apgar $1^{\circ}$ minuto; Apgar $5^{\circ}$ minuto; intercorrências no parto; intercorrências no parto (categorias); internação em enfermaria; internação em centro intensivo; ventilação mecânica; convulsão; exames neurológicos.

b) Variáveis de diagnóstico e intervenção: suspeita do atraso; idade da suspeita; quem suspeitou; notícia de PC; idade que iniciou a reabilitação; encaminhamento para estimulação.

c) Variáveis de características atuais: frequenta escola; deficiência visual; deficiência cognitiva; epilepsia; luxação de quadril; gastrostomia; tipo clínico; topografia; órteses; dispositivos auxiliares.

d) Variáveis funcionais: GMFCS; MACS; FMS Casa; FMS Escola; FMS Comunidade. 
Para testar a hipótese de associação entre duas variáveis foi realizado o teste exato de Fisher e os resultados estão descritos nas Tabelas 6 a 10, separados por categorias de variáveis.

A escolaridade materna teve associação com a habilidade manual e a locomoção da criança e, o fato de a gravidez ter sido desejada tem associação com a função motora e a locomoção em casa. Tais achados podem sugerir que na amostra, o fato de as crianças terem mães jovens e com maior grau de instrução favorece sua função manual, função motora e locomoção.

Outro aspecto observado foi com relação à idade da criança quando teve suspeita de atraso e sua habilidade manual, sugerindo que quanto mais cedo a suspeita maior a gravidade motora e, consequentemente, maior é a dificuldade nas habilidades manuais.

Tabela 6. Resultados dos testes de associação entre as variáveis funcionais e de risco.

\begin{tabular}{|c|c|c|c|c|c|}
\hline Variáveis & GMFCS & MACS & FMS - Casa & FMS - Escola & FMS - Comunidade \\
\hline Idade materna & $p=0,835$ & $p=0,318$ & $p=0,820$ & $\mathrm{p}=1,000$ & $\mathrm{p}=0,885$ \\
\hline Escolaridade materna & $p=0,116$ & $\mathrm{p}=0,009 *$ & $\mathrm{p}=0,040 *$ & $\mathrm{p}=0,029 *$ & $\mathrm{p}=0,006^{*}$ \\
\hline Gravidez planejada & $p=0,437$ & $\mathrm{p}=0,119$ & $\mathrm{p}=0,854$ & $\mathrm{p}=1,000$ & $\mathrm{p}=1,000$ \\
\hline Gravidez desejada & $\mathrm{p}=0,013 *$ & $\mathrm{p}=0,731$ & $\mathrm{p}=0,043 *$ & $\mathrm{p}=0,061$ & $\mathrm{p}=0,125$ \\
\hline Pré-natal & $\mathrm{p}=1,000$ & $\mathrm{p}=0,492$ & $\mathrm{p}=1,000$ & $\mathrm{p}=0,504$ & $\mathrm{p}=0,521$ \\
\hline Uso de álcool & $p=0,656$ & $\mathrm{p}=0,764$ & $\mathrm{p}=0,746$ & $\mathrm{p}=0,502$ & $\mathrm{p}=0,219$ \\
\hline Uso de cigarro & $\mathrm{p}=0,377$ & $\mathrm{p}=0,233$ & $\mathrm{p}=0,726$ & $\mathrm{p}=0,517$ & $\mathrm{p}=0,432$ \\
\hline Uso de drogas & $\mathrm{p}=1,000$ & $\mathrm{p}=1,000$ & $\mathrm{p}=0,553$ & $\mathrm{p}=1,000$ & $\mathrm{p}=1,000$ \\
\hline Aborto prévio & $p=0,246$ & $\mathrm{p}=0,357$ & $p=0,463$ & $\mathrm{p}=0,488$ & $\mathrm{p}=0,303$ \\
\hline $\begin{array}{l}\text { Intercorrências na } \\
\text { gestação }\end{array}$ & $p=0,672$ & $\mathrm{p}=0,195$ & $\mathrm{p}=0,375$ & $\mathrm{p}=1,000$ & $\mathrm{p}=0,388$ \\
\hline $\begin{array}{l}\text { Tipo de Intercorrência } \\
\text { na gestação }\end{array}$ & $\mathrm{p}=0,430$ & $p=0,244$ & $\mathrm{p}=0,095$ & $\mathrm{p}=0,769$ & $\mathrm{p}=0,616$ \\
\hline Tipo do parto & $\mathrm{p}=0,692$ & $\mathrm{p}=0,438$ & $\mathrm{p}=0,201$ & $\mathrm{p}=0,396$ & $\mathrm{p}=0,400$ \\
\hline Idade gestacional & $\mathrm{p}=0,292$ & $p=0,596$ & $p=0,561$ & $\mathrm{p}=0,605$ & $\mathrm{p}=0,542$ \\
\hline Peso ao nascer & $\mathrm{p}=0,529$ & $\mathrm{p}=0,346$ & $\mathrm{p}=0,392$ & $\mathrm{p}=0,855$ & $\mathrm{p}=0,494$ \\
\hline Apgar $1^{\circ}$ minuto & $p=0,678$ & $\mathrm{p}=1,000$ & $\mathrm{p}=0,365$ & $\mathrm{p}=0,637$ & $\mathrm{p}=0,335$ \\
\hline Apgar $5^{\circ}$ minuto & $\mathrm{p}=1,000$ & $\mathrm{p}=0,673$ & $\mathrm{p}=1,000$ & $\mathrm{p}=0,644$ & $\mathrm{p}=1,000$ \\
\hline Intercorrências no parto & $p=0,346$ & $\mathrm{p}=1,000$ & $\mathrm{p}=1,000$ & $p=0,563$ & $p=0,547$ \\
\hline $\begin{array}{l}\text { Tipo de intercorrência } \\
\text { no parto }\end{array}$ & $\mathrm{p}=0,691$ & $\mathrm{p}=0,340$ & $\mathrm{p}=0,909$ & $\mathrm{p}=0,921$ & $\mathrm{p}=0,785$ \\
\hline Internação & $\mathrm{p}=0,123$ & $\mathrm{p}=0,123$ & $\mathrm{p}=0,889$ & $\mathrm{p}=0,296$ & $\mathrm{p}=0,482$ \\
\hline
\end{tabular}




\begin{tabular}{|l|l|l|l|l|l|}
\hline enfermaria & & & & \\
\hline Internação sem intensivo & $\mathrm{p}=0,579$ & $\mathrm{p}=1,000$ & $\mathrm{p}=1,000$ & $\mathrm{p}=0,748$ & $\mathrm{p}=1,000$ \\
\hline Ventilação mecânica & $\mathrm{p}=0,126$ & $\mathrm{p}=1,000$ & $\mathrm{p}=0,325$ & $\mathrm{p}=0,739$ & $\mathrm{p}=0,717$ \\
\hline Convulsão & $\mathrm{p}=0,065$ & $\mathrm{p}=0,411$ & $\mathrm{p}=0,161$ & $\mathrm{p}=0,198$ & $\mathrm{p}=0,413$ \\
\hline Neuro imagem & $\mathrm{p}=0,523$ & $\mathrm{p}=1,000$ & $\mathrm{p}=0,320$ & $\mathrm{p}=0,538$ & $\mathrm{p}=0,601$ \\
\hline
\end{tabular}

Fonte: própria.

Tabela 7. Resultados dos testes de associação entre as variáveis funcionais e de diagnóstico e intervenção.

\begin{tabular}{|c|c|c|c|c|c|}
\hline Variáveis & GMFCS & MACS & FMS - Casa & FMS - Escola & FMS - Comunidade \\
\hline Suspeita de atraso & $\mathrm{p}=0,614$ & $p=0,354$ & $p=0,783$ & $\mathrm{p}=1,000$ & $\mathrm{p}=1,000$ \\
\hline $\begin{array}{l}\text { Idade da suspeita do } \\
\text { atraso }\end{array}$ & $\mathrm{p}=0,187$ & $\mathrm{p}=0,023 *$ & $\mathrm{p}=0,100$ & $\mathrm{p}=0,287$ & $\mathrm{p}=0,553$ \\
\hline $\begin{array}{l}\text { Quem suspeitou do } \\
\text { atraso }\end{array}$ & $\mathrm{p}=0,453$ & $\mathrm{p}=0,628$ & $\mathrm{p}=0,868$ & $\mathrm{p}=0,629$ & $\mathrm{p}=0,557$ \\
\hline Idade da notícia de PC & $\mathrm{p}=0,329$ & $\mathrm{p}=0,743$ & $\mathrm{p}=0,095$ & $\mathrm{p}=0,719$ & $\mathrm{p}=0,255$ \\
\hline $\begin{array}{l}\text { Idade de início da } \\
\text { reabilitação }\end{array}$ & $\mathrm{p}=0,732$ & $p=0,118$ & $\mathrm{p}=0,667$ & $\mathrm{p}=0,539$ & $\mathrm{p}=0,528$ \\
\hline Estimulação precoce & $\mathrm{p}=0,576$ & $\mathrm{p}=0,405$ & $\mathrm{p}=0,283$ & $\mathrm{p}=0,349$ & $\mathrm{p}=0,198$ \\
\hline
\end{tabular}

Fonte: própria.

Com relação aos aspectos funcionais e às características atuais (Tabela 8), houve associações especialmente com o fato de a criança frequentar escola, ter epilepsia, luxação de quadril, sua topografia e o uso de órtese e dispositivo auxiliar. Tais achado sugerem que as crianças com tais características possuem maior impacto nas suas funções motoras, habilidades manuais e locomoção. No entanto, as características atuais parecem ter pouca relação com os fatores de riscos na presente amostra, o que pode ser visualizado com maior detalhe na Tabela 9.

Por fim, a Tabela 10 nos mostra que a idade da suspeita teve associação com a deficiência cognitiva e epilepsia e que a topografia teve associação com a idade da notícia (diagnóstico), sugerindo que quanto maior seu comprometimento motor e a presença de déficits associados mais cedo a criança é diagnosticada, provavelmente por apresentarem mais sinais de alterações. 
Tabela 8. Resultados dos testes de associação entre as variáveis funcionais e características atuais.

\begin{tabular}{|c|c|c|c|c|c|}
\hline Variáveis & GMFCS & MACS & FMS - Casa & FMS - Escola & FMS - Comunidade \\
\hline Frequenta escola & $\mathrm{p}=0,004 *$ & $\mathrm{p}=0,015 *$ & $\mathrm{p}=0,002 *$ & $\mathrm{p}=0,032 *$ & $\mathrm{p}=0,070$ \\
\hline Deficiência visual & $\mathrm{p}=0,177$ & $\mathrm{p}=0,010 *$ & $\mathrm{p}=0,034 *$ & $\mathrm{p}=0,798$ & $\mathrm{p}=0,710$ \\
\hline Deficiência auditiva & $p=0,616$ & $\mathrm{p}=0,612$ & $\mathrm{p}=0,338$ & $\mathrm{p}=0,781$ & $\mathrm{p}=1,000$ \\
\hline Deficiência cognitiva & $\mathrm{p}=0,126$ & $\mathrm{p}=0,003 *$ & $\mathrm{p}=0,358$ & $\mathrm{p}=1,000$ & $\mathrm{p}=0,856$ \\
\hline Epilepsia & $\mathrm{p}=0,018 *$ & $\mathrm{p}=0,001 *$ & $\mathrm{p}=0,055$ & $\mathrm{p}=0,059$ & $\mathrm{p}=0,040 *$ \\
\hline Luxação de quadril & $\mathrm{p}=0,019 *$ & $\mathrm{p}=0,000 *$ & $\mathrm{p}=0,060$ & $\mathrm{p}=0,012 *$ & $\mathrm{p}=0,005 *$ \\
\hline Gastrostomia & $\mathrm{p}=0,151$ & $\mathrm{p}=0,081$ & $\mathrm{p}=0,138$ & $\mathrm{p}=0,216$ & $\mathrm{p}=0,238$ \\
\hline Tipo clínico & $\mathrm{p}=0,389$ & $\mathrm{p}=0,380$ & $\mathrm{p}=0,354$ & $\mathrm{p}=0,373$ & $\mathrm{p}=0,280$ \\
\hline Topografia & $\mathrm{p}=0,000 *$ & $p=0,224$ & $\mathrm{p}=0,000 *$ & $\mathrm{p}=0,000 *$ & $\mathrm{p}=0,000 *$ \\
\hline Órtese & $\mathrm{p}=0,194$ & $\mathrm{p}=0,030 *$ & $\mathrm{p}=0,161$ & $\mathrm{p}=0,046 *$ & $\mathrm{p}=0,010 *$ \\
\hline Dispositivo auxiliar & $\mathrm{p}=0,000 *$ & $\mathrm{p}=0,000 *$ & $\mathrm{p}=0,000 *$ & $\mathrm{p}=0,000 *$ & $\mathrm{p}=0,000 *$ \\
\hline
\end{tabular}

Fonte: própria. 
Tabela 9. Resultados dos testes de associação entre as variáveis de características atuais e de risco.

\begin{tabular}{|c|c|c|c|c|c|c|c|c|c|c|c|}
\hline Variáveis & $\begin{array}{c}\text { Frequenta } \\
\text { escola }\end{array}$ & $\begin{array}{c}\text { Deficiência } \\
\text { visual }\end{array}$ & $\begin{array}{c}\text { Deficiência } \\
\text { auditiva }\end{array}$ & $\begin{array}{c}\text { Deficiência } \\
\text { cognitiva }\end{array}$ & Epilepsia & $\begin{array}{l}\text { Luxação } \\
\text { quadril }\end{array}$ & Gastrostomia & $\begin{array}{c}\text { Tipo } \\
\text { Clínico }\end{array}$ & Topografia & Órtese & $\begin{array}{c}\text { Dispositivo } \\
\text { auxiliar }\end{array}$ \\
\hline Idade materna & $\mathrm{p}=0,504$ & $\mathrm{p}=0,213$ & $\mathrm{p}=0,141$ & $\mathrm{p}=0,580$ & $\mathrm{p}=0,048 *$ & $\mathrm{p}=0,037^{*}$ & $\mathrm{p}=0,586$ & $\mathrm{p}=0,702$ & $\mathrm{p}=0,754$ & $\mathrm{p}=0,786$ & $\mathrm{p}=0,474$ \\
\hline $\begin{array}{l}\text { Escolaridade } \\
\text { materna }\end{array}$ & $\mathrm{p}=0,343$ & $\mathrm{p}=0,206$ & $\mathrm{p}=0,873$ & $\mathrm{p}=0,490$ & $\mathrm{p}=0,546$ & $\mathrm{p}=0,049 *$ & $\mathrm{p}=0,343$ & $\mathrm{p}=0,884$ & $\mathrm{p}=0,547$ & $\mathrm{p}=0,207$ & $\mathrm{p}=0,132$ \\
\hline $\begin{array}{l}\text { Gravidez } \\
\text { planejada }\end{array}$ & $p=0,366$ & $p=0,308$ & $\mathrm{p}=1,000$ & $\mathrm{p}=0,194$ & $\mathrm{p}=0,562$ & $\mathrm{p}=0,871$ & $p=0,276$ & $\mathrm{p}=0,636$ & $\mathrm{p}=0,654$ & $\mathrm{p}=0,119$ & $\mathrm{p}=0,851$ \\
\hline $\begin{array}{l}\text { Gravidez } \\
\text { desejada }\end{array}$ & $\mathrm{p}=0,860$ & $\mathrm{p}=0,595$ & $\mathrm{p}=0,030 *$ & $\mathrm{p}=0,110$ & $\mathrm{p}=0,406$ & $\mathrm{p}=0,071$ & $\mathrm{p}=0,333$ & $\mathrm{p}=0,464$ & $\mathrm{p}=0,553$ & $\mathrm{p}=0,461$ & $\mathrm{p}=0,062$ \\
\hline Pré-natal & $\mathrm{p}=1,000$ & $\mathrm{p}=1,000$ & $\mathrm{p}=0,164$ & $\mathrm{p}=1,000$ & $\mathrm{p}=1,000$ & $\mathrm{p}=1,000$ & $\mathrm{p}=0,169$ & $\mathrm{p}=1,000$ & $\mathrm{p}=1,000$ & $\mathrm{p}=1000$ & $\mathrm{p}=0,186$ \\
\hline Uso de álcool & $\mathrm{p}=0,859$ & $\mathrm{p}=0,304$ & $\mathrm{p}=0,806$ & $\mathrm{p}=0,175$ & $\mathrm{p}=0,791$ & $\mathrm{p}=0,077$ & $\mathrm{p}=0,479$ & $\mathrm{p}=0,894$ & $\mathrm{p}=0,176$ & $\mathrm{p}=0,882$ & $\mathrm{p}=0,475$ \\
\hline Uso de cigarro & $\mathrm{p}=0,885$ & $\mathrm{p}=0,059$ & $\mathrm{p}=1,000$ & $\mathrm{p}=0,108$ & $\mathrm{p}=0,461$ & $\mathrm{p}=0,160$ & $\mathrm{p}=0,548$ & $\mathrm{p}=1,000$ & $\mathrm{p}=0,126$ & $\mathrm{p}=0,428$ & $\mathrm{p}=0,876$ \\
\hline Uso de drogas & $\mathrm{p}=1,000$ & $\mathrm{p}=0,390$ & $\mathrm{p}=0,086$ & $\mathrm{p}=0,475$ & $\mathrm{p}=0,356$ & $\mathrm{p}=1,000$ & $\mathrm{p}=1,000$ & $\mathrm{p}=1,000$ & $\mathrm{p}=1,000$ & $\mathrm{p}=1,000$ & $\mathrm{p}=0,085$ \\
\hline Aborto prévio & $\mathrm{p}=0,742$ & $\mathrm{p}=0,670$ & $\mathrm{p}=0,584$ & $\mathrm{p}=0,773$ & $\mathrm{p}=1,000$ & $\mathrm{p}=0,763$ & $\mathrm{p}=0,713$ & $\mathrm{p}=0,360$ & $\mathrm{p}=0,814$ & $\mathrm{p}=0,462$ & $\mathrm{p}=0,630$ \\
\hline $\begin{array}{l}\text { Intercorrências } \\
\text { na gestação }\end{array}$ & $\mathrm{p}=0,605$ & $\mathrm{p}=0,405$ & $\mathrm{p}=1,000$ & $\mathrm{p}=0,468$ & $\mathrm{p}=0,134$ & $\mathrm{p}=0,260$ & $\mathrm{p}=0,218$ & $\mathrm{p}=0,530$ & $\mathrm{p}=1,000$ & $\mathrm{p}=0,294$ & $\mathrm{p}=0,234$ \\
\hline $\begin{array}{l}\text { Tipo de } \\
\text { Intercorrência } \\
\text { na gestação }\end{array}$ & $\mathrm{p}=0,438$ & $\mathrm{p}=0,527$ & $\mathrm{p}=0,024 *$ & $\mathrm{p}=0,610$ & $\mathrm{p}=0,639$ & $\mathrm{p}=0,498$ & $\mathrm{p}=0,487$ & $\mathrm{p}=0,635$ & $\mathrm{p}=0,822$ & $\mathrm{p}=0,319$ & $p=0,074$ \\
\hline Tipo do parto & $\mathrm{p}=0,308$ & $\mathrm{p}=0,968$ & $\mathrm{p}=0,827$ & $\mathrm{p}=0,187$ & $\mathrm{p}=0,096$ & $\mathrm{p}=0,358$ & $\mathrm{p}=0,253$ & $\mathrm{p}=0,192$ & $\mathrm{p}=0,112$ & $\mathrm{p}=0,671$ & $\mathrm{p}=0,073$ \\
\hline $\begin{array}{l}\text { Idade } \\
\text { gestacional }\end{array}$ & $\mathrm{p}=0,187$ & $\mathrm{p}=0,131$ & $\mathrm{p}=0,501$ & $\mathrm{p}=0,994$ & $\mathrm{p}=0,974$ & $\mathrm{p}=0,074$ & $\mathrm{p}=0,600$ & $\mathrm{p}=0,875$ & $\mathrm{p}=0,805$ & $\mathrm{p}=0,758$ & $\mathrm{p}=0,796$ \\
\hline Peso ao nascer & $p=0,167$ & $\mathrm{p}=0,888$ & $\mathrm{p}=0,671$ & $\mathrm{p}=1,000$ & $\mathrm{p}=0,945$ & $\mathrm{p}=0,321$ & $\mathrm{p}=0,797$ & $\mathrm{p}=0,264$ & $\mathrm{p}=0,744$ & $\mathrm{p}=0,038 *$ & $\mathrm{p}=0,520$ \\
\hline Apgar $1^{\circ}$ minuto & $\mathrm{p}=1,000$ & $\mathrm{p}=0,715$ & $\mathrm{p}=1,000$ & $\mathrm{p}=0,688$ & $\mathrm{p}=0,229$ & $\mathrm{p}=0,559$ & $\mathrm{p}=1,000$ & $\mathrm{p}=0,150$ & $\mathrm{p}=0,179$ & $\mathrm{p}=0,108$ & $p=0,456$ \\
\hline
\end{tabular}




\begin{tabular}{|c|c|c|c|c|c|c|c|c|c|c|c|}
\hline Apgar $5^{\circ}$ minuto & $\mathrm{p}=0,830$ & $\mathrm{p}=0,559$ & $\mathrm{p}=0,490$ & $\mathrm{p}=1,000$ & $\mathrm{p}=0,355$ & $\mathrm{p}=0,809$ & $\mathrm{p}=1,000$ & $\mathrm{p}=0,070$ & $\mathrm{p}=0,730$ & $\mathrm{p}=0,462$ & $\mathrm{p}=0,514$ \\
\hline $\begin{array}{l}\text { Intercorrências } \\
\text { no parto }\end{array}$ & $\mathrm{p}=0,694$ & $\mathrm{p}=1,000$ & $\mathrm{p}=1,000$ & $\mathrm{p}=1,000$ & $\mathrm{p}=0,644$ & $\mathrm{p}=0,780$ & $\mathrm{p}=1,000$ & $\mathrm{p}=0,566$ & $\mathrm{p}=1,000$ & $\mathrm{p}=0,456$ & $\mathrm{p}=0,485$ \\
\hline $\begin{array}{l}\text { Tipo de } \\
\text { intercorrência } \\
\text { no parto }\end{array}$ & $\mathrm{p}=0,466$ & $\mathrm{p}=0,999$ & $\mathrm{p}=0,780$ & $\mathrm{p}=0,735$ & $\mathrm{p}=0,688$ & $\mathrm{p}=0,816$ & $\mathrm{p}=0,324$ & $\mathrm{p}=0,520$ & $\mathrm{p}=0,681$ & $\mathrm{p}=0,759$ & $\mathrm{p}=0,530$ \\
\hline $\begin{array}{ll}\text { Internação em } \\
\text { enfermaria }\end{array}$ & $\mathrm{p}=1,000$ & $\mathrm{p}=0,875$ & $\mathrm{p}=0,037 *$ & $\mathrm{p}=1,000$ & $\mathrm{p}=0,530$ & $p=0,897$ & $\mathrm{p}=1,000$ & $\mathrm{p}=0,123$ & $p=0,665$ & $p=0,589$ & $\mathrm{p}=0,235$ \\
\hline $\begin{array}{ll}\text { Internação } & \text { sem } \\
\text { intensivo } & \end{array}$ & $\mathrm{p}=0,911$ & $\mathrm{p}=0,456$ & $\mathrm{p}=0,712$ & $\mathrm{p}=0,862$ & $\mathrm{p}=0,695$ & $\mathrm{p}=0,177$ & $\mathrm{p}=0,466$ & $\mathrm{p}=0,951$ & $\mathrm{p}=0,555$ & $\mathrm{p}=0,254$ & $\mathrm{p}=0,877$ \\
\hline $\begin{array}{l}\text { Ventilação } \\
\text { mecânica }\end{array}$ & $\mathrm{p}=0,835$ & $p=0,426$ & $\mathrm{p}=0,392$ & $\mathrm{p}=0,285$ & $\mathrm{p}=1,000$ & $\mathrm{p}=0,701$ & $\mathrm{p}=0,397$ & $p=0,659$ & $\mathrm{p}=0,650$ & $\mathrm{p}=0,099$ & $\mathrm{p}=0,106$ \\
\hline Convulsão & $\mathrm{p}=0,224$ & $\mathrm{p}=0,327$ & $\mathrm{p}=0,819$ & $\mathrm{p}=0,007^{*}$ & $\mathrm{p}=0,150$ & $\mathrm{p}=0,408$ & $\mathrm{p}=0,176$ & $\mathrm{p}=0,353$ & $\mathrm{p}=0,307$ & $\mathrm{p}=0,524$ & $\mathrm{p}=0,335$ \\
\hline Neuro imagem & $p=0,754$ & $\mathrm{p}=0,639$ & $p=0,618$ & $\mathrm{p}=0,932$ & $\mathrm{p}=0,263$ & $\mathrm{p}=0,431$ & $\mathrm{p}=1,000$ & $\mathrm{p}=0,607$ & $\mathrm{p}=0,891$ & $\mathrm{p}=0,871$ & $p=0,264$ \\
\hline
\end{tabular}

Fonte: própria. 
Tabela 10. Resultados dos testes de associação entre as variáveis de características atuais e de diagnóstico e intervenção.

\begin{tabular}{|c|c|c|c|c|c|c|}
\hline Variáveis & Suspeita de atraso & Idade da suspeita & Quem suspeitou & Idade da notícia & Início da reabilitação & Estimulação precoce \\
\hline Frequenta escola & $\mathrm{p}=0,017 *$ & $\mathrm{p}=0,051$ & $\mathrm{p}=0,049 *$ & $\mathrm{p}=0,597$ & $\mathrm{p}=0,189$ & $\mathrm{p}=0,317$ \\
\hline Deficiência visual & $\mathrm{p}=0,687$ & $\mathrm{p}=0,056$ & $\mathrm{p}=0,784$ & $\mathrm{p}=0,432$ & $\mathrm{p}=0,148$ & $\mathrm{p}=0,503$ \\
\hline Deficiência auditiva & $\mathrm{p}=1,000$ & $\mathrm{p}=0,396$ & $\mathrm{p}=0,936$ & $\mathrm{p}=0,823$ & $\mathrm{p}=0,478$ & $\mathrm{p}=0,513$ \\
\hline Deficiência cognitiva & $\mathrm{p}=0,388$ & $\mathrm{p}=0,011 *$ & $\mathrm{p}=0,497$ & $\mathrm{p}=0,643$ & $\mathrm{p}=0,780$ & $\mathrm{p}=0,849$ \\
\hline Epilepsia & $\mathrm{p}=0,041 *$ & $\mathrm{p}=0,029 *$ & $p=0,764$ & $\mathrm{p}=0,749$ & $\mathrm{p}=0,458$ & $\mathrm{p}=0,208$ \\
\hline Luxação de quadril & $\mathrm{p}=0,777$ & $\mathrm{p}=0,163$ & $\mathrm{p}=0,652$ & $\mathrm{p}=0,193$ & $\mathrm{p}=0,635$ & $\mathrm{p}=0,026 *$ \\
\hline Gastrostomia & $\mathrm{p}=0,009 *$ & $p=0,272$ & $p=0,636$ & $\mathrm{p}=0,995$ & $\mathrm{p}=1,000$ & $p=0,710$ \\
\hline Alteração do movimento & $\mathrm{p}=0,110$ & $\mathrm{p}=0,455$ & $\mathrm{p}=0,490$ & $\mathrm{p}=0,901$ & $\mathrm{p}=0,096$ & $\mathrm{p}=0,692$ \\
\hline Topografia & $\mathrm{p}=0,220$ & $\mathrm{p}=0,117$ & $\mathrm{p}=0,074$ & $\mathrm{p}=0,036 *$ & $\mathrm{p}=0,812$ & $p=0,466$ \\
\hline Órtese & $\mathrm{p}=0,297$ & $\mathrm{p}=0,632$ & $\mathrm{p}=0,395$ & $\mathrm{p}=0,335$ & $\mathrm{p}=0,321$ & $\mathrm{p}=0,174$ \\
\hline Dispositivo auxiliar & $\mathrm{p}=0,233$ & $\mathrm{p}=0,758$ & $\mathrm{p}=0,822$ & $\mathrm{p}=0,731$ & $\mathrm{p}=0,921$ & $\mathrm{p}=0,579$ \\
\hline
\end{tabular}

Fonte: própria. 


\section{DISCUSSÃO}

O presente estudo teve como objetivo realizar um levantamento transversal dos fatores de risco para paralisia cerebral nas crianças e adolescentes com PC que estavam em reabilitação na rede pública no município de Ribeirão Preto - SP e verificar se havia associação destes fatores com as características clínicas e funcionais.

Analisando os dados da amostra em questão, verificamos que a ocorrência da PC no sexo masculino foi maior, representando $77,05 \%$ de nosso estudo. Este dado corrobora com Zablotsky e colaboradores (2019) que realizaram um estudo de prevalência e verificaram que meninos tiveram mais probabilidade do que as meninas de serem diagnosticados com qualquer deficiência de desenvolvimento, tais como PC.

A média de idade das crianças foi de 7 anos, sendo que a mais velha tinha 15 anos. Levando em consideração que a grande maioria da amostra realizava fisioterapia, o que é esperado por ser a PC a deficiência física mais comum na infância. No entanto, nos chama a atenção de que com esta idade o ápice do desenvolvimento motor, que acontece por volta dos 5 anos, já passou e sabe-se que a reabilitação deve dar ênfase em questões de participação e vida acadêmica, com hábitos de atividade física (HANNA et al., 2009). Seria esperado, portanto, que outras áreas de atuação fossem mais presentes nesta idade (como por exemplo: terapia ocupacional, fonoaudiologia, psicopedagogia) e nos faz levantar a questão de que talvez haja poucos serviços que ofereçam atendimentos nestas especialidades e/ou pouco é difundido sua importância. Mantendo assim o foco nas estruturas e funções corporais, buscando a normatização, o que vai em direção oposta ao que é recomendado de acordo com as "F-words" (function, family, fitness, fun, friends, future), que foi desenvolvida a partir da CIF e levando em consideração a participação e os contextos ambientais e pessoais, além das atividades e funções corporais (ROSENBAUM; GORTER, 2011).

Com relação aos fatores de risco, vários fatores foram identificados na literatura como preditores para PC, mas muitos não desenvolvem PC, sendo que quase 50\% das crianças o diagnóstico são crianças nascidas a termo e sem risco identificado no período neonatal (MCLNTYRE et al., 2011). Em adição a este fato, uma revisão sistemática de 2013 descreveu como significativamente os seguintes fatores de risco associados com PC em bebês a termo: síndrome do desconforto respiratório neonatal, aspiração de mecônio, cesariana instrumental ou de emergência, parto com asfixia, convulsões neonatais, hipoglicemia e infecções neonatais (MCLNTYRE et al., 2013). No entanto, para muitos destes fatores de risco o efeito de causalidade ainda não é claro. 
Diante destes dados, em nossa amostra, os riscos que mais chamaram a atenção por terem tido associação com algum aspecto da condição atual da criança (deficiência auditiva, deficiência cognitiva, epilepsia, luxação de quadril e uso de órtese) foram o fato de a gravidez ser desejada, a idade e escolaridade materna, presença de intercorrência na gestação, internação ao nascer, relato de convulsão e o peso ao nascer.

No que diz respeito aos dados maternos, a média de idade da mãe ao nascimento foi de 28 anos, variando de 16 a 42, sendo que a maioria possuía ensino médio. Sabe-se que as características sociodemográficas maternas e história reprodutiva estão associadas com PC e que a idade materna menor que 20 anos ou maior que 34 anos, baixa escolaridade materna, gravidezes numerosas, nuliparidade, curta ou longo intervalo entre gestações e história anterior de morte fetal intrauterina são fatores de risco para PC (DURKIN et al., 2016). No presente estudo, a escolaridade materna teve associação com a habilidade manual e a locomoção da criança e, o fato de a gravidez ter sido desejada teve associação com a função motora e a locomoção da criança em casa. Tais achados podem sugerir que na amostra, o fato de as crianças terem mães ainda jovens e com maior grau de instrução favorece sua função manual, função motora e locomoção, principalmente quando estas mães recebem orientações direcionadas para estímulos em casa, já que segundo a revisão sistemática de intervenções e tratamentos de crianças com PC (NOVAK, 2020) os programas domiciliares se mostram efetivos e com alto nível de evidência e recomendação.

Sobre as intercorrências na gestação, presentes em $90 \%$ no nosso estudo, as ocorrências clínicas da gestante foram as mais frequentes. Este achado vai ao encontro com o estudo de Fahey e colaboradores (2017) que relatam que a febre materna e a presença de infecções estão associadas a um significativo aumento do risco de PC, por afetar o cérebro fetal, mas é importante alertar também de que é possível que o feto tenha sofrido uma infecção e os sintomas não foram diagnosticados.

As infecções conhecidas como TORCH (toxoplasmose, rubéola, citomegalovírus e vírus herpes simples) também estão associadas a quadros de internação e com deficiências de neurodesenvolvimento e representam cerca de 5\% ou menos dos casos de PC nos países industrializados (JACOBSSON, 2004).

O relato de convulsão pode caracterizar o início do quadro de epilepsia, que é um comprometimento clínico frequente em crianças com PC, podendo variar sua incidência de 15 a 55-60\% sendo mais frequente no primeiro ano de vida. Costuma ser geralmente observada na quadriparesia (50 - 94\%), hemiplegia (33 - 50\%), mas raramente afeta crianças que sofrem de diplegia e o tipo atáxico de PC (16 - 27\%) (WALLACE, 2001). 
Sabe-se que o planejamento da gestação é de extrema importância como medida preventiva e reflete a saúde infantil em todo o mundo. Em nossa amostra, em 55\% dos casos a gravidez não foi planejada e em 16,67\% não foi desejada, nos indicando dificuldade de aceitação da gestação com possível negligência aos cuidados, consequentemente.

O fato de a gravidez não ter sido planejada e desejada em alguns casos pode afetar a interação mãe-bebê. Sobre esta interação, Rocha et al (2019) realizaram uma revisão sistemática sobre o impacto da interação mãe-bebê durante o primeiro ano de vida e verificaram que a qualidade da interação entre a mãe e o bebê é um fator importante que influencia o desenvolvimento do bebê especialmente na linguagem, cognição e capacidades sociais, porém, mais pesquisas são necessárias sobre a influência desta interação no desenvolvimento motor. Os autores apontam que embora tenham identificado fatores intrínsecos e extrínsecos, como prematuridade, idade do bebê, nascimentos múltiplos, ansiedade materna pré-natal, exposição materna a opióides, história de assistência social e crime possuem influência do registro na relação entre a interação mãe-bebê e o desenvolvimento do bebê, o número limitado de estudos sobre esses fatores complexos sugere que pesquisas adicionais são necessárias.

Ainda no que diz respeito aos fatores de risco, Jöud e colaboradores (2020) realizaram um estudo na Suécia para verificar a associação dos fatores de risco com a paralisia cerebral em uma coorte de 215.217 crianças estratificada por idade gestacional. As informações sobre o diagnóstico de paralisia cerebral e seu tipo clínico foi coletado no registro nacional (Programa de Vigilância e Acompanhamento da Paralisia Cerebral). Os autores encontraram que $0,2 \%$ das crianças tinham PC e entre as crianças com mais de 37 semanas de idade gestacional, os fatores de risco que tiveram associação foram: obesidade materna, malformações, indução, Apgar menor que 7 em 5 minutos e internação em centro intensivo. Entre as nascidas entre 32 e 36 semanas, os riscos foram ser pequeno para idade gestacional, ter malformações, realização de cesariana eletiva e de emergência, internação em centro intensivo (cuidados neonatais). Já nas menores que 32 semanas, nenhum fator de risco foi associado significativamente à $\mathrm{PC}$, o que os autores atribuem ao baixo número de criança deste grupo na amostra.

No presente estudo, a prematuridade (média de idade gestacional foi de 34,96 semanas) e o baixo peso (média de 2.388 gramas) chamaram a atenção por estarem abaixo do esperado e, desta forma, representarem risco para o desenvolvimento e necessitarem de acompanhamento do desenvolvimento. Sadowska e colaboradores (2020) relatam que de acordo com dados europeus, a frequência média de PC em crianças que nasceram com peso 
corporal abaixo de 1500 g cerca de é 70 vezes maior quando comparada com o grupo de crianças com peso corporal superior a $2500 \mathrm{~g}$ ao nascer. A prematuridade também é relatada no Registro de Paralisia Cerebral Australiano (2018) no qual bebês nascidos prematuros constituem $43 \%$ de toda paralisia cerebral.

Ferreira e colaboradores (2014) constataram que os prematuros apresentam maior risco de desenvolver sepse e, ainda, que crianças com sepse foram 2,5 vezes mais propensas a desenvolver alterações neuromotoras. Nesta mesma direção, Locatelli et al. (2010), ao analisar 195 casos de prematuridade com idade gestacional menor que 32 semanas constataram que havia desenvolvimento neurológico adverso grave em 45 casos e severo em 28, sendo, destes, 18 casos de PC confirmados. Em concordância, Saldir et al. (2010) também deram enfoque à prematuridade com igual idade gestacional e verificaram que um em cada quatro recém-nascidos prematuros aprestaram risco no desenvolvimento neurológico.

Com relação ao diagnóstico, segundo NOVAK (2014) o diagnóstico de PC em bebês de risco evidente costuma ser realizado antes de um ano de idade e sem risco evidente por volta dos 12 aos 24 meses. Em nosso estudo, toda a amostra apresentou histórico de risco e tinham o diagnóstico de PC segundo o profissional que a acompanhava. Em 93,44\% das crianças houve a suspeita do atraso, sem o diagnóstico precoce, sendo que em 47,27\% a suspeita foi dos médicos e 41,82\% dos pais. Em 70\% dos casos foi realizado o encaminhamento para a estimulação precoce, mas ao ser questionado sobre a notícia do diagnóstico da paralisia cerebral, 20 famílias $(32,8 \%)$ relataram não saber que o filho apresentava a condição de paralisia cerebral, sendo que destas, $40 \%$ disseram que o filho tinha outros diagnósticos (mas não paralisia cerebral e relatam que não foram informados sobre), $35 \%$ disseram que eles não tinham paralisia cerebral, $10 \%$ que o filho não tinha diagnóstico definido, $10 \%$ que o diagnóstico ainda estava em investigação e 5\% não sabia informar o nome do diagnóstico. Apesar de que os que não sabiam possuíam os filhos com idade que variava entre 1 ano e 15 anos, com média de 6,81 anos de idade, com desvio padrão de 4,41.

Esses dados nos chama a atenção para a divergência de conhecimentos entre o profissional que acompanha a criança e o familiar, já que foram os profissionais que indicaram o contato das famílias que tinham filhos com diagnóstico de PC. O diagnóstico precoce permite o acesso oportuno a intervenção em um período com melhores respostas em função da neuroplasticidade. Desta forma, o diagnóstico tardio pode ser prejudicial para o desenvolvimento de uma criança por privá-la de intervenção direcionada e específica por meses ou até anos (BOSANQUET et al., 2013). Em nossa amostra, apesar de todas as crianças estarem inseridas na reabilitação e terem de certa forma recebido intervenção e 
orientações, o real esclarecimento por parte da família pode auxiliar nas tomadas de decisões e direcionamento para intervenções mais específicas de acordo com seu quadro motor e cognitivo. Assim como uma participação mais ativa no processo de reabilitação, auxiliando nas definições de metas a serem alcançadas e do engajamento nas atividades a serem desenvolvidas.

Verificamos que a idade da suspeita do atraso de desenvolvimento teve associação com a deficiência cognitiva e epilepsia e que a topografia teve associação com a idade da notícia (diagnóstico), sugerindo que quanto maior o comprometimento motor e a presença de déficits associados mais cedo a criança é diagnosticada, provavelmente por apresentarem mais sinais de alterações. Alguns estudos sustentam essa hipótese, pelo fato de a PC ser diagnosticada historicamente mais tardiamente por não ter um biomarcador específico e levar em consideração a presença de fatores de risco, histórico de atraso ou desenvolvimento motor atípico (NOVAK, 2014; NOVAK et al., 2017).

Além da falta de informação ou da não compreensão da condição do filho poder criar falsas expectativas e interferir na adesão às orientações e aceitação da condição e possíveis adaptações, estudos populacionais mostraram que os pais geralmente preferem saber se seu filho tem PC ou tem alto risco para que eles possam iniciar a intervenção direcionada (SPITTLE et al., 2018), sendo de extrema importância a devolutiva dos profissionais de forma clara, acolhedora e objetiva, bem como um acompanhamento especializado para detecção precoce do diagnóstico.

Por muito tempo o manejo da PC se concentrou em melhorar a função motora, mas um olhar mais integral se faz necessário para compreender o que mais afeta a qualidade de vida da criança na hora de planejar, juntamente com a família, os planos de cuidados e intervenção. É recomendado utilizar a estrutura da Classificação Internacional de Funcionalidade, Incapacidade e Saúde (CIF) com seus domínios de função corporal, atividade, participação, fatores ambientais e fatores pessoais (COLVER; FAIRHURST; PHAROAH, 2014).

Com relação às funções corporais, Novak e colaboradores (2012) verificaram algumas condições comuns, no nível decrescente de frequência, incluíram dor, incapacidade de andar, luxação de quadril, problemas de controle da bexiga, distúrbios do sono, sialorreia, e dependência de alimentação por sonda. A proporção de deficiências e aspectos associados ao desenvolvimento e comportamento foi de deficiência intelectual (1 em 2), incapacidade de falar (1 em 4), epilepsia (1 em 4), distúrbio de comportamento (1 em 4), cegueira (1 em 10) e surdez (1 em 25). Em nossa amostra, em 50,88\% a família relatou que a criança acompanhava o aprendizado referente a turma dos colegas de sala, podendo ser um indicativo de deficiência 
intelectual. A presença de outras deficiências também foi verificada, sendo que $34,43 \%$ apresentaram deficiência visual (apenas 22,03\% usavam óculos), 6,67\% apresentaram deficiência auditiva, 47,54\% deficiência cognitiva, 31,15\% epilepsia associada, 24,59\% luxação de quadril, 14,75\% gastrostomia e 1,64\% usavam sonda nasogástrica.

A capacidade de completar as atividades da vida diária e ser ativo e funcional na sociedade são domínios importantes que afetam a qualidade de vida de qualquer indivíduo. Van Gorp e colaboradores (2018) rastrearam o desempenho motor em 421 indivíduos de 1 a 20 anos por meio de análise do comportamento adaptativo e relataram a idade em que os indivíduos atingiram 90\% do desempenho máximo. Indivíduos com PC que eram capazes de andar (GMFCS níveis I a III) continuaram a melhorar no desempenho motor de 6 a 8 anos de idade. Para aqueles sem deficiência intelectual e que conseguiam andar, a limitação do desempenho das atividades diárias era semelhante aos dos seus pares, mas levou mais tempo para os indivíduos com PC atingissem esses limites. Esses indivíduos continuaram a melhorar até a idade de 11 a 14 anos (atividades de autocuidado), 26 a 32 anos (atividades domésticas) e 22 a 26 anos (atividades comunitárias). Nos indivíduos com maior comprometimento motor (GMFCS IV e V) o desempenho motor foi menor e atingiram limites significativamente mais baixos de desempenho nas atividades diárias. Os autores ainda verificaram que nos indivíduos com PC e deficiência intelectual também atingiram níveis máximos mais baixos de desempenho de atividade diária e em uma idade mais precoce do que o desenvolvimento de seus pares, concluindo que a deficiência intelectual interfere no desenvolvimento motor e no desempenho de atividades diárias.

Com relação aos aspectos funcionais e às características atuais no presente estudo, houve associações especialmente com o fato de a criança frequentar escola, ter epilepsia, luxação de quadril, sua topografia e o uso de órtese e dispositivo auxiliar. Tais achado sugerem que as crianças com tais características possuem maior impacto nas suas funções motoras, habilidades manuais e locomoção. No entanto, as características atuais parecem ter pouca relação com os fatores de riscos na presente amostra.

Pelosi (2008) menciona que as limitações presentes nos alunos com deficiência física, principalmente a PC, podem ter dificuldades para andar, sentar-se, manter a cabeça posicionada adequadamente, falar, utilizar as mãos para segurar objetos ou escrever, organizar a escrita espacialmente no papel e ler texto devido às dificuldades perceptivas. As dificuldades podem incluir, ainda, utilizar o computador sem adaptações, realizar atividades de vida diária como ir ao banheiro com independência ou alimentar-se. Crianças com GMFCS nível III andam com um dispositivo manual de mobilidade (andador ou muleta), mas, na 
prática, nem todas as crianças têm acesso a estes recursos, seja pelo custo, tempo de aquisição ou critérios de dispensação via SUS (CRIPPA et al., 2017). Desta forma, a locomoção na escola pode ficar bastante restrita quando ainda se associa outras barreiras arquitetônicas, como a presença de degraus e terrenos irregulares, prejudicando a inclusão e aumentando a demanda e preocupação dos familiares (PELOSI, 2008; CASTRO et al., 2020).

Sabe-se que o que mais restringe a participação nas atividades de rotina escolar das crianças com PC são os aspectos motores. No estudo de Rézio e colaboradores (2012) os resultados indicaram que quanto maior a independência motora, maior o seu nível de participação e melhor o seu desempenho nas tarefas cognitivo/comportamentais em relação à assistência na função escolar.

A inclusão de crianças com PC nas escolas ainda tem sido um desafio, tanto para os gestores e professores, como para a família e até mesmo para as crianças. No entanto, limitar a criança dessa participação social tão relevante e decisiva da sua vida demonstra, não só um subdesenvolvimento a nível nacional, mas também uma possível piora na condição de saúde da criança como um todo. Este fato é ainda exacerbado no país após o Decreto 10.502/2020 (BRASIL, 2020) que propõe o incentivo da separação das salas de aulas e das escolas para crianças com deficiência sendo um retrocesso para a educação inclusiva além de ter um discurso excludente, caso aceito e colocado em vigor.

Segundo Bee (1995), a família pode ser destacada como responsável pelo processo de socialização da criança, sendo que, por meio dessa, a criança adquire comportamentos, habilidades e valores apropriados e desejáveis à sua cultura. A oportunidade de a criança interagir com os pares e com outras pessoas fora da família, o grau de escolaridade materna e seu baixo-nível de depressão, estilos parentais adequados, uma qualidade de interação boa com a comunidade e uma rede social fortemente estabelecida, podem ser destacados como exemplos de fatores positivos à proteção da criança (HOLDEN et al., 1998). No que diz respeito à PC, um estudo (MEI et al., 2015) verificou que as principais barreiras para participação incluíam aspectos das próprias interações dos pais com seus filhos (por exemplo, não oferecer escolhas), contato com pessoas e ambientes desconhecidos, atitudes negativas de outras pessoas e frustração das crianças. Já os facilitadores foram o apoio recebido da família e da escola da criança, estar entre crianças, ter uma rotina familiar e disposição positiva da própria criança. Estes dados reforçam a importância do envolvimento da família e o uso da CIF como norteador para identificação dos fatores contextuais no processo terapêutico.

Pensando nos fatores protetivos, a OMS (2016) lançou uma estratégia global para a saúde das mulheres e das crianças, com metas estabelecidas até 2030, no intuito de assegurar 
e prosperar a saúde e o bem-estar nesta população, de modo que todas os recém-nascidos tenham acesso a um desenvolvimento de alta qualidade na primeira infância, o que vai ao encontro dos programas de acompanhamento do desenvolvimento.

Para realizar um adequado acompanhamento do desenvolvimento é importante ter uma padronização das informações da criança, como uma boa anamnese identificando se há fatores de risco e avaliações estruturadas do desenvolvimento infantil. De acordo com Novak et al. (2017), as ferramentas com melhor validade preditiva para detectar a PC antes da idade corrigida de 5 meses são: a ressonância magnética neonatal (sensibilidade de 86 - 89\%), Prechtl Qualitative Assessment of General Movements (98\% de sensibilidade) e o Hammersmith Infant Neurological Examination (com 90\% de sensibilidade), sendo este último validado para o Brasil.

No Brasil, há a recomendação em apoiar a vigilância do desenvolvimento infantil deste 1984 e em 1995 foi incluído no Cartão (ou Caderneta) de Saúde da Criança os marcos do desenvolvimento, tornando em 2004 normativo para o registro da vigilância. No entanto, segundo a revisão sistemática de Caminha et al (2017) verificou que a prevalência de notificação da vigilância do desenvolvimento infantil é de 4,6 a 30,4\%, o que os autores justificaram a variação segundo os critérios e tamanhos amostrais diversos e a diferentes metodologias de análise sobre a adequação do preenchimento do cartão.

Hubermann e colaboradores (2016) verificaram a idade de diagnóstico e encaminhamento para estimulação precoce e mostraram que os prestadores de cuidados primários geraram uma minoria de encaminhamentos e que estes eram realizados mais tardiamente (média de 28,8 \pm 27,1 meses), motivo de preocupação devido ao seu papel na vigilância do desenvolvimento infantil. Os autores relatam que a variabilidade incrivelmente alta de condição de saúde (diferentes alterações clínicas, motoras e de alterações associadas) sugere que o conhecimento dos atributos da paralisia cerebral varia amplamente entre os prestadores de serviços nos níveis de assistência e que alertam a necessidade de ter estratégias para otimizar o encaminhamento imediato pelos prestadores de cuidados primários.

Por estes achados acima e por ser pouco usada e usada de formas diferente, o Cartão da Criança deve ser mais bem divulgado e maior atenção deve ser dada em relação ao acompanhamento e vigilância infantil, principalmente na atenção básica, por ser a porta de entrada no SUS e ser o local em que a criança realizará as consultas habituais de puericultura, podendo ainda visar ou utilizar a equipe multiprofissional do Núcleo Ampliado de Saúde da Família (NASF) para identificação precoce e monitoramento, não dependendo apenas dos encaminhamentos para especialidades, que por vezes são demorados, para fazer as avaliações 
específicas do desenvolvimento e a triagem motora. $\mathrm{O}$ uso e correto preenchimento do Cartão da Criança deve ser incentivado para acompanhar o desenvolvimento e identificar um possível atraso, sendo feito um encaminhamento para reabilitação o mais precoce possível.

Por fim, vale lembrar que esta pesquisa teve influência da pandemia causada pelo coronavírus (COVID - 19) e devido ao isolamento social e a suspensão dos atendimentos em alguns serviços, a coleta foi realizada por contato telefônico. Segundo levantamento de Schmidt e colaboradores (2020) há pontos importantes quando se realiza entrevistas de forma online, sendo eles: maior abrangência, com inclusão de pessoas de diferentes locais; redução de tempo despendido por não ter deslocamento, com consequente economia de recursos financeiros; maior segurança de participantes e pesquisadores, frente ao contexto da pandemia; possibilidade de falar com mais liberdade e abordar assuntos sensíveis, por não estar face a face com os pesquisadores e nem em locais públicos ou no serviço que frequenta. O fato de estar em casa e agendar um horário melhor para ser entrevistado pareceu ser mais conveniente e favoreceu a adesão e participação no estudo. No entanto, houve muitas perdas de contato devido ao fato de não atenderem o telefone ou o número não existir.

Apesar das coletas terem sido positivas via online, o estudo teve uma limitação quanto ao acesso aos prontuários dos serviços devido ao contexto, podendo conter neles mais informações sobre exames, laudos e outros diagnósticos ou condições clínicas associadas que auxiliariam nas análises dos dados. 


\section{CONCLUSÃO}

Foram identificados os fatores de riscos (maternos, gestacionais e perinatais) para PC mais prevalentes das crianças e adolescentes que frequentavam a reabilitação no município e realizadas análises de associação entre os fatores de risco, informações sobre diagnóstico e intervenção, as classificações funcionais (função motora grossa e habilidade manual) e locomoção, bem como com as características atuais da saúde e desenvolvimento da criança.

A escolaridade materna teve associação com a habilidade manual e a locomoção da criança e, o fato de a gravidez ter sido desejada teve associação com a função motora e a locomoção em casa. Tais achados podem sugerir que na amostra, o fato de as crianças terem mães mais jovens e com maior grau de instrução favoreceu sua função manual, função motora e locomoção.

Verificamos também que na amostra a idade da criança quando teve a suspeita do atraso do desenvolvimento teve associação com a deficiência cognitiva e epilepsia e que a topografia teve associação com a idade da notícia (diagnóstico), sugerindo que quanto maior seu comprometimento motor e a presença de déficits associados mais cedo a criança é diagnosticada, provavelmente por apresentarem mais sinais de alterações.

Com relação aos aspectos funcionais e às características atuais, houve associações especialmente com o fato de a criança frequentar escola, ter epilepsia, luxação de quadril, sua topografia e o uso de órtese e dispositivo auxiliar. Tais achado sugerem que as crianças com tais características possuem maior impacto nas suas funções motoras, habilidades manuais e locomoção. No entanto, as características atuais parecem ter pouca relação com os fatores de riscos na presente amostra.

Por fim, alertamos sobre a necessidade de um adequado acompanhamento do desenvolvimento infantil com triagem e uso de instrumentos validados e recomendados, bem como a realização do diagnóstico e intervenção multiprofissional precoce e oportuna. A família deve ser informada da condição da criança e atuar em conjunto com os profissionais para que o tratamento seja focado no contexto da família e a criança tenha uma participação ativa, tanto na escola como na comunidade. 


\section{REFERÊNCIAS 1}

ACPR GROUP. Australian Cerebral Palsy Register Report. Sydney: Cerebral Palsy Alliance, 2013.

AMORIM, M.M.R.; LEITE, D.F.B; GADELHA, T.G.N.; MUNIZ, A.G.V.; MELO, A.S.O.; ROCHA, A.M. Fatores de risco para macrossomia em recém-nascidos de uma maternidade escola no Nordeste do Brasil. Revista Brasileira de Ginecologia e Obstetrícia, São Paulo, v. 31, n. 5, p. 241-248, 2009.

APGAR, V. A proposal for a new metod of evaluation of the newborn infant. Current Researches in Anesthesia and Analgesia, Cleveland, [S.1.], v. 32, p. 260-267, 1953.

BEE, H. L. The developing child. New York: Harper Collins College Publishers, 1995.

BOSANQUET, M. et al. A systematic review of tests to predict cerebral palsy in young children. Developmental Medicine and Child Neurology, Oxford, v. 55, p. 418-426, 2013.

BRASIL. Ministério da Saúde. Atenção à saúde do recém-nascido: guia para os profissionais de saúde. Brasília, 2011.

. Ministério da Saúde. Atenção ao pré-natal de baixo risco. Brasília, 2012a.

. Ministério da Saúde. Decreto $\mathbf{N}^{\mathbf{0}} \mathbf{1 0 . 5 0 2}$, de 30 de setembro de 2020. Brasília, 2020. Brasília, 2013.

Ministério da Saúde. Diretrizes de atenção à pessoa com paralisia cerebral.

Ministério da Saúde. Diretrizes nacionais de assistência ao parto normal: versão resumida. Brasília, 2017.

Ministério da Saúde. Nota técnica para organização da rede de atenção à saúde com foco na atenção primária à saúde e na atenção ambulatorial especializada - Saúde da mulher na gestação, parto e puerpério. Sociedade Beneficente Israelita Brasileira Albert Einstein. São Paulo, 2019.

Brasília, 2010.

Ministério da Saúde. Política Nacional de Saúde da Pessoa com Deficiência.

Ministério da Saúde. Pré-natal e puerpério: atenção qualificada e humanizada manual técnico. Brasília, 2005.

$2012 b$.

Ministério da Saúde. Resolução No 466, de 12 de dezembro de 2012. Brasília,

Ministério da Saúde. Resolução N 510, de 07 de abril de 2016. Brasília, 2016.

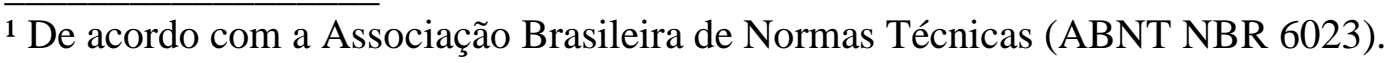


Ministério da Saúde. Manual de Ambiência dos Centros Especializados em Reabilitação (CER) e das Oficinas Ortopédicas. Brasília, 2017.

BRONFEnBRENNER, U. A Ecologia do Desenvolvimento Humano. Porto Alegre: Artmed, 1996.

CAMINHA, M. F. C.; SILVA, S. L.; LIMA, M. C.; AZEVEDO, P. T. A. C. C.; FIGUEIRA, M. C. S.; FILHO, M. B. Surveillance of child development: an analysis of brazil's situation. Revista Paulista de Pediatria, São Paulo, v. 35, n. 1, p. 102-109, 2017.

CASTRO, G. G.; CAMARGOS, A. S.; FARIAS, M. S. Barreiras de acessibilidade urbana: cotidiano das famílias de crianças com deficiências neurológicas. REFACS, Uberaba, v. 8, p. 694-701, 2020. Supl. 2.

Centers for Disease Control and Prevention. Cerebral palsy. Disponível em: https://www.cdc.gov/ncbddd/cp/facts.html. Acesso em: 04 jan. 2021.

COLVER, A.; FAIRHURSR, C.; PHAROAH, P. O. Cerebral palsy. Lancet, London, v. 383, n. 9924, p. 1240-1249, 2014.

COURVILLE, C. B. Contributions to the study of cerebral anoxia. II. The mechanism and nature of consequent structural alterations. Bulletin of the Los Angeles Neurological Society, Los Angeles, v. 15, n. 3, p. 129-154, 1950.

CRIPPA, J. N.; GONÇALVES, A. G.; BARBA, P. C. S. D.; LOURENÇO, G. F. O acesso da criança com paralisia cerebral aos recursos de tecnologia assistiva na percepção dos cuidadores. Revista Diálogos e Perspectivas em Educação Especial, Marília, v. 4, n. 2, p. 85-98, 2017.

CYPEL, S. Fundamentos do desenvolvimento infantil: da gestação aos 3 anos. São Paulo, Fundação Maria Cecília Souto Vidigal, 2013.

DIRKIN, M. S.; BENEDICT R. E.; CHRISTENSEN, D.; DUBOIS, L. A.; FITZGERALD, R. T.; KIRBY, R. S.; MAENNER, M. J.; BRAUM, K. V. N.; WINGATE, M. S.; YEARGINALLSOPP, M. Prevalence of cerebral palsy among 8-year-old children in 2010 and preliminary evidence of trends in its relationship to low birthweight. Paediatric and Perinatal Epidemiology, Oxford, v. 30, n. 5, p. 496-510, 2016.

DYE, T.D.; WOJTOWCZ, M.A. Organizational variation, satisfaction, and women's time investment in prenatal care. Paediatric and Perinatal Epidemiology, Oxford, v. 13, p. 158169, 1999.

EINSPIELER, C.; PRECHTL, H. F. Prechtl's assessment of general movements: a diagnostic tool for the functional assessment of the young nervous system. Mental Retardation and Developmental Disabilities Research Reviews, New York, v. 11, n. 1, p. 61-67, 2005. 
ELIASSON, A.C.; KRUMLINDE-SUNDHOLM, L.; RÖSBLAD, B.; BECKUNG, E.; ARNER, M.; OHRVALL, A. M.; ROSENBAUM, P. The Manual Ability Classification System (MACS) for children with cerebral palsy: scale development and evidence of validity and reliability. Developmental Medicine and Child Neurology, London, v. 48, p. 549-554, 2006.

ELIASSON, A.C.; KRUNLINDE-SUNDHOLM, L. Mini-Manual Ability Classification System for children with cerebral palsy 1 - 4 years of age. Disponível em: https://www.macs.nu/files/Mini-MACS_English_2016.pdf. Acesso em: 19 abril 2020.

EVANS, P.M.; ALBERMAN, E. Recording motor defects of children with cerebral palsy. Developmental Medicine and Child Neurology, Oxford, v. 27, p. 404-406, 1985.

EVANS, P. Standardization of recording and reporting cerebral palsy. Developmental Medicine and Child Neurology, Oxford, v. 29, p. 272, 1987.

FAHEY, M. C.; MACLENNAN, A. H.; KRETZSCHMAR, D.; GECZ, J.; KRUER, M. C. The genetic basis of cerebral palsy. Developmental Medicine and Child Neurology, Oxford, v. 59, n. 5, p. 462-469, 2017.

FARIAS, N.; BUCHALLA, C. M. A Classificação Internacional de Funcionalidade, Incapacidade e Saúde da Organização Mundial da Saúde: Conceitos, Usos e Perspectivas. Revista Brasileira de Epidemiologia, São Paulo, v. 8, n. 2, p. 187-189, 2015.

FELICE, T. M. N.; SANTOS, J. L. F.; PFEIFER, L. I. Estudo retrospectivo de fatores de risco materno, pré e perinatal para paralisia cerebral na rede pública de saúde. Medicina, Ribeirão Preto, v. 52, p. 179-91, 2019.

FERRAZ, T. R.; NEVES, E. T. Fatores de risco para baixo peso ao nascer em maternidades públicas: um estudo transversal. Revista Gaúcha de Enfermagem, Porto Alegre, v. 32, n. 1, p. 86-92, 2011.

FERREIRA, R. C.; MELLO, R. R.; SILVA, K. S. Neonatal sepsis as a risk factor for neurodevelopmental changes in preterm infants with very low birth weight. Jornal de Pediatria, Porto Alegre, v. 90, p. 293-299, 2014.

FUNAYAMA, C. A. R.; PENNA, M. A.; TURCATO, M. F.; CALDAS, C. A. T.; SANTOS, J. S.; MORETTO, D. Paralisia cerebral diagnóstico etiológico. Medicina, Ribeirão Preto, v. 33, p. 155-160, 2000.

GALEA, C.; MCINTYRE, S.; SMITHERS-SHEEDY, H.; REID, S. M.; GIBSON, C.; DELACY, M. et al. Cerebral palsy trends in Australia (1995-2009): a population-based observational study. Developmental Medicine and Child Neurology, Oxford, v. 61, n. 2, p. 186-193, 2019.

GAZMARIAN, J. A.; ARRIGTON, M. P. A.; BAILEY, C. M.; SCHWARTZ, M. S. W.; KOPLAN, J. P. Prenatal care or low-income women enrolled in a managed-care organization. Obstetrics \& Gynecology, New York, v. 94, p. 177-184, 1999. 
GLADSTONE, M. A review of the incidence and prevalence, types and aetiology of childhood cerebral palsy in resource-poor settings. Annals of Tropical Paediatrics, New York, v. 30, n. 3, p. 181-196, 2010.

GRAHAM, H. K.; HARVEY, A.; RODDA, J.; NATTRASS, G. R.; PIRPIRIS, M. The Functional Mobility Scale (FMS). Journal of Pediatric Orthopaedics, New York, v. 24, n. 5, p. 514-520, 2004.

HAMILTON LC. Statistics with STATA. Belmont, California: Brooks/Cole-Thomson Learning, 2004.

HANNA, S. E.; ROSENBAUM, P. L.; BARTLETT, D. J.; PALISANO, R. J.; WALTER, S. D.; AVERY, L.; RUSSEL, D. J. Stability and decline in gross motor function among children andyouth with cerebral palsy aged 2 to 21 years. Developmental Medicine and Child Neurology, Oxford, v. 51; n. 4, p.295-302, 2009.

HIDECKER, M. J.; PANETH, N.; ROSENBAUM, P. L.; KENT, R. D.; LILLIE, J.; EULENBERG, J. B.; et al. Developing and validating the Communication Function Classification System for individuals with cerebral palsy. Developmental Medicine and Child Neurology, Oxford, v. 53, n. 8, p. 704-10, 2011.

HIMPENS, E.; VAN DEN BROECK, C.; OOSTRA, A.; CALDERS, P.; VANHAESEBROUCK, P. Prevalence, type, distribution, and severity of cerebral palsy in relation to gestational age: a meta-analytic review. Developmental Medicine and Child Neurology, Oxford, v. 50, n. 5, p. 334-340, 2008.

HOLDEN, G. W.; GEFFNER, R.; JOURILES, E. N. Children exposed to marital violence: theory, research, and applied issues. Washington: American Psychology Association, 1998.

HOWARD, J.; SOO, B.; GRAHAM, H. K.; BOYD, R. N.; REID, S.; LANIGAN, A.; WOLFE, R.; REDDIHOUGH, D. S. Cerebral palsy in Victoria: motor types, topography and gross motor function. Journal of Paediatrics and Child Health, Melbourne, v. 41, n. 9-10, p. 479-483, 2005.

HUBERMANN, L.; BOYCHUCK, Z.; SHEVELL, M.; MAJNEMER, A. Age at Referral of Children for Initial Diagnosis of Cerebral Palsy and Rehabilitation: Current Practices. Journal of Child Neurology, Littleton, v. 31, n. 3, p. 364-369, 2016.

JACOBSSON, B.; HAGBERG, G. Antenatal risk factors for cerebral palsy. Best practice and research. Clinical obstetrics and gynaecology, Amsterdam, v. 18, n. 3, p. 425-436, 2004.

JAW, T. S.; SHEU, R. S.; LIU, G. C.; CHOU, M. S. Magnetic resonance images of neuronal migration anomalies. Kaohsiung Journal of Medical Sciences, Kaohsiung City, v. 14, n. 8, p. 504-513, 1998.

JOSEPH, K. S.; ALLEN, A. C.; LUTFI, S.; MURPHY-KAULBECK, L.; VINCER, M. J.; WOOD, E. Does the risk of cerebral palsy increase or decrease with increasing gestational age? BMC Pregnancy and Childbirth, London, v. 3, n. 1, p. 8, 2003. 
JÖUD, A.; SEHLSTEDT, A.; KÄLLÉN, K.; WESTBOM, L.; RYLANDER, L. Associations between antenatal and perinatal risk factors and cerebral palsy: a Swedish cohort study. British Medical Journal, p. 1-8, 2020.

KHANDAKER, G.; MUHIT, M.; KARIM, T.; SMITHERS-SHEEDY, H.; NOVAK, I.; JONES, C. et al. Epidemiology of cerebral palsy in Bangladesh: a population-based surveillance study. Developmental Medicine and Child Neurology, Oxford, v. 61, n. 5, p. 601-609, 2019.

KLEINER, A. F. R; AYRES, T. G.; SARAIVA, P. M.; BATISTELA, R. A.; PIETROBON, R. S.; GOBBI, L. T. B. Mobilidade funcional em indivíduos com paralisia cerebral espástica de acordo com o tipo e a idade. Revista Portuguesa de Ciências do Desporto, Porto, v. 8, n. 3, p. 406-413, 2008.

LITTLE, W. J. On the influence of abnormal parturition, difficult labours, premature birth, and asphyxia neonatorum, on the mental and physical condition of the child, especially in relation to deformities. Clinical Orthopaedics and Related Research, Philadelphia, v. 46, p. 7-22, 1966.

LOCATELlI, A.; ANDREANI, M.; PIZZARDI, A.; PATERLINI, G.; STOPPA, P.; GHIDINI, A. Antenatal variables associated with severe adverse neurodevelopmental outcome among neonates born at less than 32 weeks. European Journal of Obstetrics \& Gynecology and Reproductive Biology, Amsterdam, v. 152, n. 2, p. 143-147, 2010.

MAC KEITH, R.C.; POLANI, P.E. The Little Club: memorandum on terminology and classification of cerebral palsy. Cerebral Palsy Bulletin, Oxford, v.5, p.27-35, 1959.

MAITRE, N. L.; SLAUGHTER, J. C.; ASCHNER, J. L. Early prediction of cerebral palsy after neonatal intensive care using motor development trajectories in infancy. Early Human Development, Amsterdam, v. 89, p. 781-786, 2013.

MCINTYRE, S.; MORGAN, C.; WALKER, K.; NOVAK, I. Cerebral palsy - don't delay. Developmental Disabilities Research Reviews, Hoboken, v. 17, n. 2, p. 114-129, 2011.

MEI, C.; REILLY, S.; REDDIHOUGH, D.; MENSAH, F.; GREEN, J.; PENNINGTON, L.; MORGAN, A. T. Activities and participation of children with cerebral palsy: parent perspectives. Disability and Rehabilitation, London, v. 37, n. 23, p. 2164-2173. 2015.

MENDES, E.V. As redes de atenção à saúde. Brasília: Organização Pan-Americana da Saúde, 2011. Disponível em: https://www.paho.org/bra/index.php?option=com_docman\&view=download\&category_slug= servicos-saude-095\&alias $=1402$-asredes-atencao-a-saude-2a-edicao-2\&Itemid=965. Acesso em: 14 nov. 2019.

MORRIS, C. Definition and classification of cerebral palsy: a historical perspective. Developmental Medicine and Child Neurology Supplement, Oxford, v. 109, p. 3-7, 2007.

NOVAK, I.; HINES, M.; GOLDSMITH, S.; BARCLAY, R. Clinical prognostic messages from a systematic review on cerebral palsy. Pediatrics, v. 130, n. 5, p. 1285-1312, 2012. 
NOVAK, I. et al. Early, accurate diagnosis and early intervention in cerebral palsy: advances in diagnosis and treatment. JAMA Pediatrics, Chicago. v. 171, p. 897-907, 2017.

NOVAK, I. Evidence-Based Diagnosis, health care, and rehabilitation for children with cerebral palsy. Journal of Child Neurology, Littleton, v. 29, n. 8, p. 1141-1156, 2014.

NOVAK, I. et al. State of the Evidence Traffic Lights 2019: Systematic Review of Interventions for Preventing and Treating Children with Cerebral Palsy. Current Neurology and Neuroscience Reports, Philadelphia, v. 20, n. 2, p. 1-21, 2020.

Organização Mundial de Saúde. CIF: Classificação Internacional de Funcionalidade, Incapacidade e Sáude [Centro colaborador da Organização Mundial da Saúde para a Família de Classificações Internacionais em Português]. São Paulo: Editora da Universidade de São Paulo, 2003.

PAKULA, A. T.; VAN NAARDEN BRAUN, K.; YEARGIN-ALLSOPP, M. Cerebral Palsy: Classification and Epidemiology. Physical Medicine and Rehabilitation Clinics of North America, Philadelphia, v. 20, n. 3, p. 425-452, 2009.

PALISANO, R. J.; TIEMAN, B. L.; WALTER, S. D.; BARTLETT, D. J.; ROSENBAUM, P. L.; RUSSELL, D.; HANNA, S. E. Effect of environmental setting on mobility methods of children with cerebral palsy. Developmental Medicine and Child Neurology, Oxford, v. 45, p. 113-120, 2003.

PALISANO, R. J.; ROSENBAUM, P.; BARTLETT, D.; LIVINGSTON, M. H. Content validity of the expanded and revised Gross Motor Function Classification System. Developmental Medicine and Child Neurology, Oxford, v. 50, n. 10, p. 744-750, 2008.

PELOSI, M. B. Inclusão e tecnologia assistiva. 2007. 303f. Tese (Doutorado em Educação) Faculdade de Educação, Universidade do Estado do Rio de Janeiro, Rio de Janeiro, 2008.

PEREIRA, H.V. Paralisia Cerebral. Residência Pediátrica, Rio de Janeiro, v.8 (supl 1), p. 49-55, 2018.

PFEIFER, L. I.; SILVA, D. B. R.; FUNAYAMA, C. A. R.; \& SANTOS, J. L. Classification of cerebral palsy: association between gender, age, motor type, topography and gross motor function. Arquivos de Neuro-Psiquiatria, São Paulo, v. 67, p. 1057-1061, 2009.

RAMEY, C. T.; RAMEY, S. L. Early intervention and early experience. American Psychologist, Washington, v. 53, p. 109-120, 1988.

Register ACPR. Report of the Australian Cerebral Palsy Register: birth years 1995-2012. November 2018.

REPPOLD, C. T.; PACHECO, J.; BARDAGI, M.; HUTZ, C. Prevenção de problemas de comportamento e desenvolvimento de competências psicossociais em crianças e adolescentes: uma análise das práticas educativas e dos estilos parentais. In: HUTZ, C. S., (Org.), Situações de risco e vulnerabilidade na infância e na adolescência: aspectos teóricos e estratégias de intervenção. São Paulo: Casa do Psicólogo, p. 7-51, 2002. 
RÉZIO, G. S.; CUNHA, J. O. V.; FORMIGA, C. K. M. R. Estudo da independência funcional, motricidade e inserção escolar de crianças com Paralisia Cerebral. Revista Brasileira de Educação Especial, v. 18, p. 601-614, 2012.

ROCHA, N. A. C. F.; SILVA, F. P. S.; SANTOS, M. M.; DUSING, S. C. Impact of motherinfant interaction on development during the first year of life: A systematic review. Journal of Child Health Care, London, p. 1-21, 2019.

ROMEO, D. M.; CIONI, M.; SCOTO, M.; MAZZONE, L.; PALERMO, F.; ROMEO, M. G. Neuromotor development in infants with cerebral palsy investigated by the Hammersmith Infant Neurological Examination during the first year of age. European Journal of Paediatric Neurology, London, v. 12, n. 1, p. 24-31, 2008.

ROSENBAUM, P.; PANETH, N.; LEVITON, A.; GOLDSTEIN, M.; BAX, M.; DAMIANO, D.; DAN, B.; JACOBSSON, B. A report: the definition and classification of cerebral palsy April 2006. Developmental Medicine and Child Neurology Supplement, Oxford, v. 109, p. 8-14, 2007.

ROSEMBAUM, P; GORTER, J. W. The 'F-words' in childhood disability: I swear this is how we should think! Child: Care, Health and Development, v. 38, n. 4, p. 457-463, 2011.

ROTTA, N.T. Paralisia Cerebral, novas perspectivas terapêuticas. Jornal de Pediatria, Porto Alegre, v.78 (Supl. 1), p.48-54, 2002.

SADOWSKA, M.; SARECKA-HUJAR, B.; KOPYTA, I. Cerebral Palsy: Current Opinions on Definition, Epidemiology, Risk Factors, Classification and Treatment Options. Neuropsychiatric Disease and Treatment, Albany, v. 16, p. 1505-1518, 2020.

SALDIR, M.; SARICI, S. U.; BAKAR, E. E.; OZCAN, O. Neurodevelopmental status of preterm newborns at infancy, born at a tertiary care center in Turkey. American Journal of Perinatology, New York, v. 27, n. 2, p. 121-128, 2010.

SCHMIDT, B.; PALAZZI, A.; PICCININI, C. A. Entrevistas online: potencialidades e desafios para coleta de dados no contexto da pandemia de COVID-19. REFACS (online), v. 8, n. 4, p. 960-966, 2020. Disponível em: http://seer.uftm.edu.br/revistaeletronica/index.php/refacs/article/view/4877. Acesso em: 23 fev. 2021

SELLERS, D.; MANDY, A.; PENNINGTON, L.; HANKINS, M.; MORRIS, C. Development and reliability of a system to classify the eating and drinking ability of people with cerebral palsy. Developmental Medicine and Child Neurology, Oxford, v. 56, n. 3, p. 245-51, 2014.

SILVA, D.B.R.; PFEIFER, L.I.; FUNAYAMA, C.A.R. Sistema de classificação da habilidade manual para crianças com paralisia cerebral 4-18 anos. Hamilton - Canadá, 2010. Disponível em: http://www.macs.nu/files/MACS_Portuguese-Brazil_2010.pdf Acesso em: 23 mar. 2021. 
SILVA, D.B.R.; PFEIFER, L.I.; FUNAYAMA, C.A.R. Gross Motor Function Classification System Expanded \& Revised (GMFCS E \& R): reliability between therapists and parents in Brazil. Brazilian Journal of Physical Therapy, São Carlos, v. 17, n. 5, p. 458-463, 2013.

SPITTLE, A. J.; MORGAN, C.; OLSEN, J. E.; NOVAK, I.; CHEONG, J. L. Y. Early diagnosis and treatment of cerebral palsy in children with a history of preterm birth. Clinics in Perinatology, Philadelphia, v. 45, n. 3, p. 409-420, 2018.

SPONG, C.Y. Defining "term" pregnancy: recommendations from the defining "term" pregnancy workgroup. Journal of the American Medical Association, Chicago, v. 309, n. 23, p. 2445-6, 2013.

TÂMEGA, I. D. E.; FILHO, A. D. A. B.; PINTO, E. A. L. D. C. Growth in children with encephalopathy, a longitudinal study from the 6th to the 24th month. International Journal of Nutrition and Metabolism, Gillingham, v. 3, n. 6, p. 65-71, 2011.

VAN GORP, M.; ROEBROECK, M. E.; SWAN TAN, S. Activity Performance curves of individuals with cerebral palsy. Pediatrics, v. 142, n. 5, 2018.

WALLACE, S. J. Epilepsy in cerebral palsy. Developmental Medicine and Child Neurology, Oxford, v. 43, n. 10, p. 713-717, 2001.

WHEATER, M.; RENNIE, J. M. Perinatal infection is an important risk factor for cerebral palsy in very-low-birthweight infants. Developmental Medicine and Child Neurology, Oxford, v. 42, n. 6, p. 364-367, 2000.

WORLD HEALTH ORGANIZATION. Strategies toward Ending Preventable Maternal Mortality (EPMM), 2015. Disponível em: http://www.who.int/reproductivehealth/topics/maternal_perinatal/epmm/en/. Acesso em: 13 fev. 2018.

. Estratégia global para a saúde das mulheres, das crianças e dos adolescentes (20162030). Every Woman Every Child, 2016.

Every Newborn: an Action Plan to End Preventable Deaths (ENAP), 2014. Disponível em: http://apps.who.int/iris/bitstream/10665/127938/1/9789241507448_eng.pdf. Acesso em: 13 fev. 2018.

ZABLOTSKY, B.; BLACK, L. I.; MAENNER, M. J.; SCHIEVE, L. A.; DANIELSON, M. L.; BITSKO, R. H.; BLUMBERG, S. J.; KOGAN, M. D.; BOYLE, C. A. Prevalence and Trends of Developmental Disabilities among Children in the United States: 2009-2017. Pediatrics, v. 144, n. 4, p. 1-11, 2019.

ZARRINKALAM, R.; RUSSO, R.N.; GIBSON, C.S.; VAN ESSEN, P.; PEEK, A.K.; HAAN, E.A. CP or not CP? A review of diagnoses in a cerebral palsy register. Pediatric Neurology, New York, v. 42, n. 3, p. 177-180, 2010. 


\section{APÊNDICE I}

\section{Período Gestacional e Peri Natal das Crianças com Paralisia Cerebral}

Identificação da criança:

Data da coleta: Local:

\section{Dados pessoais}

Nome da criança:

Data Nascimento: Idade: Sexo: ( ) Feminino ( ) Masculino

Endereço: Telefones:

Nome da mãe:

Data Nascimento: Idade: Estado civil:

Escolaridade: Profissão:

Nome do pai:

Data Nascimento: Idade: Estado civil:

Escolaridade: Profissão:

Houve planejamento para a gravidez? ( ) Sim ( ) Não

Gestação por técnicas de reprodução assistida? ( ) Sim ( ) Não

Foi uma gravidez desejada? ( ) Sim ( ) Não

Em qual mês/semana descobriu a gravidez?

\section{Pré-natal}

Realizou pré-natal: ( ) Sim ( ) Não Local:

Tem cartão da gestante? ( ) Sim ( ) Não

Data da primeira consulta de pré-natal: Tempo de gestação:

Número de consultas no 10 trimestre: 20 trimestre: 3o trimestre:

Fez exames? ( ) Sim ( ) Não Se sim, quais?

Tomou vacinas? ( ) Sim ( ) Não Se sim, quais?

Uso de bebida alcóolica: ( ) Não ( ) Sim, na gestação ( ) Sim, antes da gestação Uso de cigarros: ( ) Não ( ) Sim, na gestação ( ) Sim, antes da gestação ( ) Uso de drogas: ( ) Não ( ) Sim, na gestação ( ) Sim, antes da gestação ( ) Não sabe Doenças cardíacas: ( ) Não ( ) Sim, na gestação ( ) Sim, antes da gestação ( ) Não sabe Observação: 
Doenças respiratórias: ( ) Não ( ) Sim, na gestação ( ) Sim, antes da gestação ( ) Não sabe Observação:

Doenças neurológicas: ( ) Não ( ) Sim, na gestação ( ) Sim, antes da gestação ( ) Não sabe Observação:

Doenças autoimunes: ( ) Não ( ) Sim, na gestação ( ) Sim, antes da gestação ( ) Não sabe Observação:

Problemas psiquiátricos: ( ) Não ( ) Sim, na gestação ( ) Sim, antes da gestação ( ) Não sabe Observação:

Problemas ginecológicos: ( ) Não ( ) Sim, na gestação ( ) Sim, antes da gestação ( ) Não sabe Observação:

Pressão alta: ( ) Não ( ) Sim, na gestação ( ) Sim, antes da gestação ( ) Não sabe Diabetes: ( ) Não ( ) Sim, na gestação ( ) Sim, antes da gestação ( ) Não sabe Herpes: ( ) Não ( ) Sim, na gestação ( ) Sim, antes da gestação ( ) Não sabe Sarampo: ( ) Não ( ) Sim, na gestação ( ) Sim, antes da gestação ( ) Não sabe Catapora: ( ) Não ( ) Sim, na gestação ( ) Sim, antes da gestação ( ) Não sabe Rubéola: ( ) Não ( ) Sim, na gestação ( ) Sim, antes da gestação ( ) Não sabe Febre alta: ( ) Não ( ) Sim, na gestação ( ) Sim, antes da gestação ( ) Não sabe Anemia: ( ) Não ( ) Sim, na gestação ( ) Sim, antes da gestação ( ) Não sabe Toxoplasmose: ( ) Não ( ) Sim, na gestação ( ) Sim, antes da gestação ( ) Não sabe Sífilis: ( ) Não ( ) Sim, na gestação ( ) Sim, antes da gestação ( ) Não sabe Infecção urinária: ( ) Não ( ) Sim, na gestação ( ) Sim, antes da gestação ( ) Não sabe Corrimento vaginal: ( ) Não ( ) Sim, na gestação ( ) Sim, antes da gestação ( ) Não sabe Hipotireoidismo: ( ) Não ( ) Sim, na gestação ( ) Sim, antes da gestação ( ) Não sabe Hipertireoidismo: ( ) Não ( ) Sim, na gestação ( ) Sim, antes da gestação ( ) Não sabe Observações:

Outra doença na gestação: ( ) Não ( ) Sim Qual:

Sofreu ameaça de aborto nesta gestação: ( ) Não ( ) Sim

Aborto em gestações anteriores: ( ) Não ( ) Sim, espontâneo ( ) Sim, provocado Ameaça de prematuridade: ( ) Não ( ) Sim

Utilizou remédio na gestação: ( ) Não ( ) Sim Qual: Internação durante a gestação: ( ) Não ( ) Sim

Se Sim, Motivo: Tempo: Intercorrências na gestação: Ocorrências clínicas da gestante: ( ) Não ( ) Sim, (infecção de urina, problemas gastrointestinais, diabetes, hipertensão, pico ipertensivo, 
taquicardia, dengue ou suspeita de dengue, sinusite, bronquite, vírus do papiloma humano (HPV) não tratado ou tratado inadequadamente, cólica renal, infecções (toxoplasmose, erisipela, sífilis, hepatite, citomegalovírus), anemia, infeç̧ão renal, pielonefrite, candidíase, infecções ginecológicas, paralisia facial de Bell, obesidade, dislipidemia, alteração nos triglicérides, hipotensão, tonturas, alimentação não saudável, perda de peso, anorexia, problemas com a tireoide, crise convulsiva)

Alterações na gestação: ( ) Não ( ) Sim,

(sangramentos, pré-natal de risco por intercorrências em exames e consultas, placenta envelhecida, descolamento de placenta, hipotonia uterina, necessidade de repouso, risco de aborto, contrações precoces, perda de líquido amniótico, necessidade de inibição do parto, banda amniótica, polihidrâmio, fator Rh negativo e tomou vacina e teve reação)

Pouco preparo: ( ) Não ( ) Sim,

(pré-natal tardio, mãe usou medicamentos sem saber que estava grávida, não sabia da gravidez e não fez o pré-natal)

Quedas e baques: ( ) Não ( ) Sim,

(quedas, queda por acidente automobilístico, deu aula de educação física, trabalhou muito na gestação, sofreu violência do companheiro ou do pai)

Problemas emocionais: ( ) Não ( ) Sim,

(dificuldade de aceitação, dificuldade para dormir, depressão, relatos de situação e momentos de estresse)

\section{Características do parto e nascimento}

Tipo de parto: ( ) Normal ( ) Cesárea ( ) Fórceps ( ) Não sabe

Se normal, fez episiotomia (corte, pique): ( ) Sim ( ) Não ( ) Não sabe

Se cesárea, qual foi o motivo:

( ) sofrimento fetal (batidas do coração do bebê diminuiu ou o bebê evacuou dentro da barriga da mãe)

( ) desproporção feto-pélvica (bacia pequena / bebê grande)

( ) distócia de apresentação (bebê sentado / posição errada)

() hemorragia materna (teve sangramento)

( ) parada de progressão (parou o trabalho de parto ou pararam as dores)

( ) eclâmpsia, pré-eclâmpsia (pressão alta) ( ) pós-maturidade (passou o tempo)

( ) morte fetal (o bebê morreu) ( ) diabetes materna (açúcar no sangue)

( ) cesáreas anteriores ( ) laqueadura (para ligar as trompas) 
( ) mãe pediu ( ) médico optou

( ) já estava agendada ( ) cirurgias ginecológicas anteriores

() Outro: ( ) Não sabe

Parto múltiplo: ( ) Não ( ) Sim, quantidade: ( ) primeira ( ) segunda ( ) terceira

Local: ( ) Centro de Referência da Saúde da Mulher de Ribeirão Preto (MATER)

( ) Hospital das Clínicas de Ribeirão Preto

( ) Hospital Santa Casa de Misericórdia de Ribeirão Preto

( ) Posto de saúde. Qual:

( ) Hospital Materno Infantil Sinhá Junqueira

( ) Hospital Santa Lydia de Ribeirão Preto

Idade gestacional: ( ) termo ( ) a termo ( ) pós termo Semanas:

Peso ao nascer: Apgar 10 minuto:

Apgar 50 minuto:

Teve intercorrências: ( ) Não ( ) Sim Qual:

Intercorrências peri natais: ( ) Não ( ) Sim,

(trabalho de parto demorado, pouca e nenhuma dilatação, bolsa rota, placenta grau III, placenta presa, descolamento de placenta, parto induzido, pouco líquido amniótico, polihidrâmio, cesárea de urgência, lesão uterina, problemas com a anestesia para cesárea, presença de infecções, apresentação pélvica e posicionamento não adequado, uso de fórceps, problemas com o cordão umbilical)

Intercorrências com a mãe: ( ) Não ( ) Sim,

(alterações na pressão arterial, pico hipertensivo, citomegalovírus, pré-eclâmpsia, infecção, sangramento ou hemorragia no trabalho de parto ou parto, situação estressante, ausência de assistência médica, mãe faleceu no parto, mãe alcoolizada no momento do parto)

Intercorrências com o bebê: ( ) Não ( ) Sim,

(anóxia, dificuldade ou desconforto respiratório, hipoglicemia, aspiração ou ingestão de mecônio, icterícia, incompatibilidade sanguínea, sofrimento fetal, sopro cardíaco, cianótico, alterações na estatura do bebê, choro abafado, ausência de movimentos ao nascer, crise convulsiva, parada cardíaca, lavagem do estômago, hipotermia, fratura de clavícula ou costela, precisou amadurecer o pulmão, edemas na cabeça, má formação)

Tempo do parto:

Tempo de internação da criança (enfermaria):

Tempo de internação da criança (unidade de terapia intensiva):

Usou ventilação mecânica? ( ) Sim ( ) Não ( ) Não sabe

Teve convulsões? ( ) Sim ( ) Não ( ) Não sabe 
Fez exames de neuroimagem? ( ) Sim ( ) Não ( ) Não sabe

Teve suspeita de atraso: ( ) Não ( ) Sim

Se sim, era devido ao qual fato?

Com qual idade?

De quem era a suspeita: ( ) pais ( ) familiares ( ) médico ( ) outros

Quando recebeu a notícia da paralisia cerebral? Idade da criança:

Quando e onde iniciou reabilitação? Idade da criança e Local:

Foi encaminhada para o Serviço de Estimulação Precoce? ( ) Não ( ) Sim, Qual:

Se sim, acompanhou neste serviço até qual idade?

Por qual motivo parou:

( ) meu filho recebeu alta e estava bem ( ) meu filho recebeu alta por abandono

( ) foi encaminhado para outro serviço ( ) não gostei do serviço e resolvi parar

() esqueci dos retornos e não voltei ( ) era muito longe da minha casa

( ) não tinha quem levasse meu filho ( ) não entendi motivo do acompanhamento

\section{Atualmente}

Escola: ( ) Não ( ) Sim, regular ( ) Sim, especial Série:

Acompanha o conteúdo acadêmico: ( ) Sim ( ) Não ( ) Não sabe

Deficiência visual: ( ) Sim ( ) Não ( ) Não sabe ( ) Se Sim, qual:

Usa óculos: ( ) Sim ( ) Não ( ) Não sabe

Deficiência auditiva: ( ) Sim ( ) Não ( ) Não sabe Se Sim, qual:

Alteração cognitiva (compreensão): ( ) Sim ( ) Não ( ) Não sabe

Epilepsia ou crise convulsivas: ( ) Sim ( ) Não ( ) Não sabe

Síndrome associada: ( ) Sim ( ) Não ( ) Não sabe Se Sim, qual:

Luxação quadril: ( ) Sim ( ) Não ( ) Não sabe

Gastrostomia: ( ) Sim ( ) Não ( ) Não sabe

Sonda nasogástrica: ( ) Sim ( ) Não ( ) Não sabe

Cirurgia prévia: ( ) Sim ( ) Não ( ) Não sabe Se Sim, qual:

Medicamentos:

Terapias: ( ) Fisioterapia ( ) Fonoaudiologia ( ) Terapia Ocupacional ( ) Psicologia ( ) Outro Local: 


\section{APÊNDICE II}

\section{Coleta II - A Criança com Paralisia Cerebral}

Nome da criança:

Data Nascimento:

Idade:

Identificação da criança:

Data do preenchimento:

Local:

Identificação do informante:

Profissão: ( ) Fisioterapeuta ( ) Terapeuta ocupacional ( ) Fonoaudiólogo ( ) Outro:

Tempo de formação (anos): $\quad$ Anos de experiência na área:

Alterações do movimento:

( ) Espástica ( ) Atáxica ( ) Discinética ( ) Não classificável

Topografia:
() Unilateral - Hemi esquerdo
() Unilateral - Hemi direito
() Bilateral, diparesia
() Bilateral, quadriparesia
() Distonia
( ) Coreo-ateóide
() Ataxia

Órteses: ( ) AFO (suropodálica) () posicionamento membro superior () Cock up ( ) SMO (supramaleolar) () reação ao solo ( ) mola / flexível ( ) Outro:

Dispositivos: () andador anterior () andador posterior () cadeira de rodas

( ) parapodium ( ) Outro:

GMFCS - Sistema de Classificação da Função Motora Grossa:

\section{GMFCS (04 a 06 anos de idade):}

( ) Nível I - As crianças sentam-se na cadeira, mantêm-se sentadas e levantam-se dela sem a necessidade de apoio das mãos. As crianças saem do chão e da cadeira para a posição em pé sem a necessidade de objetos de apoio. As crianças andam nos espaços internos e externos e sobem escadas. Iniciam habilidades de correr e pular. 
( ) Nível II - As crianças sentam-se na cadeira com ambas as mãos livres para manipular objetos. As crianças saem do chão e da cadeira para a posição em pé, mas geralmente requerem uma superfície estável para empurrar-se ou impulsionar-se para cima com os membros superiores. As crianças andam sem a necessidade de um dispositivo manual de mobilidade em espaços internos e em curtas distâncias em espaços externos planos. As crianças sobem escadas segurando-se no corrimão, mas são incapazes de correr e pular.

( ) Nível III - As crianças sentam-se em cadeira comum, mas podem necessitar de apoio pélvico e de tronco para maximizar a função manual. As crianças sentam-se e levantam-se da cadeira usando uma superfície estável para empurrar-se ou impulsionar-se para cima com seus braços. As crianças andam com um dispositivo manual de mobilidade em superfícies planas e sobem escadas com a assistência de um adulto. As crianças frequentemente são transportadas quando percorrem longas distâncias e quando em espaços externos em terrenos irregulares.

( ) Nível IV - As crianças sentam em uma cadeira, mas precisam de um assento adaptado para controle de tronco e para maximizar a função manual. As crianças sentam-se e levantam-se da cadeira com a ajuda de um adulto ou de uma superfície estável para empurrar-se ou impulsionar-se com seus braços. As crianças podem, na melhor das hipóteses, andar por curtas distâncias com o andador e com supervisão do adulto, mas tem dificuldades em virar e manter o equilíbrio em superfícies irregulares. As crianças são transportadas na comunidade. As crianças podem adquirir auto locomoção utilizando uma cadeira de rodas motorizada.

( ) Nível V - As deficiências físicas restringem o controle voluntário do movimento e a habilidade para manter posturas antigravitacionais de cabeça e tronco. Todas as áreas da função motora estão limitadas. As limitações funcionais no sentar e ficar em pé não são completamente compensadas por meio do uso de equipamento adaptativo e tecnologia assistiva. No nível $\mathrm{V}$, as crianças não têm como se movimentar independentemente e são transportadas. Algumas crianças alcançam auto locomoção usando cadeira de rodas motorizada com extensas adaptações.

\section{GMFCS (06 a 12 anos de idade):}

( ) Nível I - As crianças caminham em casa, na escola, em espaços externos e na comunidade. As crianças são capazes de subir e descer meio-fios e escadas sem assistência física ou sem o uso de corrimão. As crianças apresentam habilidades motoras grossas tais como correr e saltar, mas a velocidade, equilíbrio e a coordenação são limitados. As crianças podem participar de atividades físicas e esportes dependendo das escolhas pessoais e fatores ambientais.

( ) Nível II - As crianças caminham na maioria dos ambientes. As crianças podem apresentar dificuldade em caminhar longas distâncias e de equilíbrio em terrenos irregulares, inclinações, áreas com muitas pessoas, espaços fechados ou quando carregam objetos. As crianças sobem e descem escadas segurando em corrimão ou com assistência física se não houver este tipo de apoio. Em espaços externos e na comunidade, as crianças podem andar com assistência física, um dispositivo manual de mobilidade, ou utilizar a mobilidade sobre rodas quando percorrem longas distâncias. As crianças têm, na melhor das hipóteses, apenas habilidade mínima para realizar as habilidades motoras grossas tais como correr e pular. As limitações no desempenho das habilidades motoras grossas podem necessitar de adaptações para permitirem a participação em atividades físicas e esportes.

( ) Nível III - As crianças andam utilizando um dispositivo manual de mobilidade na maioria dos espaços internos. Quando sentadas, as crianças podem exigir um cinto de segurança para alinhamento pélvico e equilíbrio. As transferências de sentado para em pé e do chão para posição em pé requerem assistência física de uma pessoa ou uma superfície de apoio. Quando movem-se por 
longas distâncias, as crianças utilizam alguma forma de mobilidade sobre rodas. As crianças podem subir ou descer escadas segurando em um corrimão com supervisão ou assistência física. As limitações na marcha podem necessitar de adaptações para permitir a participação em atividades físicas e esportes, incluindo a auto-propulsão de uma cadeira de rodas manual ou mobilidade motorizada.

( ) Nível IV - As crianças utilizam métodos de mobilidade que requerem assistência física ou mobilidade motorizada na maioria dos ambientes. As crianças requerem assento adaptado para o controle pélvico e do tronco e assistência física para a maioria das transferências. Em casa, as crianças movem-se no chão (rolar, arrastar ou engatinhar), andam curtas distâncias com assistência física ou utilizam mobilidade motorizada. Quando posicionadas, as crianças podem utilizar um andador de apoio corporal em casa ou na escola. Na escola, em espaços externos e na comunidade, as crianças são transportadas em uma cadeira de rodas manual ou utilizam mobilidade motorizada. As limitações na mobilidade necessitam de adaptações que permitam a participação nas atividades físicas e esportes, incluindo a assistência física e/ou mobilidade motorizada.

( ) Nível V - As crianças são transportadas em uma cadeira de rodas manual em todos os ambientes. As crianças são limitadas em sua habilidade de manter as posturas anti-gravitacionais da cabeça e tronco e de controlar os movimentos dos braços e pernas. Tecnologia assistiva é utilizada para melhorar o alinhamento da cabeça, o sentar, o levantar e/ou a mobilidade, mas as limitações não são totalmente compensadas pelo equipamento. As transferências requerem assistência física total de um adulto. Em casa, as crianças podem se locomover por curtas distâncias no chão ou podem ser carregadas por um adulto. As crianças podem adquirir auto-mobilidade utilizando a mobilidade motorizada com adaptações extensas para sentar-se e controlar o trajeto. As limitações na mobilidade necessitam de adaptações para permitir a participação nas atividades físicas e em esportes, inclusive a assistência física e uso de mobilidade motorizada.

\section{MACS - Sistema de Classificação da Habilidade Manual}

( ) Nível I - Manipula objetos facilmente e com sucesso. No máximo, limitações na facilidade de realizar tarefas manuais que requerem velocidade e precisão. Porém, quaisquer limitações nas habilidades manuais não restringem a independência nas atividades diárias.

( ) Nível II - Manipula a maioria dos objetos mas com a qualidade e / ou velocidade da realização um pouco reduzida. Certas atividades podem ser evitadas ou serem realizadas com alguma dificuldade; maneiras alternativas de realização poderiam ser utilizadas, mas as habilidades manuais geralmente não restringem a independência nas atividades diárias.

( ) Nível III - Manipula objetos com dificuldade; necessita de ajuda para preparar e/ ou modificar as atividades. O desempenho é lento e obtido com sucesso limitado em relação à qualidade e quantidade. Atividades são realizadas independentemente se elas tiverem sido organizadas ou adaptadas. 
( ) Nível IV - Manipula uma variedade limitada de objetos facilmente manipuláveis em situações adaptadas. Desempenham parte das atividades com esforço e com sucesso limitado. Requer suporte e assistência contínuos e/ ou equipamento adaptado para mesmo assim realizar parcialmente a atividade.

( ) Nível V - Não manipula objetos e tem habilidade severamente limitada para desempenhar até mesmo ações simples. Requer assistência total.

FMS - Escala de Mobilidade Funcional (as distâncias são um guia, o ambiente é o relevante)

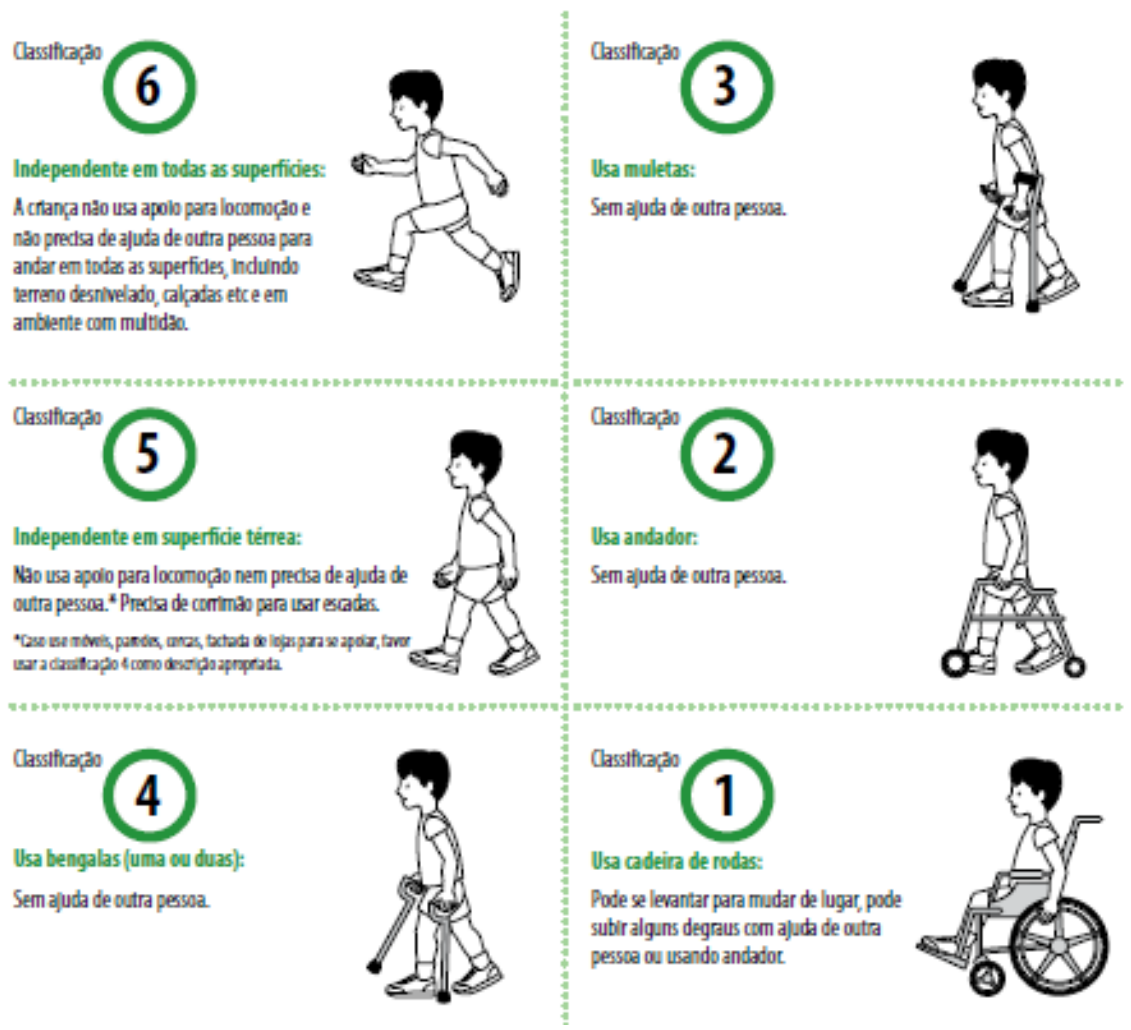

Como sua criança se locomove em curtas distâncias em casa? (5m)
() $6 \quad$ () 5
() 4
() 3
() 2
( ) 1
() Engatinha
( ) Sem classificação

Como sua criança se locomove na sala de aula e entre as salas na escola? (50m)
( ) 6
() 5
() 4
() 3
() 2
( ) 1
() Engatinha
( ) Sem classificação

Como sua criança se locomove em longas distâncias (ex: para ir ao shopping)? (500m)
( ) 6
( ) 5
() 4
() 3
() 2
( ) 1
() Engatinha
( ) Sem classificação 


\title{
APÊNDICE III
}

\author{
TERMO DE CONSENTIMENTO LIVRE E ESCARECIDO - TCLE (Obrigatório \\ para as pesquisas Científicas em Seres Humanos - Resolução nº 466/12- CNS)
}

\begin{abstract}
Título da Pesquisa: "Estudo retrospectivo de fatores de risco para paralisia cerebral" Pesquisadora responsável: Thamires Máximo Neves Felice / thamiresmnf@gmail.com Orientadora: Luzia Iara Pfeifer / luziara@ fmrp.usp.br / (16) 3602-4976 Departamento de Neurociências e Ciências do Comportamento - Hospital das Clínicas de Ribeirão Preto. Comitê de Ética em Pesquisa: 3602-2228. Av. Bandeirantes, 3900 - Monte Alegre - CEP 14.049-900 Ribeirão Preto - SP.
\end{abstract}

Convidamos você e seu (a) filho (a) a participar desta pesquisa. No caso de concordar em participar da pesquisa, favor assinar este documento ao final. Objetivos da pesquisa: Identificar os fatores de riscos de atraso de desenvolvimento mais comuns em Ribeirão Preto, correlaciona os fatores de risco das crianças com paralisia cerebral com a saúde materna, a gestação, parto e pós-parto, topografia (tipo de lesão no corpo) e alterações do movimento. Procedimentos do estudo: A aplicação do questionário terá duração de aproximadamente 30 minutos, e será realizada por contato telefônico ou ambiente seguro que permita a realização da avaliação sem interferência externa, sendo que você poderá estar presente na sala de avaliação acompanhando a avaliação e todo o procedimento, podendo ser filmado para facilitar posterior análise. A avaliação vai verificar a topografia e alterações do movimento e poderá utilizar até quatro instrumentos (dois para avaliar a mobilidade funcional, um para a função manual e um que avalia a capacidade de alinhamento da coluna). Garantimos que nem você e, nem sua criança serão identificados e as informações coletadas serão utilizadas nesta pesquisa contribuindo com a sensibilização de políticas públicas para prevenção e tratamento de criança com paralisia cerebral. Riscos e Desconfortos: Esta pesquisa, na fase que envolve a entrevista telefônica e a aplicação de questionários, pode trazer como risco possíveis desconfortos decorrentes de determinadas perguntas, contudo, garantimos a minimização destes incômodos ao tornar claro que você só responderá a questões que julgar pertinentes. Entendemos também que as avaliações que serão aplicadas são, de modo geral, entendidas pelas crianças como algo lúdico, de forma que as mesmas não percebem que estão sendo avaliadas e se divertem durante o processo, todavia, as avaliações poderão ser realizadas de uma só vez ou em dois momentos distintos, caso seja verificado que a criança esteja cansada e não desempenhando adequadamente as atividades avaliadas. Você estará livre para autorizar sua criança a participar ou não do mesmo, ou para retirá-la deste em qualquer momento do seu processo sem nenhum prejuízo. Custo/Reembolso para o participante: Não há nenhum valor econômico a receber ou a pagar por sua participação no estudo. Confidencialidade da pesquisa: Garantimos seu anonimato bem como o da sua criança e, se houver necessidade da filmagem será a partir da autorização dos pais e/ou responsável. Após a análise dos dados as gravações serão destruídas. Qualquer esclarecimento sobre o estudo poderá ser dado sempre que necessário. Ao final da pesquisa, será dada uma devolutiva aos pais sobre o que foi identificado na avaliação de sua criança. Garantimos que sua criança, se for de sua expressa vontade, receberá uma via do Termo de Consentimento Livre e Esclarecido, assinado e rubricado pelo pesquisador. Se você tiver quaisquer dúvidas e quiser mais informações sobre os seus direitos como participante de pesquisa ou sobre os aspectos éticos do estudo, você pode ligar para o Comitê de Ética em Pesquisa do Hospital das Clínicas da Faculdade de Medicina de Ribeirão Preto da Universidade de São Paulo. Av. Bandeirantes, 3900, Campus 
Universitário, Monte Alegre, Subsolo, Ribeirão Preto/SP, CEP: 14048-900, Brasil. (16) 36022228 de segunda a sexta-feira das 08:00 as 17:00.

$\mathrm{Eu}$ RG abaixo assinado, tendo recebido os esclarecimentos acima, e ciente dos meus direitos, e sendo responsável pela criança —, autorizo a participação deste estudo. Declaro estar ciente: a) do objetivo deste estudo; b) da segurança de que eu e minha criança não seremos identificados e de que toda a informação obtida será estritamente confidencial; c) de que eu e minha criança teremos a liberdade de manifestar recusa em participar deste estudo em qualquer etapa do processo; d) de que eu e minha criança podemos contar com orientações que se fizerem necessárias antes e durante a pesquisa; e) de que tenho direito a indenização conforme as leis vigentes no país, caso ocorra dano decorrente de participação na pesquisa.

Ribeirão Preto, de de 20

Assinatura dos Pais e/ou Responsável

Eu, Thamires Máximo Neves Felice, pesquisadora Responsável pelo estudo me comprometo a cumprir as normas de segurança, respeitando as dúvidas dos responsáveis e suas crianças, bem como o sigilo dos dados e a recusa eventual de algum participante sempre procurando zelar pelo bem-estar e ética.

Thamires Máximo Neves Felice

Versão 03 - 07/05/2020 


\section{ANEXO I}

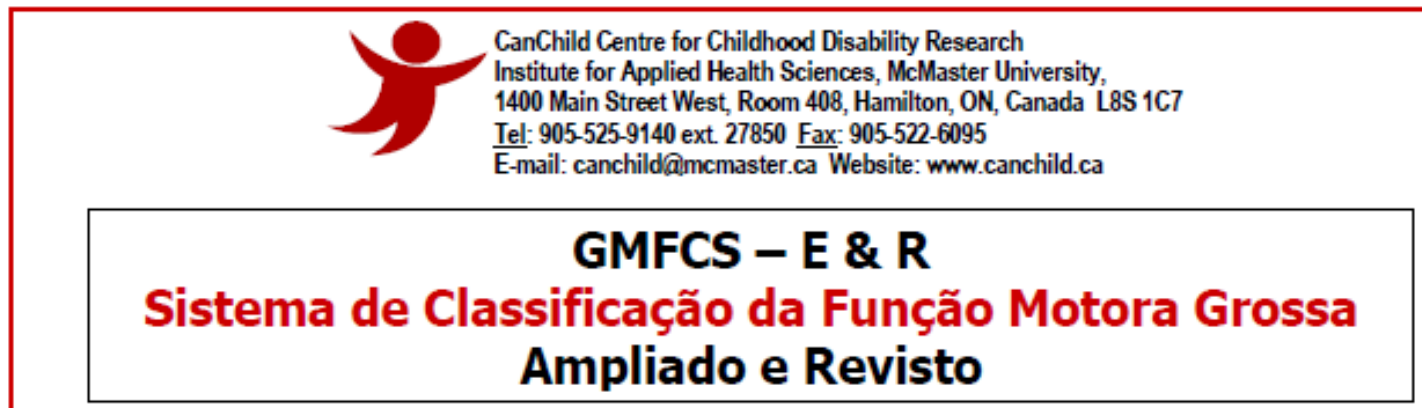

GMFCS - E \& R @ 2007 CanChild Centre for Childhood Disability Research, McMaster University Robert Palisano, Peter Rosenbaum, Doreen Bartlett, Michael Livingston

GMFCS (ㄱ) 1997 CanChild Centre for Childhood Disability Research, McMaster University Robert Palisano, Peter Rosenbaum, Stephen Walter, Dianne Russell, Ellen Wood, Barbara Galuppi (Reference: Dev Med Child Neurol 1997;39:214-223)

GMFCS - E \& R 일 Versão Brasileira

Traduzido por Daniela Baleroni Rodrigues Silva, Luzia lara Pfeifer e Carolina Araújo Rodrigues Funayama (Programa de PósGraduação em Neurociências e Ciências do Comportamento - Faculdade de Medicina de Ribeirão Preto, Universidade de São Paulo)

\section{INTRODUÇÃO E INSTRUÇÕES AO USUÁRIO}

O Sistema| de Classificação da Função Motora Grossa (GMFCS) para paralisia cerebral é baseado no movimento iniciado voluntariamente, com ênfase no sentar, transferências e mobilidade. Ao definirmos um sistema de classificação em cinco níveis, nosso principal critério é que as distinções entre os níveis devam ser significativas na vida diária. As distinções são baseadas nas limitações funcionais, na necessidade de dispositivos manuais para mobilidade (tais como andadores, muletas ou bengalas) ou mobilidade sobre rodas, e em menor grau, na qualidade do movimento. As distinções entre os Niveis I e II não são tão nitidas como a dos outros níveis, particularmente para crianças com menos de dois anos de idade.

O GMFCS ampliado (2007) inclui jovens entre 12 e 18 anos de idade e enfatiza os conceitos inerentes da Classificação Internacional de Funcionalidade, Incapacidade e Saúde da Organização Mundial da Saúde (CIF). Nós sugerimos que os usuários estejam atentos ao impacto que os fatores ambientais e pessoais possam ter sobre 0 que se observa sobre as crianças e jovens ou no que eles relatam fazer. 0 enfoque do GMFCS está em determinar qual nivel melhor representa as habilidades e limitações na função motora grossa que a criança ou o jovem apresentam. A ênfase deve estar no desempenho habitual em casa, na escola e nos ambientes comunitários (ou seja, no que eles fazem), ao invés de ser no que se sabe que eles são capazes de fazer melhor (capacidade). Portanto, é importante classificar o desempenho atual da função motora grossa e não incluir julgamentos sobre a qualidade do movimento ou prognóstico de melhora.

0 enfoque de cada nível é o método de mobilidade que é mais característico no desempenho após os 6 anos de idade. As descrições das habilidades e limitações funcionais para cada faixa etária são amplas e não se pretende descrever todos os aspectos da função da criança/jovem individualmente. Por exemplo, um bebê com hemiplegia que é incapaz de engatinhar sobre suas mãos e joelhos, mas que por outro lado se encaixa na descrição do Nivel I (ou seja, é capaz de puxar-se para ficar em pé e andar), seria classificada no nível I. A escala é ordinal, sem intenção de que as distâncias entre os niveis sejam consideradas iguais entre os niveis ou que as crianças e jovens com paralisia cerebral sejam igualmente distribuídas nos cinco níveis. Um resumo das distinções entre cada par de niveis é fornecido para ajudar na determinação do nível que mais se assemelha à função motora 
grossa atual da criança ou do jovem.

Nós reconhecemos que as manifestações da função motora grossa sejam dependentes da idade, especialmente durante a lactância e primeira infância. Para cada nivel são fornecidas descrições separadas em diferentes faixas etárias. Deve-se considerar a idade corrigida de crianças com menos de 2 anos de idade se elas forem prematuras. As descrições para faixa etária de 6 a 12 anos e de 12 a 18 anos de idade refletem o possivel impacto dos fatores ambientais (por exemplo, distâncias na escola e na comunidade) e fatores pessoais (por exemplo, necessidades energéticas e preferências sociais) nos métodos de mobilidade.

Um esforço foi feito para enfatizar as habilidades ao invés das limitações. Assim, como princípio geral, a função motora grossa das crianças e jovens que são capazes de realizar funções descritas em certo nivel será provavelmente classificada neste nível de função ou em um nível acima; ao contrário, a função motora grossa de crianças e jovens que não conseguem realizar as funçôes de certo nivel devem ser classificadas abaixo daquele nivel de função.

\section{DEFINIÇÕES OPERACIONAIS}

Andador de apoio corporal - um dispositivo de mobilidade que apóia a pelve e o tronco. A criança/jovem é fisicamente posicionada (o) no andador por outra pessoa.

Dispositivo de mobilidade manual - bengalas, muletas e andadores anteriores e posteriores que não apóiam o tronco durante a marcha.

Assistência fisica - Outra pessoa ajuda manualmente a criança/o jovem a se mover.

Mobilidade motorizada - A criança/o jovem controla ativamente o joystick ou o interruptor elétrico que permite uma mobilidade independente. A base de mobilidade pode ser uma cadeira de rodas, um scooter ou outro tipo de dispositivo de mobilidade motorizado.

Cadeira de rodas manual de auto-propulsão- a criança/o jovem utiliza os braços e as mãos ou os pés ativamente para impulsionar as rodas e se mover.

Transportado - Uma pessoa manualmente empurra o dispositivo de mobilidade (por exemplo, cadeira de rodas, carrinho de bebê ou de passeio) para mover a criança/ jovem de um lugar ao outro.

Andar - A menos que especificado de outra maneira, indica nenhuma ajuda física de outra pessoa, ou uso de qualquer dispositivo de mobilidade manual. Uma órtese (ou seja, uma braçadeira ou tala) pode ser usada.

Mobilidade sobre rodas - Refere-se a qualquer tipo de dispositivo com rodas que permite movimento (por exemplo, carrinho, cadeira de rodas manual ou motorizada).

\section{CARACTERISTICAS GERAIS PARA CADA NIVEL}

NÍVEL I - Anda sem limitações

NíVEL II - Anda com limitaçōes

NIVEL III - Anda utilizando um dispositivo manual de mobilidade

NÍVEL IV - Auto-mobilidade com limitações; pode utilizar mobilidade motorizada.

NÍVEL V - Transportado em uma cadeira de rodas manual. 


\section{DISTINCÕES ENTRE OS NIVEIS}

Distinções entre os niveis I e II - crianças e jovens do nível II, quando comparados às crianças e jovens do nivel I, têm limitações para andar por longas distâncias e equilibrar-se; podem precisar de um dispositivo manual de mobilidade ao aprender a andar; podem utilizar um dispositivo com rodas quando caminham por longas distâncias em espaços externos e na comunidade; requerem o uso de corrimão para subir e descer escadas; e não são capazes de correr e pular.

Distinçôes entre os níveis II e III - As crianças e os jovens no nivel II são capazes de andar sem um dispositivo manual de mobilidade depois dos quatro anos de idade (embora possam optar por utilizá-lo às vezes). As crianças $\mathrm{e}$ os jovens do nivel III precisam de um dispositivo manual de mobilidade para andar em espaços internos e o uso de mobilidade sobre rodas fora de casa e na comunidade.

Distinções entre os niveis III e IV - as crianças e jovens que estão no nivel III sentam-se sozinhos ou requerem no máximo um apoio externo limitado para sentar-se; eles são mais independentes nas transferências para a postura em pé e andam com um dispositivo manual de mobilidade. As crianças e jovens no nivel IV sentam-se (geralmente apoiados), mas a autolocomoção é limitada. É mais provável que as crianças e jovens no Nivel IV sejam transportadas em uma cadeira de rodas manual ou que utilizem a mobilidade motorizada.

Distinções entre os Niveis IV e V - As crianças e jovens no Nivel V têm graves limitações no controle da cabeça e tronco e requerem tecnologia assistiva ampla e ajuda física. A autolocomoção é conseguida apenas se a criança/ jovem pode aprender como operar uma cadeira de rodas motorizada.

\section{Sistema de Classificação da Função Motora Grossa - Ampliado e Revisto (GMFCS - E \& R)}

\section{ANTES DO ANIVERSÁRIO DE 2 ANOS}

NÍVEL I: Bebês sentam-se no chão, mantém-se sentados e deixam esta posição com ambas as mãos livres para manipular objetos. Os bebês engatinham (sobre as mãos e joelhos), puxam-se para ficar em pé e dão passos segurando-se nos móveis. Os bebês andam entre 18 meses e 2 anos de idade sem a necessidade de aparelhos para auxiliar a locomoção.

NÍVEL II: Os bebês mantêm-se sentados no chão, mas podem necessitar de ambas as mãos como apoio para manter o equilíbrio. Os bebês rastejam em prono ou engatinham (sobre mãos e joelhos). Os bebês podem puxar-se para ficar em pé e dar passos segurando-se nos móveis.

NÍVEL III: Os bebês mantêm-se sentados no chão quando há apoio na parte inferior do tronco. Os bebês rolam e rastejam para frente em prono.

NÍVEL IV: Os bebês apresentam controle de cabeça, mas necessitam de apoio de tronco para sentarem-se no chão. Os bebês conseguem rolar para a posição supino e podem rolar para a posição prono.

NÍVEL V: As deficiências físicas restringem o controle voluntário do movimento. Os bebês são incapazes de manter posturas antigravitacionais de cabeça e tronco em prono e sentados. Os bebês necessitam da assistência do adulto para rolar..

\section{ENTRE O SEGUNDO E O QUARTO ANIVERSÁRIO}

NÍVEL I: As crianças sentam-se no chão com ambas as mãos livres para manipular objetos. Os movimentos de sentar e levantarse do chão são realizadas sem assistência do adulto. As crianças andam como forma preferida de locomoção, sem a necessidade de qualquer aparelho auxiliar de locomoção.

NÍVEL II: As crianças sentam-se no chão, mas podem ter dificuldades de equilíbrio quando ambas as mãos estão livres para manipular objetos. Os movimentos de sentar e deixar a posição sentada são realizados sem assistência do adulto. As crianças puxam-se para ficar em pé em uma superficie estável. As crianças engatinham (sobre mãos e joelhos) com padrão alternado, andam de lado segurando-se nos móveis e andam usando aparelhos para auxiliar a locomoção como

(4) 2007 Canchild page 3 of 6 
forma preferida de locomoção.

NÍVEL III: As crianças mantêm-se sentadas no chão freqüentemente na posição de W (sentar entre os quadris e os joelhos em flexão e rotação interna) e podem necessitar de assistência do adulto para assumir a posição sentada. As crianças rastejam em prono ou engatinham (sobre as mãos e joelhos), frequentemente sem movimentos alternados de perna, como métodos principais de auto-locomoção. As crianças podem puxar-se para levantar em uma superfície estável e andar de lado segurando-se nos móveis por distâncias curtas. As crianças podem andar distâncias curtas nos espaços internos utilizando um dispositivo manual de mobilidade (andador) e ajuda de um adulto para direcioná-la e girá-la.

NÍVEL IV: As crianças sentam-se no chão quando colocadas, mas são incapazes de manter alinhamento e equilibrio sem o uso de suas mãos para apoio. As crianças frequentemente necessitam de equipamento de adaptação para sentar e ficar em pé. A autolocomoção para curtas distâncias (dentro de uma sala) é alcançada por meio do rolar, rastejar em prono ou engatinhar sobre as mãos e joelhos sem movimento alternado de pernas.

NÍVEL V: As deficiências físicas restringem o controle voluntário do movimento e a capacidade de manter posturas antigravitacionais de cabeça e tronco. Todas as áreas de função motora estão limitadas. As limitações funcionais do sentar e ficar em pé não são completamente compensadas por meio do uso de equipamentos adaptativos e de tecnologia assistiva. No nivel V, as crianças não têm meios para se mover independentemente e são transportadas. Somente algumas crianças conseguem a autolocomoção utilizando uma cadeira de rodas motorizada com extensas adaptações.

\section{ENTRE O QUARTO E O SEXTO ANIVERSÁRIO}

NÍVEL I: As crianças sentam-se na cadeira, mantêm-se sentadas e levantam-se dela sem a necessidade de apoio das mãos. As crianças saem do chão e da cadeira para a posição em pé sem a necessidade de objetos de apoio. As crianças andam nos espaços internos e externos e sobem escadas. Iniciam habilidades de correr e pular.

NÍVEL II: As crianças sentam-se na cadeira com ambas as mãos livres para manipular objetos. As crianças saem do chão e da cadeira para a posição em pé, mas geralmente requerem uma superfície estável para empurrar-se ou impulsionar-se para cima com os membros superiores. As crianças andam sem a necessidade de um dispositivo manual de mobilidade em espaços internos e em curtas distâncias em espaços externos planos. As crianças sobem escadas segurando-se no corrimão, mas são incapazes de correr e pular.

NÍVEL III: As crianças sentam-se em cadeira comum, mas podem necessitar de apoio pélvico e de tronco para maximizar a função manual. As crianças sentam-se e levantam-se da cadeira usando uma superficie estável para empurrar-se ou impulsionarse para cima com seus braços. As crianças andam com um dispositivo manual de mobilidade em superficies planas e sobem escadas com a assistência de um adulto. As crianças frequentemente são transportadas quando percorrem longas distâncias e quando em espaços externos em terrenos irregulares.

NÍVEL IV: As crianças sentam em uma cadeira, mas precisam de um assento adaptado para controle de tronco e para maximizar a função manual. As crianças sentam-se e levantam-se da cadeira com a ajuda de um adulto ou de uma superfície estável para empurrar-se ou impulsionar-se com seus braços. As crianças podem, na melhor das hipóteses, andar por curtas distâncias com 0 andador e com supervisão do adulto, mas tem dificuldades em virar e manter 0 equilíbrio em superficies irregulares. As crianças são transportadas na comunidade. As crianças podem adquirir autolocomoção utilizando uma cadeira de rodas motorizada.

NÍVEL V: As deficiências físicas restringem o controle voluntário do movimento e a habilidade para manter posturas antigravitacionais de cabeça e tronco. Todas as áreas da função motora estão limitadas. As limitações funcionais no sentar e ficar em pé não são completamente compensadas por meio do uso de equipamento adaptativo e tecnologia assistiva. No nivel $V$, as crianças não têm como se movimentar independentemente e são transportadas. Algumas crianças alcançam autolocomoção usando cadeira de rodas motorizada com extensas adaptações.

\section{ENTRE O SEXTO E O DÉCIMO SEGUNDO ANIVERSÁRIO}

Nível I: As crianças caminham em casa, na escola, em espaços externos e na comunidade. As crianças são capazes de subir e descer meio-fios e escadas sem assistência física ou sem o uso de corrimão. As crianças apresentam habilidades motoras grossas tais como correr e saltar, mas a velocidade, equilibrio e a coordenação são limitados. As crianças podem participar de atividades físicas e esportes dependendo das escolhas pessoais e fatores ambientais. 
Nível II: As crianças caminham na maioria dos ambientes. As crianças podem apresentar dificuldade em caminhar longas distâncias e de equilibrio em terrenos irregulares, inclinações, áreas com muitas pessoas, espaços fechados ou quando carregam objetos. As crianças sobem e descem escadas segurando em corrimão ou com assistência física se não houver este tipo de apoio. Em espaços externos e na comunidade, as crianças podem andar com assistência fisica, um dispositivo manual de mobilidade, ou utilizar a mobilidade sobre rodas quando percorrem longas distâncias. As crianças têm, na melhor das hipóteses, apenas habilidade mínima para realizar as habilidades motoras grossas tais como correr e pular. As limitações no desempenho das habilidades motoras grossas podem necessitar de adaptações para permitirem a participação em atividades físicas e esportes.

Nível III: As crianças andam utilizando um dispositivo manual de mobilidade na maioria dos espaços internos. Quando sentadas, as crianças podem exigir um cinto de segurança para alinhamento pélvico e equilíbrio. As transferências de sentado para em pé e do chão para posição em pé requerem assistência fisica de uma pessoa ou uma superficie de apoio. Quando movem-se por longas distâncias, as crianças utilizam alguma forma de mobilidade sobre rodas. As crianças podem subir ou descer escadas segurando em um corrimão com supervisão ou assistência física. As limitações na marcha podem necessitar de adaptações para permitir a participação em atividades fisicas e esportes, incluindo a auto-propulsão de uma cadeira de rodas manual ou mobilidade motorizada.

Nível IV: As crianças utilizam métodos de mobilidade que requerem assistência física ou mobilidade motorizada na maioria dos ambientes. As crianças requerem assento adaptado para o controle pélvico e do tronco e assistência física para a maioria das transferências. Em casa, as crianças movem-se no chão (rolar, arrastar ou engatinhar), andam curtas distâncias com assistência física ou utilizam mobilidade motorizada. Quando posicionadas, as crianças podem utilizar um andador de apoio corporal em casa ou na escola. Na escola, em espaços externos e na comunidade, as crianças são transportadas em uma cadeira de rodas manual ou utilizam mobilidade motorizada. As limitações na mobilidade necessitam de adaptações que permitam a participação nas atividades físicas e esportes, incluindo a assistência física e/ou mobilidade motorizada.

Nível V: As crianças são transportadas em uma cadeira de rodas manual em todos os ambientes. As crianças são limitadas em sua habilidade de manter as posturas anti-gravitacionais da cabeça e tronco e de controlar os movimentos dos braços e pernas. Tecnologia assistiva é utilizada para melhorar 0 alinhamento da cabeça, o sentar, o levantar e/ou a mobilidade, mas as limitações não são totalmente compensadas pelo equipamento. As transferências requerem assistência fisica total de um adulto. Em casa, as crianças podem se locomover por curtas distâncias no chão ou podem ser carregadas por um adulto. As crianças podem adquirir auto-mobilidade utilizando a mobilidade motorizada com adaptações extensas para sentar-se e controlar o trajeto. As limitaçöes na mobilidade necessitam de adaptações para permitir a participação nas atividades físicas e em esportes, inclusive a assistência física e uso de mobilidade motorizada.

\section{ENTRE O DÉCIMO SEGUNDO E DÉCIMO OITAVO ANIVERSÁRIO}

Nível I: Os jovens andam em casa, na escola, em espaços externos e na comunidade. Os jovens são capazes de subir e descer meio-fios sem a assistência física e escadas sem o uso de corrimão. Os jovens desempenham habilidades motoras grossas tais como correr e pular, mas a velocidade, o equilíbrio e a coordenação são limitados. Os jovens podem participar de atividades físicas e esportes dependendo de escolhas pessoais e fatores ambientais.

Nível II: Os jovens andam na maioria dos ambientes. Os fatores ambientais (tais como terrenos irregulares, inclinações, longas distâncias, exigências de tempo, clima e aceitação pelos colegas) e preferências pessoais influenciam as escolhas de mobilidade. Na escola ou no trabalho, os jovens podem andar utilizando um dispositivo manual de mobilidade por segurança. Em espaços externos e na comunidade, os jovens podem utilizar a mobilidade sobre rodas quando percorrem longas distâncias. Os jovens sobem e descem escadas segurando em um corrimão ou com assistência fisica se não houver corrimão. As limitações no desempenho de habilidades motoras grossas podem necessitar de adaptações para permitir a participação nas atividades físicas e esportes.

Nível III: Os jovens são capazes de caminhar utilizando um dispositivo manual de mobilidade. Os jovens no nivel III demonstram mais variedade nos métodos de mobilidade dependendo da habilidade física e de fatores ambientais e pessoais, quando comparados a jovens de outros níveis. Quando estäo sentados, os jovens podem precisar de um cinto de segurança para alinhamento pélvico e equilíbrio. As transferências de sentado para em pé e do chão para em pé requerem assistência física de uma pessoa ou de uma superfície de apoio. Na escola, os jovens podem auto-impulsionar uma cadeira de rodas manual ou utilizar a mobilidade motorizada. Em espaços externos e na comunidade, os jovens são transportados em uma cadeira de rodas ou utilizam mobilidade motorizada. Os jovens podem subir e descer escadas segurando em um corrimão com supervisão ou assistência fisica. As limitaçōes na marcha podem necessitar de adaptações para permitir a participação em atividades físicas e esportes incluindo a auto-propulsão de uma cadeira de rodas manual ou mobilidade motorizada.

Nível IV: Os jovens usam a mobilidade sobre rodas na maioria dos ambientes. Os jovens necessitam de assento adaptado para o controle pélvico e do tronco. Assistência física de 1 ou 2 pessoas é necessária para as transferências.

(c) 2007 CanChild page 5 of 6 
Os jovens podem apoiar o peso com as pernas para ajudar nas transferências para ficar em pé. Em espaços internos, os jovens podem andar por curtas distâncias com assistência física, utilizam a mobilidade sobre rodas, ou, quando posicionados, utilizam um andador de apoio corporal. Os jovens são fisicamente capazes de operar uma cadeira de rodas motorizada. Quando o uso de uma cadeira de rodas motorizada não for possivel ou não disponivel, os jovens são transportados em uma cadeira de rodas manual. As limitações na mobilidade necessitam de adaptações para permitir a participação nas atividades físicas e esportes, inclusive a assistência física e/ou mobilidade motorizada.

Nível V: Os jovens são transportados em uma cadeira de rodas manual em todos os ambientes. Os jovens são limitados em sua habilidade para manter as posturas antigravitacionais da cabeça e tronco e o controle dos movimentos dos braços e pernas. Tecnologia assistiva é utilizada para melhorar 0 alinhamento da cabeça, o sentar, o ficar de pé, e a mobilidade, mas as limitações não são totalmente compensadas pelo equipamento. Assistência física de 1 ou 2 pessoas ou uma elevação mecânica é necessária para as transferências. Os jovens podem conseguir a auto-mobilidade utilizando a mobilidade motorizada com adaptações extensas para sentar e para o controle do trajeto. As limitações na mobilidade necessitam de adaptações para permitir a participação nas atividades físicas e esportes incluindo a assistência física e o uso de mobilidade motorizada. 


\section{ANEXO II}

Informaçōes aos usuários

- Sistema de Classificação da Habilidade Manual (MACS) descreve como as crianças com paralisia cerebral $(\mathrm{PC})$ usam suas mãos para manipular objetos em atividades diárias. O MACS descreve cinco niveis. Os niveis são baseados na habilidade da criança em iniciar sozinha a manipulação de objetos e a necessidade de assistência ou adaptação para realizar atividades manuais na vida diária. O folheto do MACS também descreve as diferenças entre os niveis
adjacentes para tornar mais fácil a determinação de qual nivel corresponde melhor à habilidade Uas crianças na manipulaçáo de objetos.

Os objetos referidos são aqueles relevantes e apropriados à idade da criança, usados em tarefas como comer, vestr-se, brincar, desenhar ou escrever. Trata-se de objetos que estão dentro do espaço pessoal das crianças, excluindo-se aqueles que estão fora do seu alcance. Objetos usados em atividades avançadas que requerem habilidades especiais como tocar um instrumento não estăo inclu

Quando atribuir o nivel da criança no MACS, escolha o nível que melhor descreve o desempenho global típico em casa, na escola ou na comunidade. A motivação e a habilidade cognitiva da criança também afetam a capacidade de manipular objetos e, consequentemente, influenciam o nivel do MACS. Para obter informaçóes acerca de como a criança manipula vários objetos no diaa-dia e necessário perguntar a alguem que conhece bem a criança. O MACs visa classificar o que

O MACS é uma descrição funcional que pode ser usada como complemento do diagnóstico de paralisia cerebral e seus subtipos. O MACS avalla a habilidade global da criança na manipulaçáa diferenças de funcão entre as mãos; objetos apropriados à idade. MACS não pretende explicar as razões para os déficits na habilidade manual.

O MACS pode ser usado para crianças e adolescentes na faixa etária entre 4 e 18 anos, O MACS pode ser usado para crianças e adolescentes na faixa etária entre 4 e 18 anos,
entretanto alguns conceitos devem ser estabelecidos em relação à idade da criança.
Naturalmente há diferenças entre os objetos que uma criança de 4 anos é capaz de manipular e aqueles que um adolesçente manipula O mesmo se apliça em relação à independência - uma criança mais nova precisa de maior ajuda e supervisão que uma criança mais velha.

O MACS abrange todo o espectro de limitações funcionais entre crianças com paralisia cerebral e seus subtipos. Alguns subtipos podem ser encontrados em todos os níveis do MACS, como a paralisia cerebral bilateral, enquanto outros são encontrados em poucos níveis, como na paralisia cerebral unilateral. O nivel I inclui crianças com pequenas limitaçōes, enquanto limitaçoes normal fossem classificadas de acordo com o MACS, seria necessário um nivel " 0 ".

Contudo, cada nivel inclui crianças com funçöes relativamente variadas. É improvável que o MACS seja sensivel a mudanças após uma intervenção; há toda a probabilidade de que os niveis do MACS sejam estáveis ao longo do tempo.

Os cinco niveis do MACS constituem uma escala ordinal, que significa que os itens são "ordenados", mas as diferenças entre os niveis não são necessaria

- Tradutores: Ms Daniela Baleroni Rodrigues Silva, Profa Dra Luzia lara Pfeifer e Profa Dra. Carolina Araúio Rodrigues Funayama Programa de Pós-Graduacão era

Neurociências e Ciências do Comportamento, Faculdade de Medicina de Ribeirão Preto, Universidade de São Paulo

E-mail:ann-christin.eliasson@ki.se;

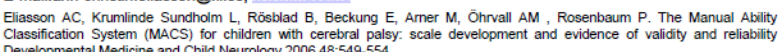

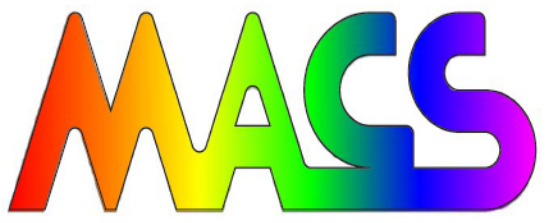

Manual Ability Classification System Sistema de Classificação da Habilidade Manual para crianças com paralisia cerebral 4-18 anos

MACS classifica como as crianças com paralisia cerebral usam suas mãos para manipular objetos em atividades diárias.

MACS descreve como crianças usam habitualmente suas mãos para (a)

> Para obter informação sobre a maneira como a criança manipula varios objetos no seu cotidiano, e necessário questionar alguen

> Os objetos que a criança manipula devem ser adequados à sua idade.

> O MACS classifica a habilidade global da criança para manipular objetos e não cada mão separadamente.

\section{5 , updated 2010}

Distinções entre os níveis I e II S crianças no nivel I podem ter limitações para manipular objetos muito pequenos, pesados ou frágeis, o que requer controle motor fino minucisoso ou coordenç dempentin qualidade do desempenho é menor, ou o desempenho é mais lento. Derenças funcionais entre as mãos podem limitar a eficácia do desempenho. Crianças no nivel II geralmente tentam simplificar a manipulação dos objetos, por exemplo, utilizando uma superfície de suporte ao invés de manipular objetos com as duas mãos.

Em qual situação a criança é independente e até que ponto ela precisa de suporte e adaptação?

I. Manipula objetos facilmente e com sucesso. No máximo, limitações na facilidade de realizar tarefas manuais que requerem velocidade e precisão. Porém, quaisquer limitações nas habilidades manuais não restringem a independência nas atividades diárias.

II. Manipula a maioria dos objetos mas com a qualidade e I ou velocidade da realização um pouco reduzida. Certas atividades podem ser evitadas on serem realizadas com alguma dificuldade; maneiras alternativas de realização poderiam ser utilizadas, mas as habilidades manuais geralmente não restringem a independência nas atividades diárias.

III. Manipula objetos com dificuldade; necessita de ajuda para preparar e/ ou modificar as atividades. O desempenho é lento e obtido com sucesso limitado em relação à qualidade e quantidade. Atividades são realizadas independentemente se elas tiverem sido organizadas ou adaptadas.

IV. Manipula uma variedade limitada de objetos facilmente manipuláveis em situaçöes adaptadas. Desempenham parte das atividades com esforço e com sucesso limitado Requer suporte e assistência continuos e/ inipamento adaptado, para mesmo assim realizar parcialmente equipamen

V. Näo manipula objetos e tem habilidade severamente limitada para desempenhar até mesmo ações simples. Requer assistência total.
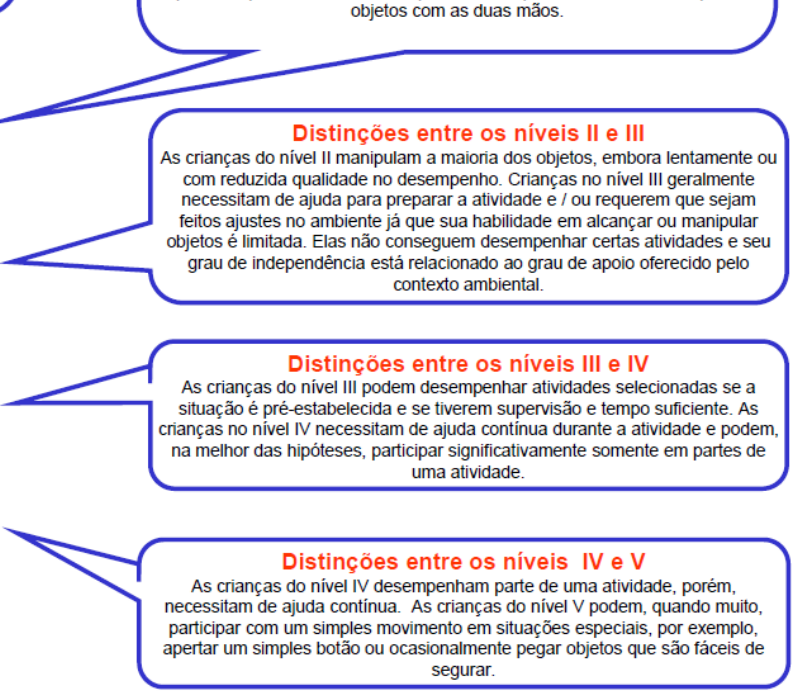
Information for users

The Mini-Manual Ability Classification System (Mini-MACS) is a classification system that describes how children with cerebral palsy (CP) aged 1-4 years use their hands when handling objects in daily activities. Ability is ranked on five levels based on the children's self-initiated ability and their need for assistance or adaptation when handling objects. This brochure also describes differences between adjacent levels to make it easier to determine the most appropriate level. Mini-MACS is a functional subtypes.

The description concern how the children handle objects relevant for age. The objects referred to are those commonly found in the children's environment which they us when performing tasks, such as playing, drawing, eating, or dressing. How childre handle toys often gives a good idea of their manual ability. Obviously, a 12-month-old motivation and cognitive ability also influence the ability to handle objects and consequently, the Mini-MACS level.

When assessing a child's Mini-MACS level, choose the level that best describes the child's usual performance in the daily environment. To better understand what a child who knows the child well. The questions should be phrased to obtain a description the type of objects the child handles, in what situations, and how. Mini-MACS levels reflect what the child usually does, not his or her best performance as demonstrated in a specific test situation.

Mini-MACS assesses the child's general ability to handle everyday objects, not the function of each hand separately. Mini-MACS does not intend to explain the underlying reasons for impaired manual capacity.

The Mini-MACS system spans the entire spectrum of functional limitation found among children with CP and covers all CP sub diagnoses. Level I includes children with mino limitations, if any, while children with severe disabilities are usually classified on leve usually occurs at levels I-III. Mini-MACS does not include children without physica disabilities; if it did, they would be classified as level " 0 ". However, no such level exists!

Since Mini-MACS consists of only five levels, each level includes children with relatively varied function. Consequently, Mini-MACS is a classification system, probably not sensitive to changes and should therefore not be used to evaluate development or interventions. Mini-MACS can be used to describe and differentiate into five levels functional aspects on how a suspected CP diagnosis affects children's
manual ability.

The five-level Mini-MACS scale is ordinal, which means that the differences between levels are not necessarily equal, nor are children with $\mathrm{CP}$ equally distributed across the five levels

GAnn-Christin Eliasson, Lena Krumlinde-Sundholm, 2013

\section{Mini-MACS}

\section{Mini-Manual Ability Classification System for children with cerebral palsy 1 - 4 years of age}

The Manual Ability Classification System (MACS) described how children aged 4-18 years with CP use their hands when handling objects in daily years.

> Mini-MACS classifies children's ability to handle objects that are relevant for their age and development as well as their need for support and assistance in such situations.

> Mini-MACS describes how children usually use their hands to handle objects, such as toys, in various settings. In other words, it describes wha they ordinarily do, rather than what is known to be their best capacity.

> Mini-MACS classifies the child's overall ability to handle objects, not the ability of each hand separately.

> To find out how a child handles various objects in everyday life, it is necessary to ask someone who knows the child well such knowledge cannot be obtained through specific testing. The questions should be phrased to obtain a description of the type of objects the child handles daily, in what situations, and how.

\section{Mini-MaCS}

What do you need to know to use Mini-MACS?

Mini-MACS users need to find out what objects the child usually handles and how they handle them: with ease or difficulty, quickly or slowly, with precision or randomly? when playing and during meals, or when participating in usual activities of daily living.

Ask questions about the child's self-initiated ability and how much adult help and support the child needs to handle everyday objects, e.g. toys.

Below is a description of the five Mini-MACS levels of children's self-initiated ability and their need for assistance or adaptation when handling objects.

I. Handles objects easily and successfully. The child may have a slight limitation in performing actions that require precision and coordination between the hands but they can still perform them The child may need somewhat more adult assistance when handling objects compared to other children of the same age.

II. Handles most objects, but with somewhat reduced quality and/or speed of achievement. Some actions can only be performed and accomplished with some difficulty and after practice. The child may try an alternative approach, such as using only one hand. The child need adult assistance to handle objects more frequently compared to children at the same age.

III. Handles objects with difficulty. Performance is slow, with limited variation and quality. Easily managed objects are handled independently for short periods. The child often needs adult help and support to handle objects.

IV. Handles a limited selection of easily managed objects in simple actions. The actions are performed slowly, with exertion and/or random precision. The child needs constant adult help and support to handle objects.

v. Does not handle objects and has severely limited ability to perform even simple actions. At best, the child can push, touch, press, or hold on to a few items, in constant interaction with an adult.
Distinctions between Levels I and II

Children in Level I may have slightly more difficulty handling items that require good fine motor skills compared to children without disabilities of the same age.

Children in Level II handle essentially the same objects as children in Level I, but they may encounter problems performing tasks and/or take longer to perform them, so they often ask for help. Functional differences between hands may cause performance to be less effective. They may need more guidance and practice to learn how to handle objects compared with children in Level I.

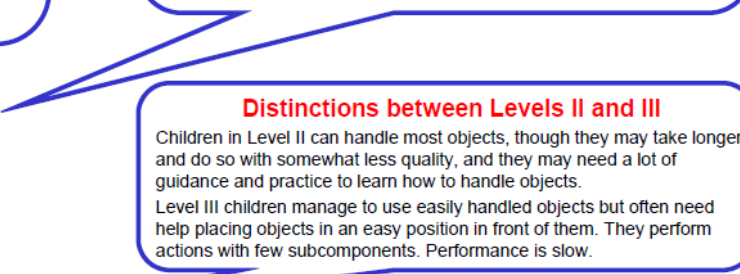

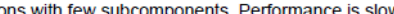

\section{Distinctions between Levels III and IV} Children in Level III manage to use easily handled objects independently for short periods. They perform actions with few subcomponents, and for short periods. They perform actions

At best, children in Level IV can perform simple actions such as

$$
\begin{aligned}
& \text { grasping and releasing easily handled objects that are offered in an } \\
& \text { adapted position. They need constant help. }
\end{aligned}
$$

\section{Distinctions between Levels IV and V Children in Level IV perform individual actions with a very limited} selection of objects and need constant help.

At best, children in Level $\mathrm{V}$ perform simple movements in special situations. For example, they can press a simple button or hold single, simple objects. 
ANEXO III

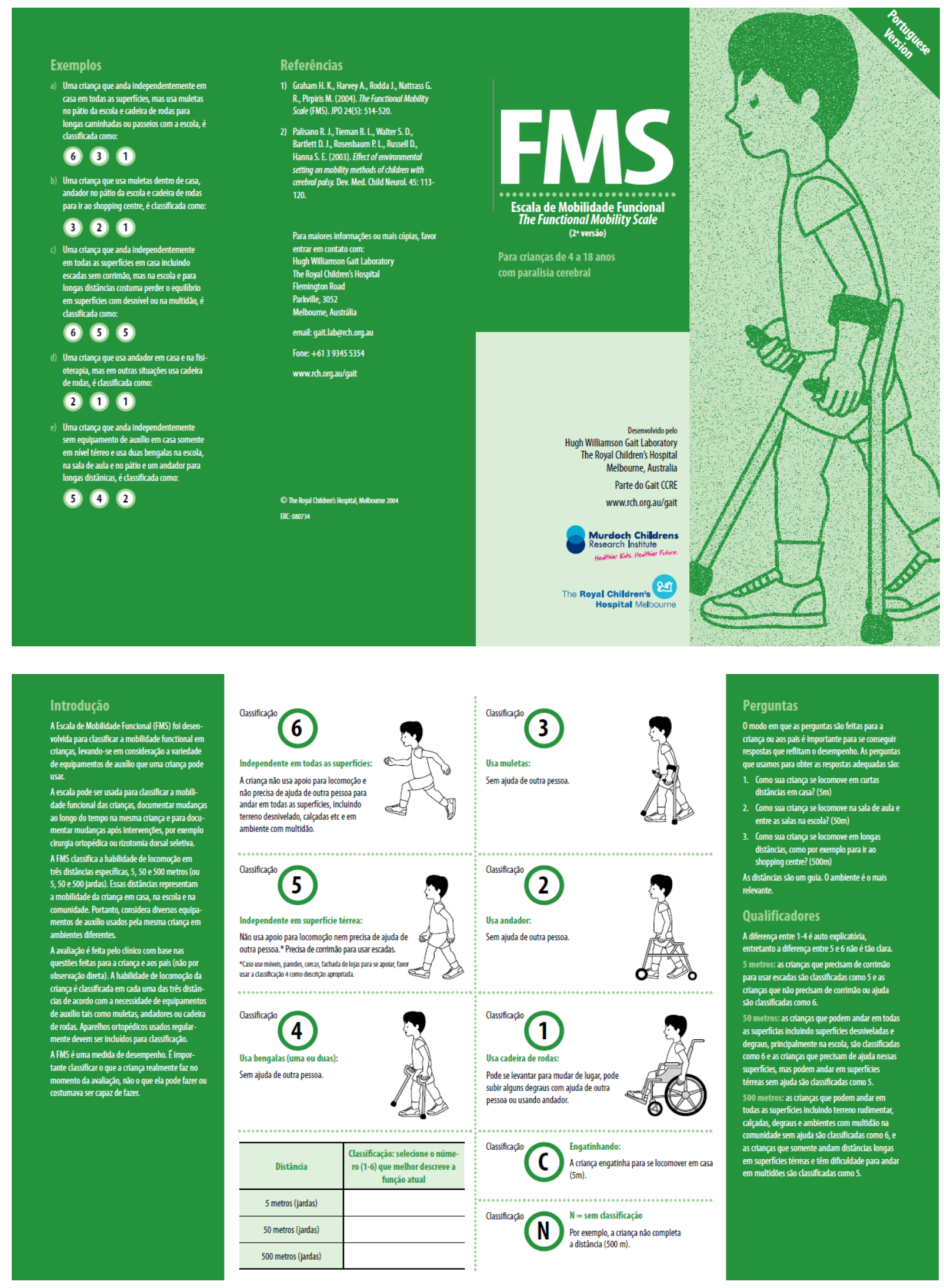

